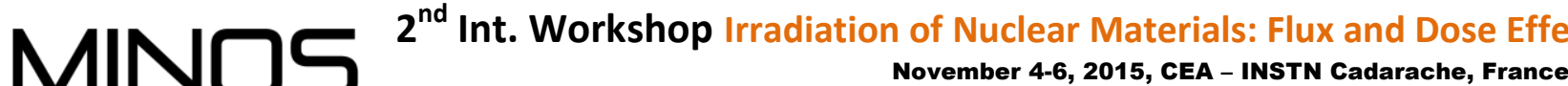

\section{Effect of Clear Bands on Intergranular Stresses and IASCC Early Damage}

\author{
Maxime SAUZAY ${ }^{1}$, Mohamed OULD MOUSSA ${ }^{1}$, Bob DIAWARA ${ }^{2}$, François LEBREAU ${ }^{2}$ \\ ${ }^{1}$ CEA-DEN-DMN, Service de Recherches Métallurgiques Appliquées, SRMA (Saclay, France) \\ ${ }^{2}$ CNRS-ENSCP (UMR7045), Laboratoire de Physico-Chimie des Surfaces, Paris-Tech, (Paris, France)
}

Slip localization is a common feature in post-irradiated metallic poly-crystals undergoing tensile straining. This effect takes place for instance in the form of thin slip bands called channels or clear bands, formed after the local vanishing of irradiation defects induced interactions with gliding dislocations [1-3]. Channel impingement towards grain boundaries (GBs) should induce local stress concentrations along GBs, in the quasi-elastic surrounding matrix. It has been shown extensively that this trigger GB crack initiation [2-3].

Since the fifties, the clear band stress fields have been modeled using the dislocation pile-up theory, which leads to stress singularities similar to the LEFM ones [4]. But such theory does not allow fair predictions of GB fracture, neither in inert or PWR environment [5]. In practice, channel thickness is at least $50 \mathrm{~nm}$ depending on material, temperature and loading conditions. As a matter of fact, many slip planes are plastically activated through the channel thickness. Numerous crystalline finite element (FE) computations have been carried out using microstructure inputs varying in broad ranges (slip band aspect ratio and spacing). Slip bands (low critical resolved shear stress) are embedded in a matrix or small aggregates (high CRSS). Microstructure inputs as well as plasticity parameters are evaluated based on TEM observations and dislocation dynamics computation results. High local stress fields are highlighted (Fig. 1a) but they are nevertheless considerably lower than the ones deduced from the pile-up theory (Fig. 1b). Analytical formulae are deduced from the numerous FE results, accounting for channel thickness, grain size, channel density and crystal / GB orientations $[6,7]$.

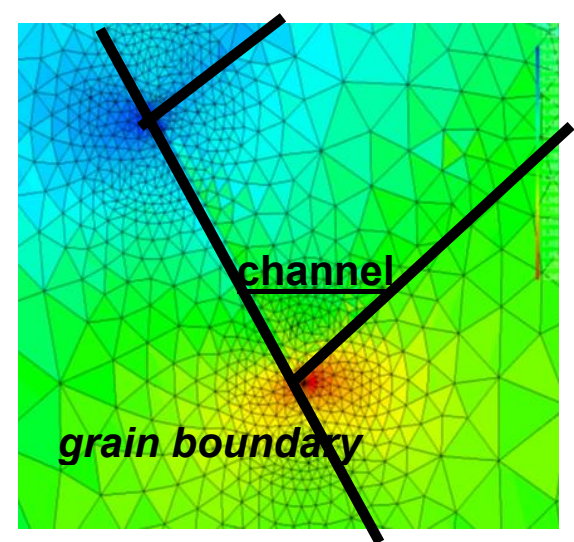

a)

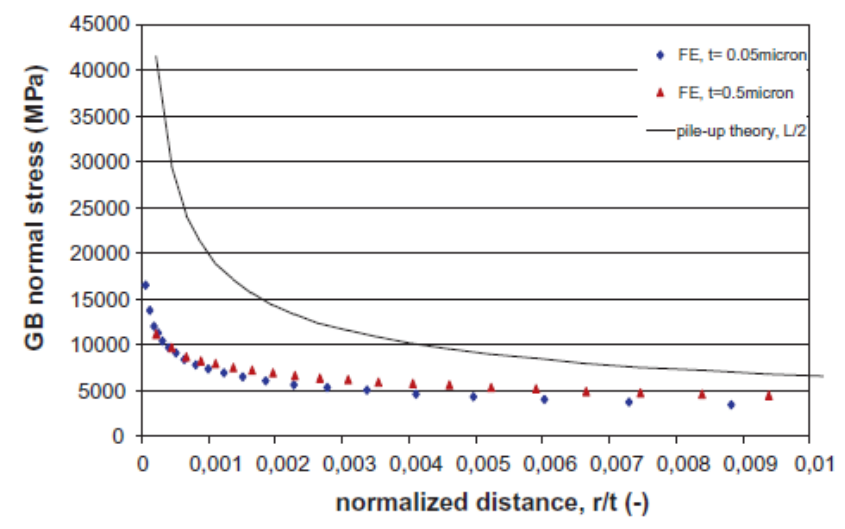

b)

Fig. 1: a) local stress concentration at the GB; b) comparison between the GB stress fields computed using the pile-up theory [4] or by the FE method for various clear band thicknesses.

Grain boundary fracture is simulated using a double criterion based on both critical normal stress and fracture energy as deduced from atomistic computations of GB fracture. The critical stress is deduced from the fracture energy using the universal-binding-energy relationship (UBER). In the case of brittle fracture, the fracture energy is defined as the two fresh free surface energy values minus the GB energy. A close-from expression giving the remote tensile stress to GB fracture is then deduced [6,7]. Finally, GB fracture of pre-irradiated SS (dose > $10 \mathrm{dpa}$ ) loaded in either inert or pressurized water reactor (PWR) environment is predicted for comparison with the existing experimental results obtained in similar conditions. 
In the case of inert environment, free surface and GB energy values are easily found in literature. The predicted remote tensile stress to GB fracture is then equal to the yield stress in agreement with various experimental data (Fig. 2a). In the case of PWR environment, GBs are assumed to be oxidized up to a depth of a few $\mu \mathrm{m}$ due to $\mathrm{Cr}$ depletion induced by the strong RIS observed at high irradiation dose [2]. Either literature data have been used (iron oxides [8]) or they have been computed by the DFT method for various GBs and by accounting for hydratation / hydroxylation of the fresh free surfaces in PWR water $\left(\mathrm{Cr}_{2} \mathrm{O}_{3}\right.$ oxide). Using the lowest fracture energies corresponding to the weakest GBs, the predicted remote tensile stress to oxidized GB fracture is about one-half of the yield stress (Fig. 2b), once more in fair agreement with many experimental data despite no parameter fitting is required.

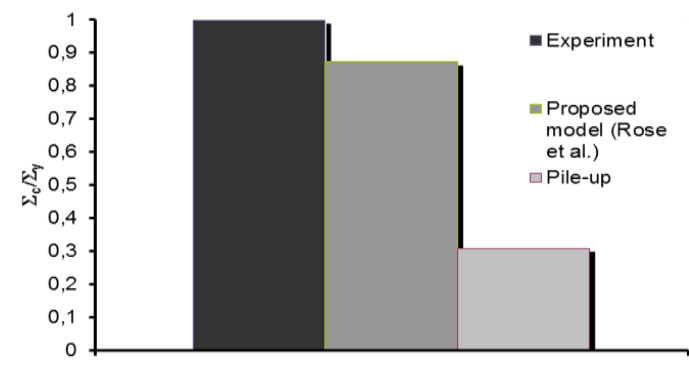

a)

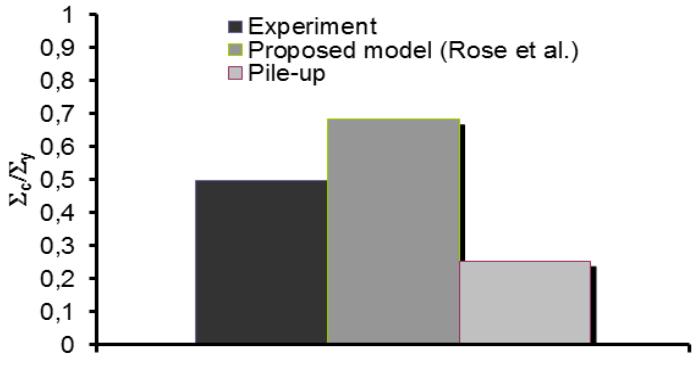

b)

Fig. 2: predicted and measured remote stress to GB crack initiation: a) inert environment [6]; b) PWR environment $\left(\mathrm{Cr}_{2} \mathrm{O}_{3}\right.$ oxide).

In relationship with the more complex topic of irradiation induced stress corrosion cracking (IASCC) occurring in-service conditions, the influence of irradiation dose, strain rate and irradiation creep is finally quantitatively discussed. Due to the complex loading history highlighted by structural FE analysis, strain peaks may induce the formation of clear bands or twin bands. The study of the effect of irradiation creep on the relaxation of the induced GB stress fields shows clearly that the relaxation requires many months due to the linear irradiation creep law. Such durations allows GB oxidation mechanisms to occur leading to a weakening of the GB fracture parameters in the vicinity of the free surfaces. This allows the previous scenario of early damage initiation to occur. Finally, the effect cold-working which induces slip localization in the as-received material is discussed. This research work was supported by the European project PERFORM60 (FP7-232612).

\section{References}

[1] J. S. Robach, I. M. Robertson, B. D. Wirth, A. Arsenlis, In-situ transmission electron microscopy observations and molecular dynamics simulations of dislocation-defect interactions in ionirradiated copper. Phil. Mag. 83 (2003) 955.

[2] G.S. Was, Fundamentals of radiation materials science: metals and alloys. Springer (2007).

[3] B Cui, J Kacher, M McMurtrey, GS Was, IM Robertson. Influence of irradiation damage on slip transfer across grain boundaries. Acta Mater. 65 (2014) 15.

[4] A.N. Stroh, A theory of the fracture of metals. Adv. Physics 6 (1957) 418.

[5] P. Evrard, M. Sauzay, Modelling of the effect of dislocation channel on intergranular microcrack nucleation in pre-irradiated austenitic stainless steels during low strain rate tensile loading. J. Nucl. Mater. 405 (2010) 83.

[6] M. Sauzay, K. Vor, Influence of plastic slip localization on grain boundary stress fields and microcrack nucleation. Eng. Fract. Mech. 110 (2013) 330

[7] M. Sauzay, M. Ould Moussa, Prediction of grain boundary stress fields and microcrack initiation induced by slip band impingement, Int. J. Fract. 184 (2013) 215.

[9] De Leew, T. G. Cooper, Geochim. Cosmochim, Surface simulation studies of the hydration of white rust $\mathrm{Fe}(\mathrm{OH})(2)$, goethite alpha- $\mathrm{FeO}(\mathrm{OH})$ and hematite alpha- $\mathrm{Fe}_{2} \mathrm{O}_{3}$. Acta 71 (2007) 1655. 
Effect of clear bands on intergranular stresses \& IASCC early damage

M. Sauzay ${ }^{1}$, M. Ould Moussa ${ }^{1}$, B. Diawara² \& F. Lebreau²

${ }^{1}$ CEA SACLAY, DEN/DMN, France

${ }^{2}$ Ecole Supérieure de Chimie de Paris, France

maxime.sauzay@cea.fr 


\section{Summary}

Introduction: slip localization \& grain boundary fracture

1- hypothesis

2- grain boundary stress fields

3- Effect of parallel channels

4- grain boundary crack initiation criterion

5- Comparison to experimental observations (irrad. 316L)

6- conclusions \& work in progress 
- Clear Bands (pre-irradiation, followed by constant strain rate tests $\left(10^{-8}-10^{-3} / \mathrm{s}\right)$

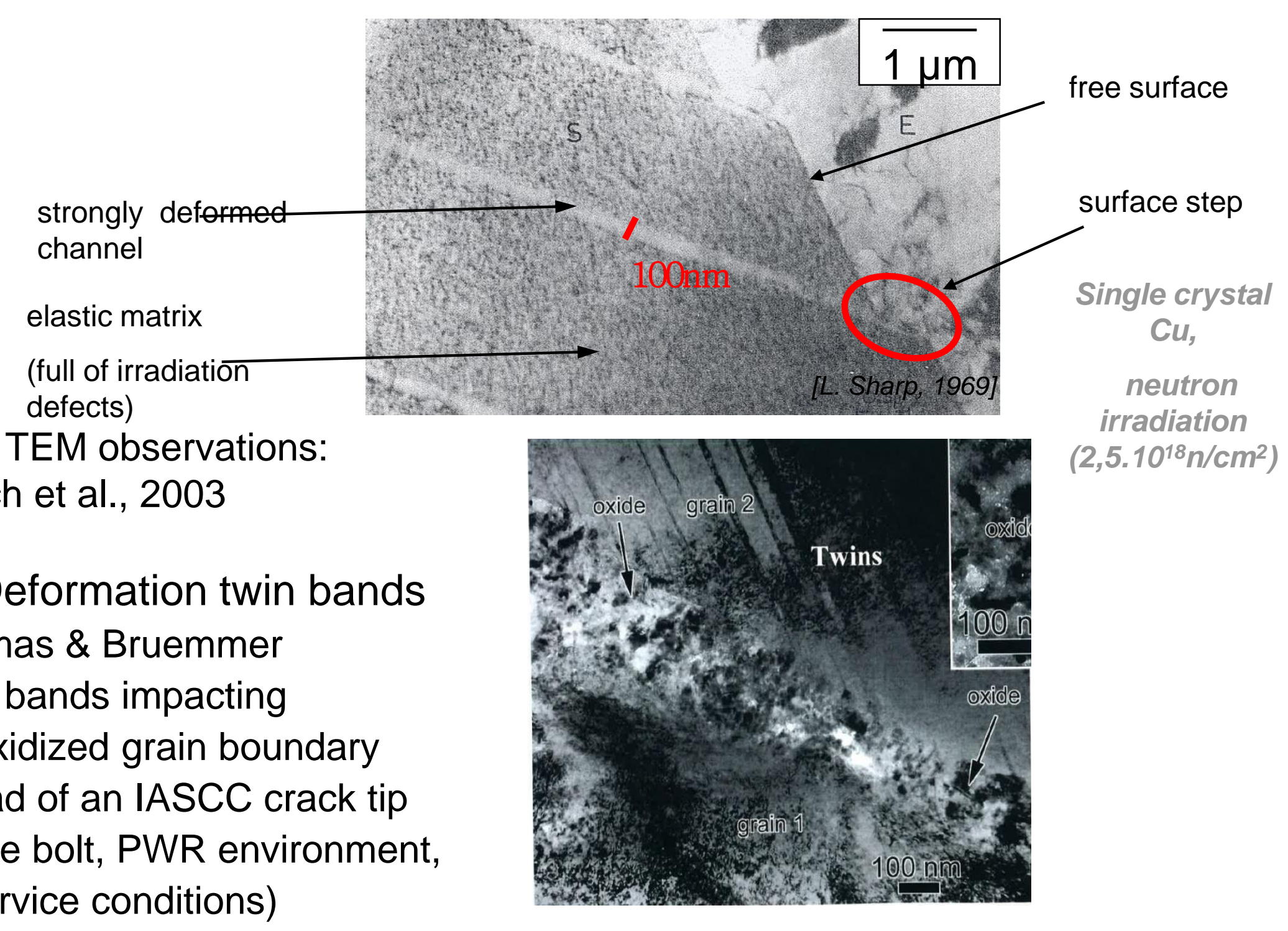

In-situ TEM observations:

Robach et al., 2003

- Deformation twin bands Thomas \& Bruemmer

Twin bands impacting an oxidized grain boundary Ahead of an IASCC crack tip (baffle bolt, PWR environment, in-service conditions)
Single crystal $\mathrm{Cu}$,

neutron irradiation $\left(2,5.10^{18} \mathrm{n} / \mathrm{cm}^{2}\right)$ 

of slip bands \& grain boundaries

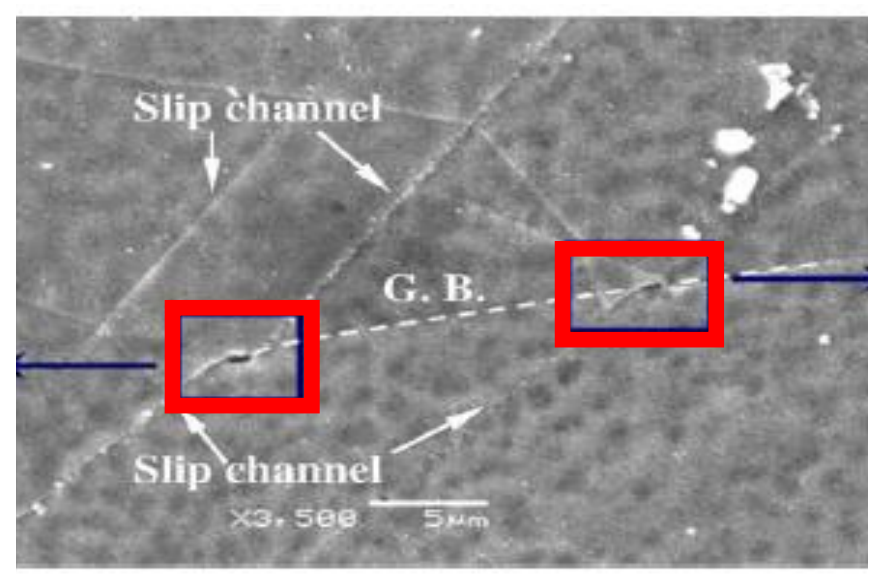

Clear Bands (pre-irradiated materials)

Austenitic stainless steel irradiated and loaded in water environnement up to $1 \%$ (Jiao et al.)

Nishioka et al., 2008: crack initiation without environment effect

Fukuyama et al., 2008; PWR environment
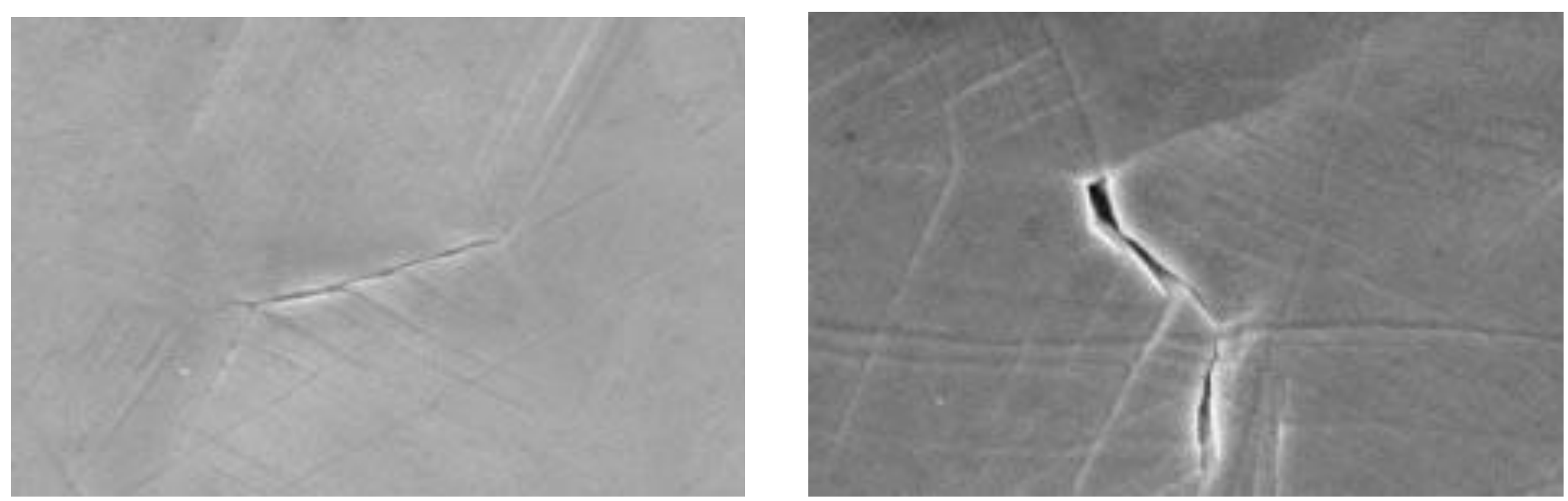

Deformation twin bands

(Bruemmer \& Thomas), ahead of IASCC crack in a baffle bolt 


\section{Cea Introduction: discrete versus continuum modelling}

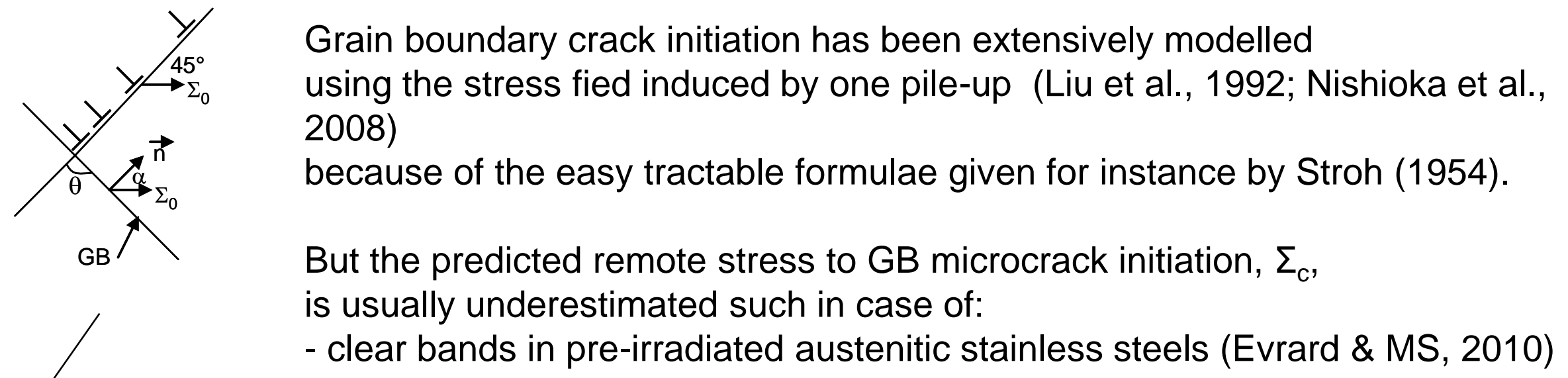

Continuum modelling may be of interest for computing:

- GB stress fields and comparison with classical pile-up one

- GB microcrack initiation criterion $\rightarrow$ easy to use as for the pile-up theory?

- Comparison to experimental data

$>200$ atomic

planes

(clear band)

$\rightarrow \underline{\text { Involved microstructure lengths: }}$

grain size (SEM): $L=5 \mu \mathrm{m}$ to $500 \mu \mathrm{m} \quad$ (used in the pile-up theory) = grain size for channels \& twin bands

width (TEM): $\mathrm{t}=0.02 \mu \mathrm{m}$ to $1 \mu \mathrm{m}$ (neglected in the pile-up theory) 


\section{1- pile-up theories and applications}

\section{Pile-up theory:}

Suitable if parallel dislocations pile-up on the same atomic slip system. Length: Lile-up, Schmid factor: $f=T / \Sigma_{0}$, critical shear stress, $T_{0}$ :

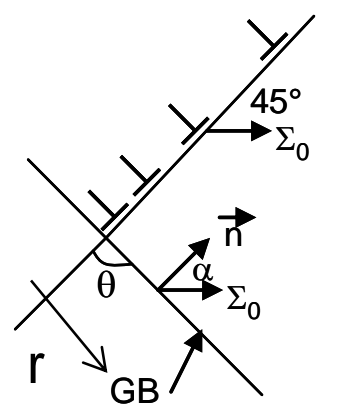

Eshelby, Frank and Nabarro (1951), Cottrell (1951), Stroh (1954)

$\rightarrow$ discrete dislocations

Leibfried (1951), Head and Louat (1955)

$\rightarrow$ continous distributions of dislocations (densities)

Driving force:

$\mathrm{f} \Sigma_{0}-\tau_{0}$

Asymptotic expression ( $b<<r<<$ Lile-up), for instance stress normal to the $G B$ :

$$
\sigma_{n n}^{\text {pile }-u p}(r)=\operatorname{cste}(\theta) \frac{f \Sigma_{0}-\tau_{0}}{\sqrt{2 \pi}}\left(\sqrt{\frac{L^{\text {pile }-u p}}{r}}\right)
$$

$\rightarrow$ Straighforward use if an assumption is made concerning the pile-up length, $L^{\text {pile-up, usually assumed to be close to one-half of the grain size, } L(\text { ??) }}$

Grain boundary crack initiation has been extensively modelled using the stress fied induced by one pile-up (Liu et al., 1992; Nishioka et al., 2008) because of the easy tractable formulae given for instance by Stroh (1954). 


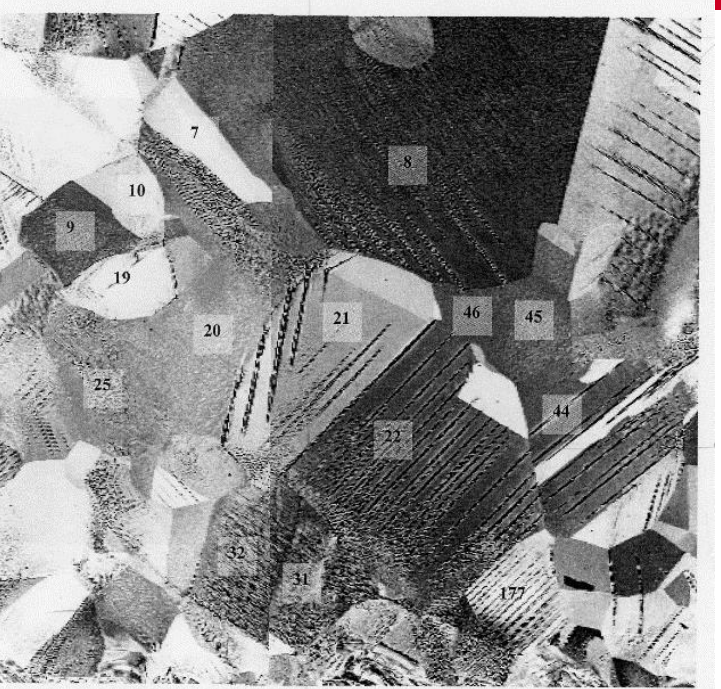

Elastic behaviour

matrix full of defects

assuming displacement \& force continuity at the $G B$

No slip transfert condition (see GB fracture during the in-situ TEM observations of I.

Robertson
Weakly deformed matrix around and between channels: no active source, strong pinning effect of irradiation defects (Sharp, $1967 \rightarrow$ TEM; Young, $1962 \rightarrow$ surface edge pits)

Strongly deformed channels due to easy dislocation glide much less obstacles to dislocation motion. Length generally close to the grain size, L

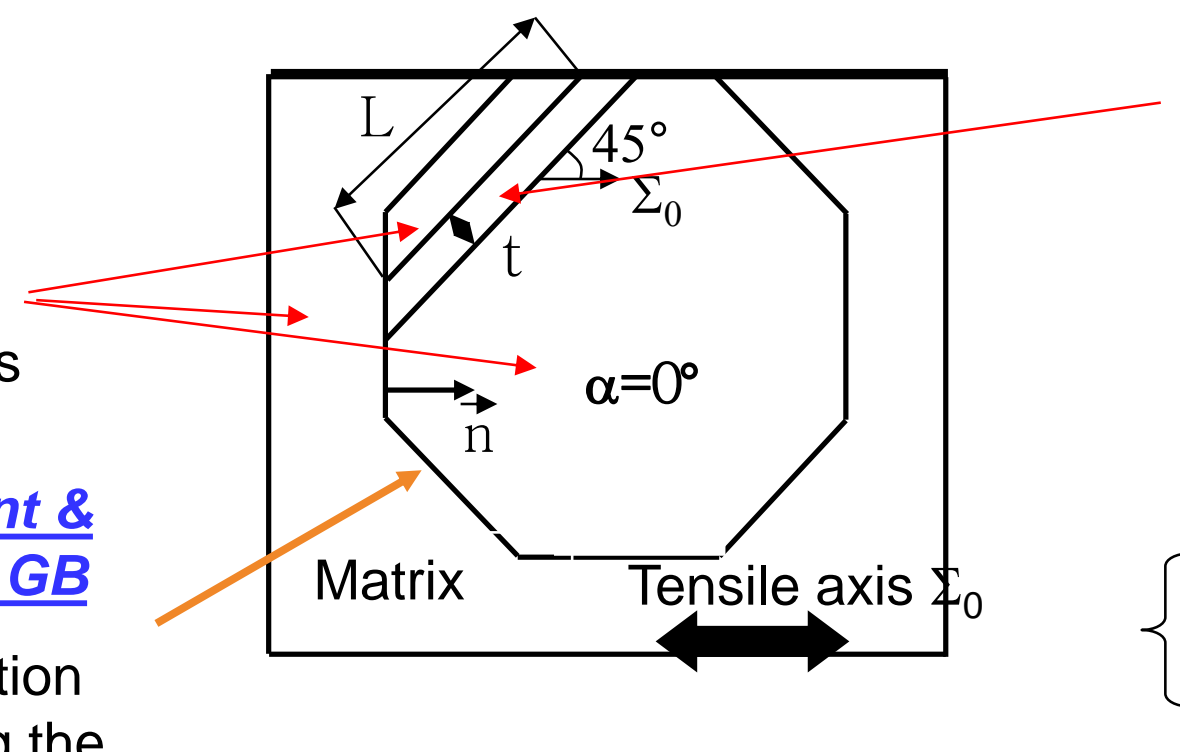

Elastic-plastic behaviour Slip band

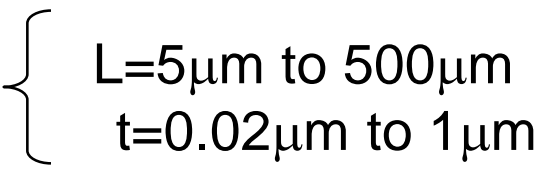




\section{Cea 1 crystalline constitutive laws: channel parameter adjustment}

- Time independent behavior

Tests: $10^{-7} / \mathrm{s} \rightarrow 10^{-2} / \mathrm{s} \&$ Sharp (1967): even at the microstructure scale!

- Quasi perfect plasticity (weak hardening coefficient) $\rightarrow$ channel microstructure similar to the stage I microstructure of non-irradiated copper single crystal (Sharp, 67)

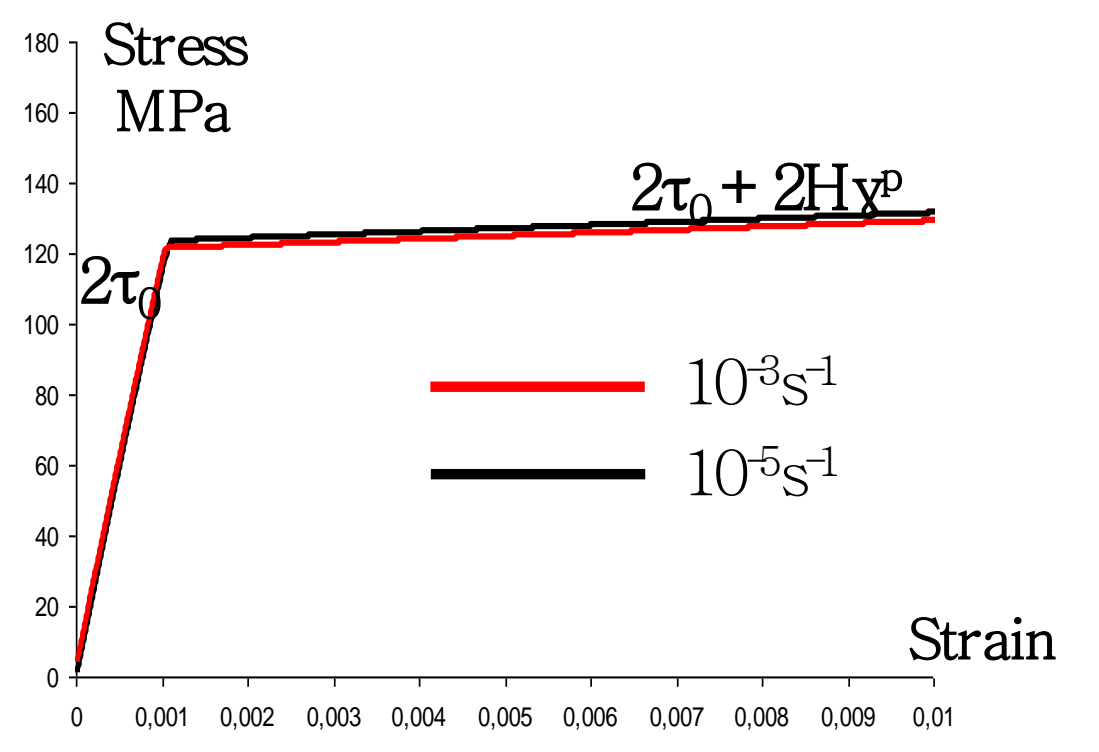

+ Nogaret et al. (DDD),

+ Victoria (experiments)

Three parameters

$\rightarrow$ Critical shear stress: $\mathrm{T}_{0}$

$\rightarrow$ Hardening slope: $\mathrm{H}$

$\rightarrow$ Latent hardening parameter: $q$

Study of the influence of each parameter

(MS \& Vor, Eng. Fract. Mech., 2013)

Stress-strain curve of well-oriented crystal adjustment of $\mathrm{T}_{0}: \quad \sim 10-100 \mathrm{MPa}$

- experimental single crystal tensile curves (Yao et al., 2002, 2004)

- dislocation dynamics outputs (Nogaret et al, 2008)

Finite strain or small perturbation theory $\rightarrow$ rather similar results; plane strain 


\section{Cea 1 Constitutive laws \& FE computations: microstructures}
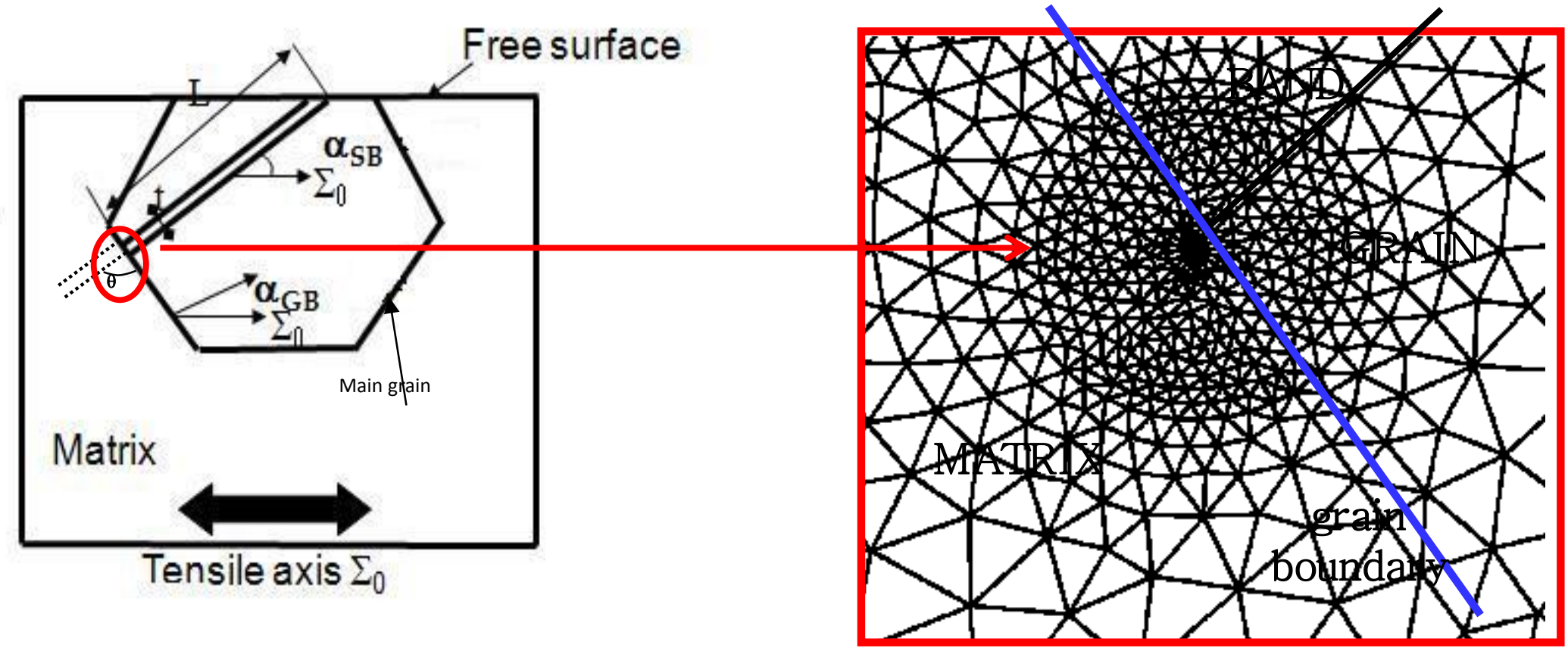

$\theta=90-\alpha_{\mathrm{SB}}+\alpha_{\mathrm{GB}}$
$\left\{\begin{array}{l}\alpha_{\mathrm{SB}}=40-70^{\circ} \\ \alpha_{\mathrm{GB}}=10-50^{\circ}\end{array}\right.$

Study of the mesh size effect: numerical relative error $<5 \%$

Schmid factor: $\quad f=T / \Sigma_{0}=\cos \left(\alpha_{S B}\right) \sin \left(\alpha_{S B}\right)$

Homogeneous isotropic elasticity $(\mathrm{Y}, \mathrm{v})$ 


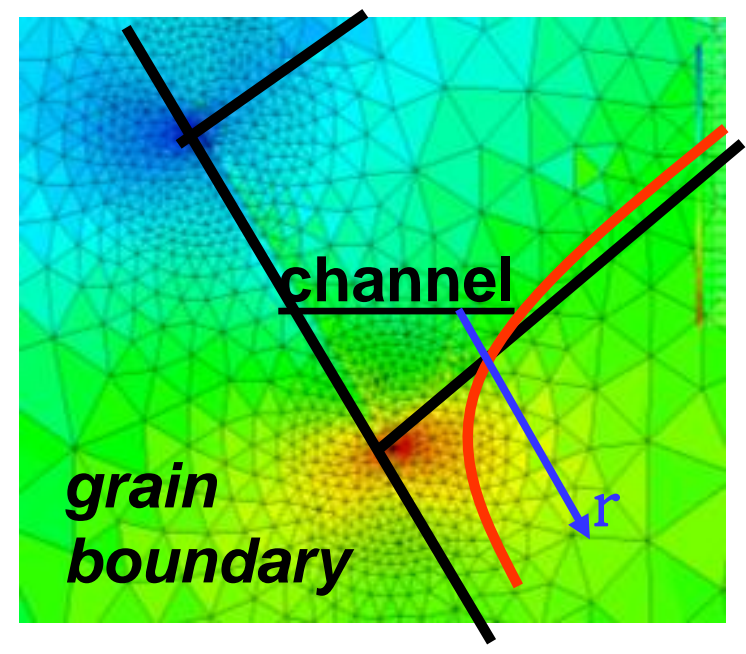

$\rightarrow$ Computation of:

Normal \& shear stresses along the grain boundary at a distance ' $r$ ' of the band: plot of $r \rightarrow \sigma_{n n}(r)$ assuming displacement \& force continuity at the $G B$

Normal stress at the grain boundary far from the slip band defined

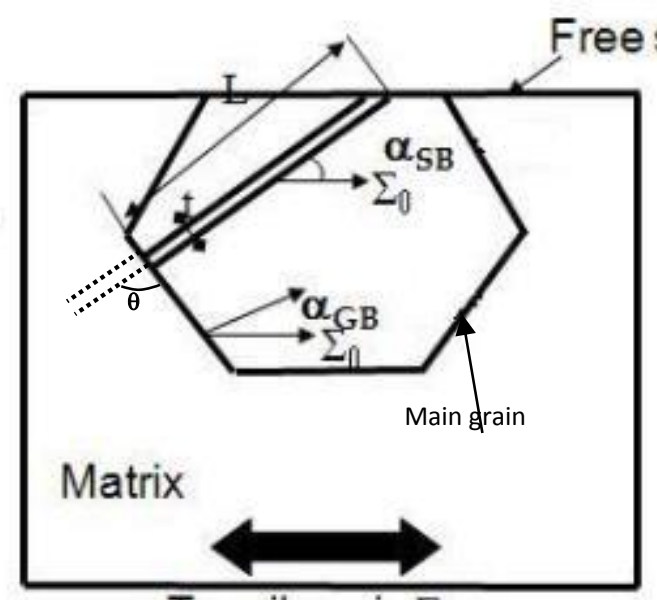

Tensile axis $\Sigma_{0}$

$$
\Sigma_{n}^{\infty}=\Sigma_{0} \cos ^{2} \alpha_{G B}
$$

Far away from the channel: $\Sigma_{n}(r) \rightarrow \Sigma_{n}^{\infty}$

$\Sigma_{0}=2 \mathrm{~T}_{0}-800 \mathrm{MPa} \leq$ macroscopic yield stress in austenitic steels irradiated at high dose 

'close-field': $\quad \underline{r<<t<L}$
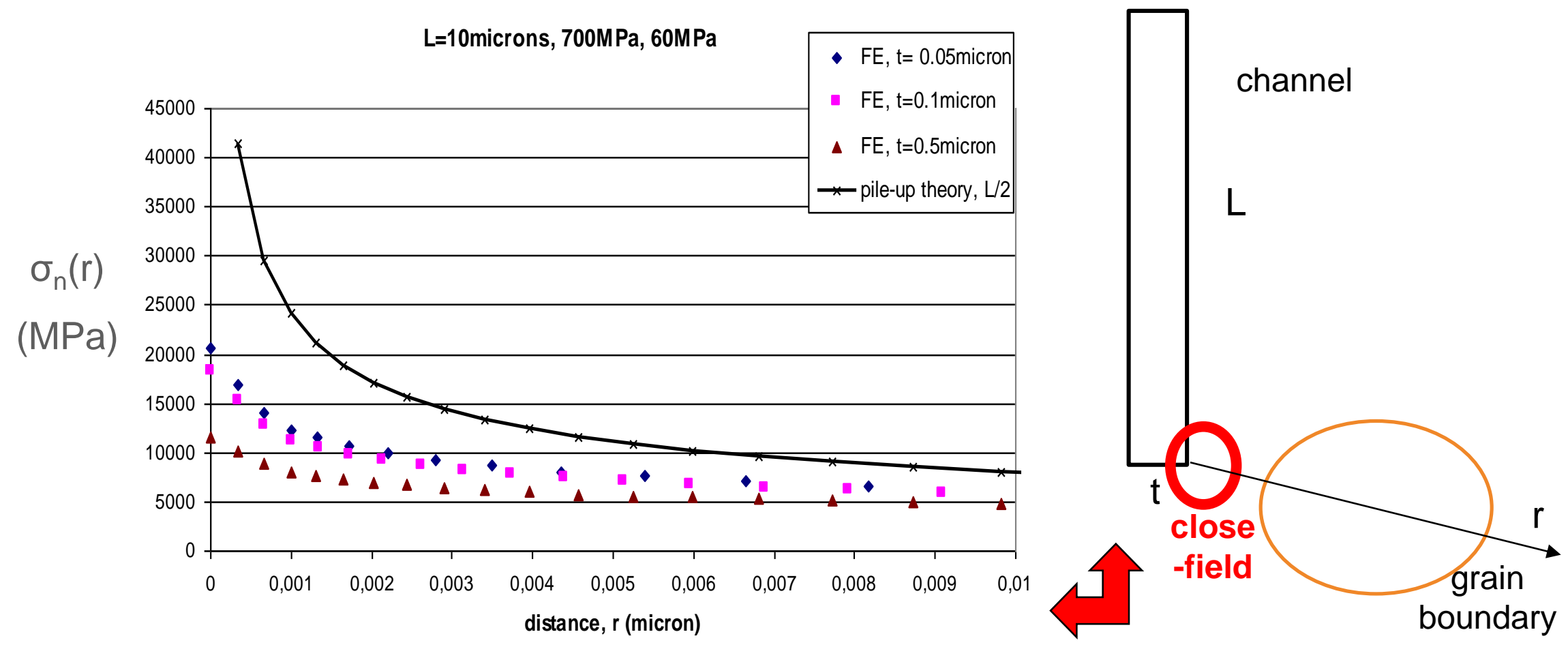

- Large overestimation by the pile-up theory

using a length equal to one-half of the grain size (factor 2-3)

-Very close to the intersection of the channel and grain boundary:

weaker singularity due to the notch effect $\quad \rightarrow \sigma_{n}(r) \sim 1 / r^{\alpha}, \alpha=0.27<0.5 \quad(r<<t)$

slip band plasticity

single slip (only 1 stress degree of freedom saturated) 


\section{'far-field' $\quad \underline{\mathrm{t}<\mathrm{r}<<\mathrm{L}}$}
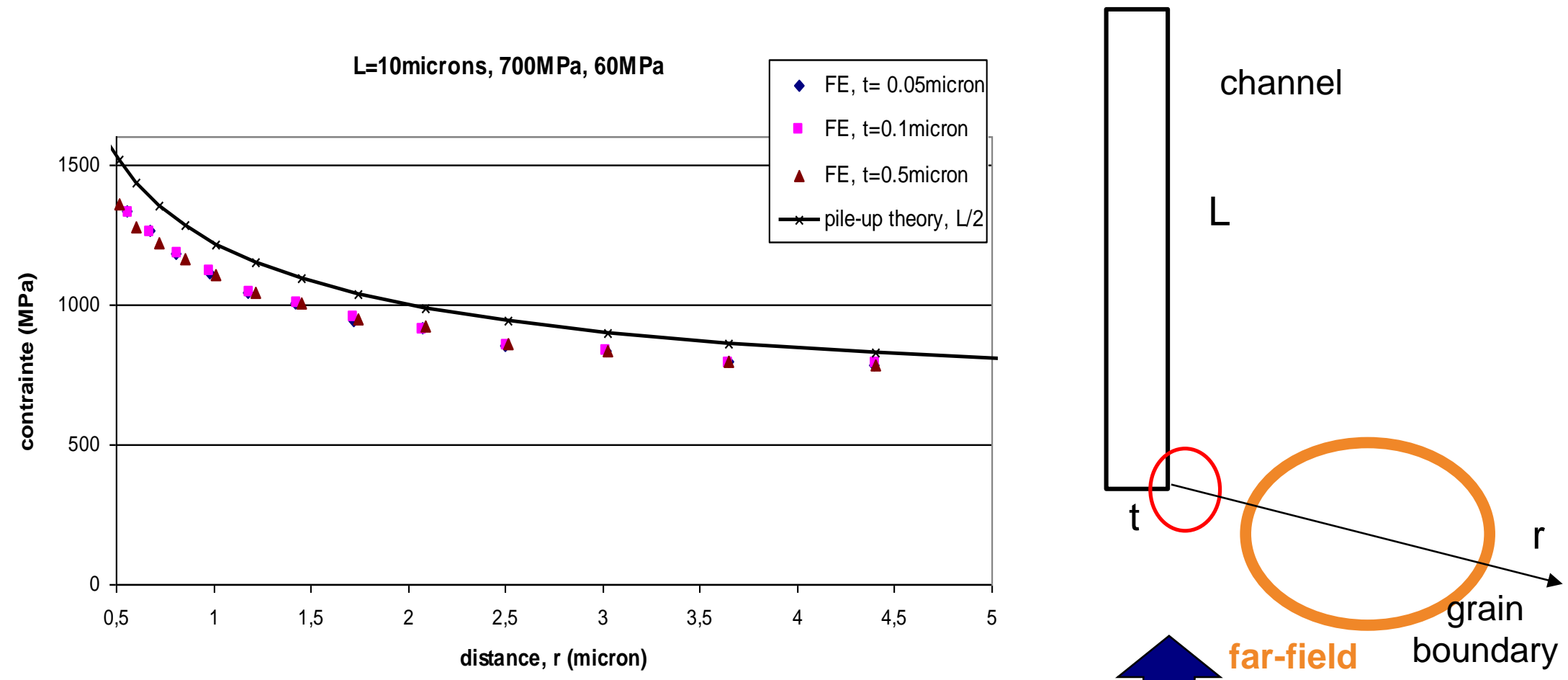

-Whatever the grain size $\mathrm{L}$ and the aspect ratio, $\mathrm{L} / \mathrm{t}$, the discrepancy between the pile-up theory prediction and the curves computed by the FE method is lower $10 \%$

-In fact, if $r>t$, the stress singularity is very close to the pile-up or crack one as expected (Leguillon et al., 2007) 


\section{Enhanced analytical formulae}

(Sauzay \& Vor, Eng. Fract. Mech., 2013)

GB stress field close-form expressions valid for $r<<t<<L, \alpha(\theta)=1-\lambda(\theta)=0.27<0.5$ :

$$
\begin{array}{ll}
\sigma_{n n}(r)=A_{n n}(\theta)\left(f \Sigma_{0}-\tau_{0}\right) \sqrt{\frac{L}{t}\left(\frac{t}{r}\right)^{1-\lambda}+\Sigma_{n}^{\infty}} & \begin{array}{r}
\alpha_{\mathrm{SB}}=45^{\circ}, \alpha_{\mathrm{GB}}=33^{\circ} \\
\theta=90-\alpha_{\mathrm{SB}}+\alpha_{\mathrm{GB}}
\end{array} \\
\tau_{n m}(r)=A_{n m}(\theta)\left(f \Sigma_{0}-\tau_{0}\right) \sqrt{\frac{L}{t}\left(\frac{t}{r}\right)^{1-\lambda}+T_{n}^{\infty}} &
\end{array}
$$

Whatever:

slip band length (grain size)

slip band thickness

$$
\begin{aligned}
\mathrm{L}: & 5-100 \mu \mathrm{m} \\
\mathrm{t}: & 0.02-1 \mu \mathrm{m}
\end{aligned}
$$

Young's modulus (aluminium, copper, nickel, 316L steel)

slip band initial critical shear stress $\mathrm{T}_{0}: 0: 10-100 \mathrm{MPa}$

q $>>1 \quad$ (imposed single slip)

remote tensile stress: $\Sigma_{0}=2 \mathrm{~T}_{0}-800 \mathrm{MPa}$

Pile-up singularity: GB normal stress field

$$
\sigma_{n n}{ }^{\text {pile-up }}(r)=A_{n n}{ }^{\text {pile-up }}(\theta)\left(f \Sigma_{0}-\tau_{0}\right) \sqrt{\frac{L}{r}}+\Sigma_{n}^{\infty}
$$

No SB thickness dependence and strong uncertainty concerning: L ${ }^{\text {pile-up }} \sim \mathrm{L} / 2$ 


\section{2 numerical evaluation of the stress singularity parameters?}

For a given microstructure $\left(\alpha_{S B}, \alpha_{G B}\right)$, with $\theta=90-\alpha_{S B}+\alpha_{G B}$, what are the values of $A_{n n}(\theta), A_{n m}(\theta)$ and $\alpha(\theta)$ ?

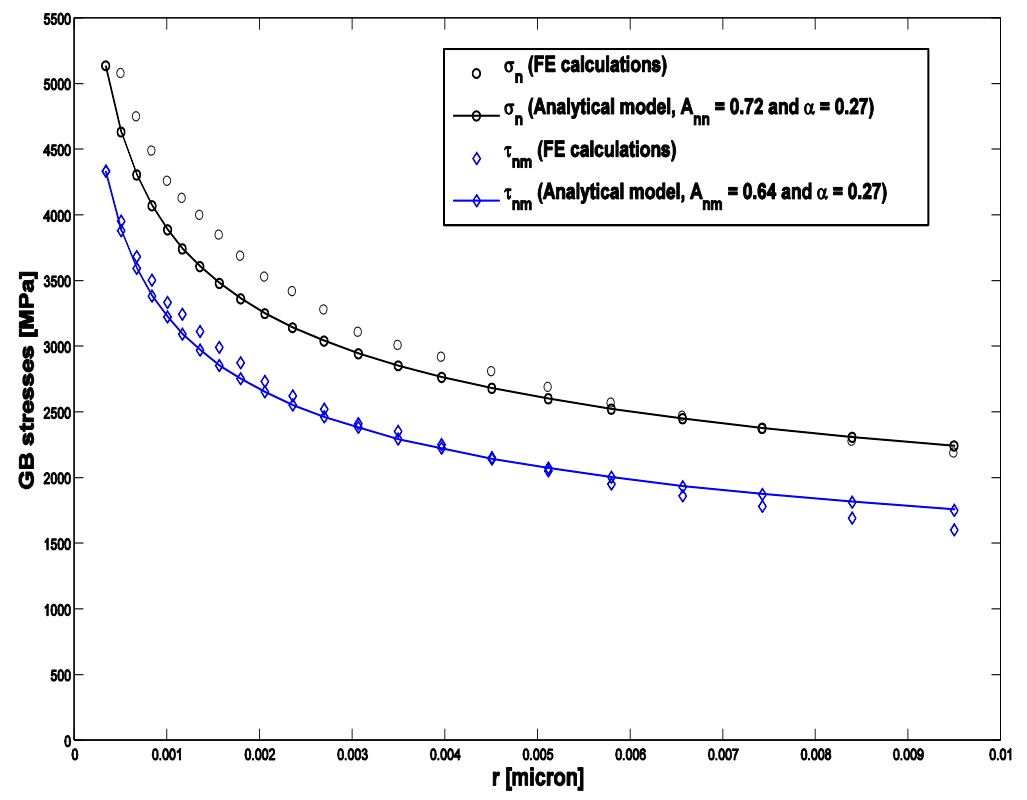

For each set of angle parameters, $\alpha_{\mathrm{SB}}$ and $\alpha_{\mathrm{GB}}$, for instance $45^{\circ}$ and $33^{\circ}$ $\left(\theta=78^{\circ}\right)$, the coefficients are adjusted using:

- one GB normal stress and one GB shear stress curves computed by FE for

- only one set of slip band characteristic sizes $(L=10.7 \mu \mathrm{m}, t=0.09 \mu \mathrm{m})$,

- only one remote tensile stress magnitude $\left(\Sigma_{0}=393 \mathrm{MPa}\right)$ 


\section{Validation of the close-form expressions (I)}

Comparison with the curves computed by the FE method: relative difference lower than $7 \%$ for $r<<t$ whatever $L$ and $\Sigma_{0}$
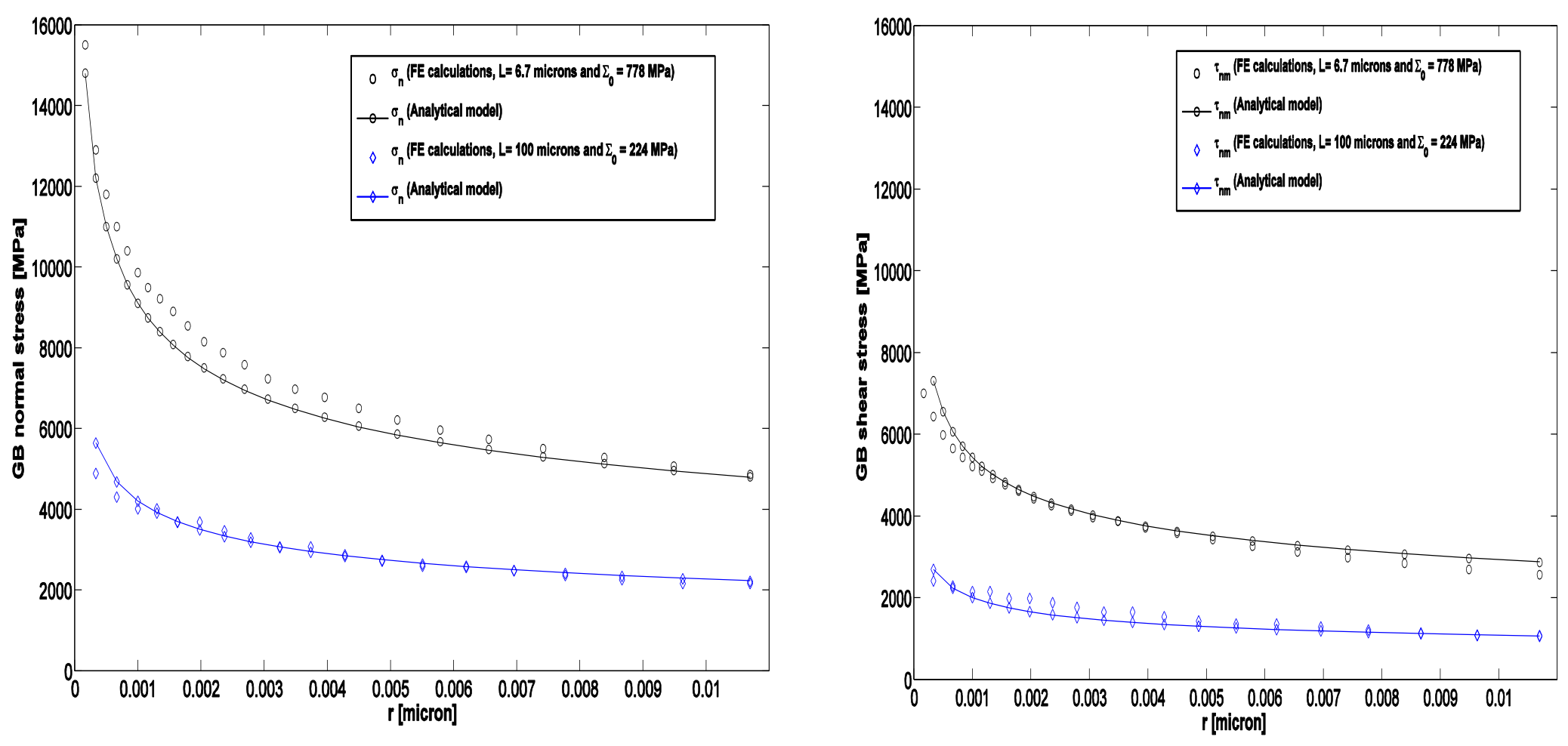

$\mathrm{L}=6 / 100 \mu \mathrm{m}$ and $\Sigma_{0}=200 / 800 \mathrm{MPa}$ 
Comparison with the curves computed by the FE method: relative difference lower than $7 \%$ for $r<<t$ whatever $t$ and $\Sigma_{0}$
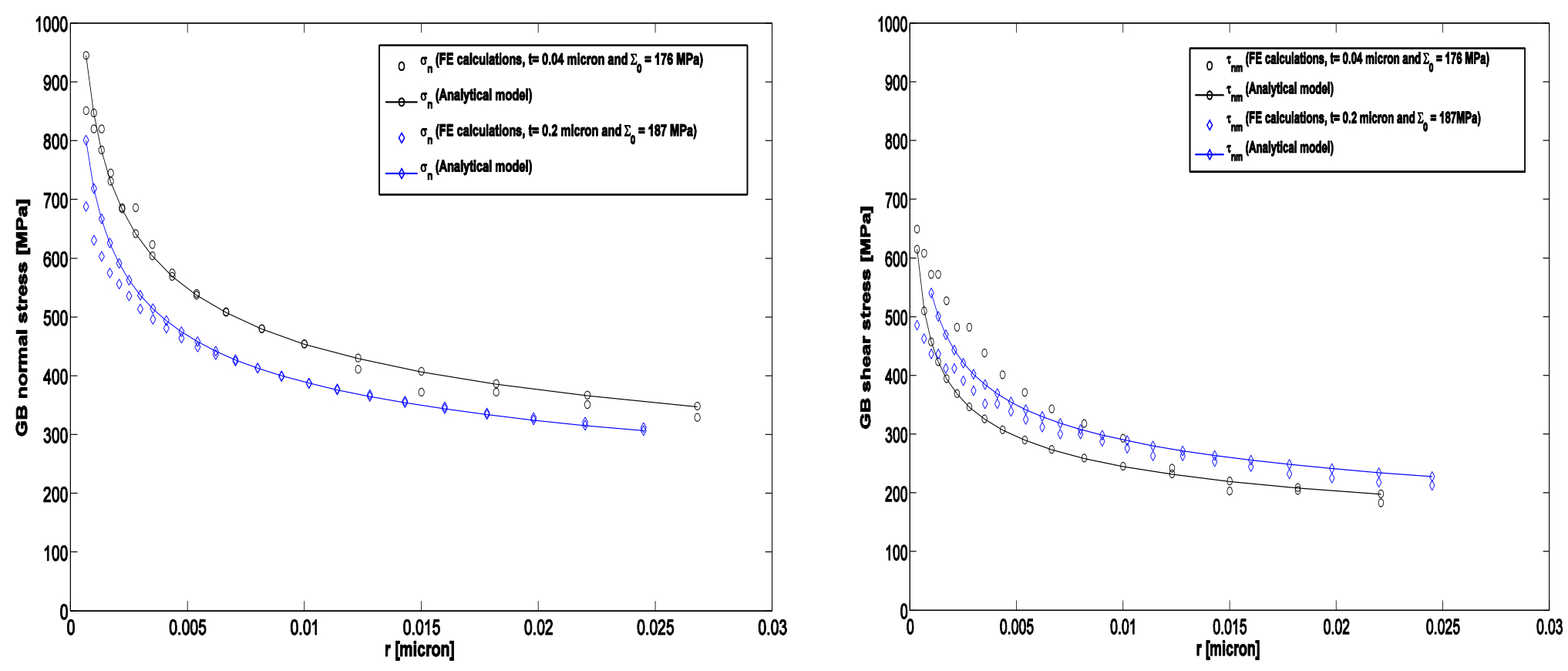

$\mathrm{t}=40 / 200 \mathrm{~nm}$ 
The influent parameter is: $\theta=90-\alpha_{\mathrm{SB}}+\alpha_{\mathrm{GB}}$

$$
\left(\alpha_{\mathrm{SB}}=40-70^{\circ}, \alpha_{\mathrm{GB}}=5^{\circ}-50^{\circ}\right)
$$

It does not affect the stress exponent value, $\alpha$, but affects the values of the GB normal and shear stress coefficients, $A_{n n}(\theta)$ and $A_{n m}(\theta)$
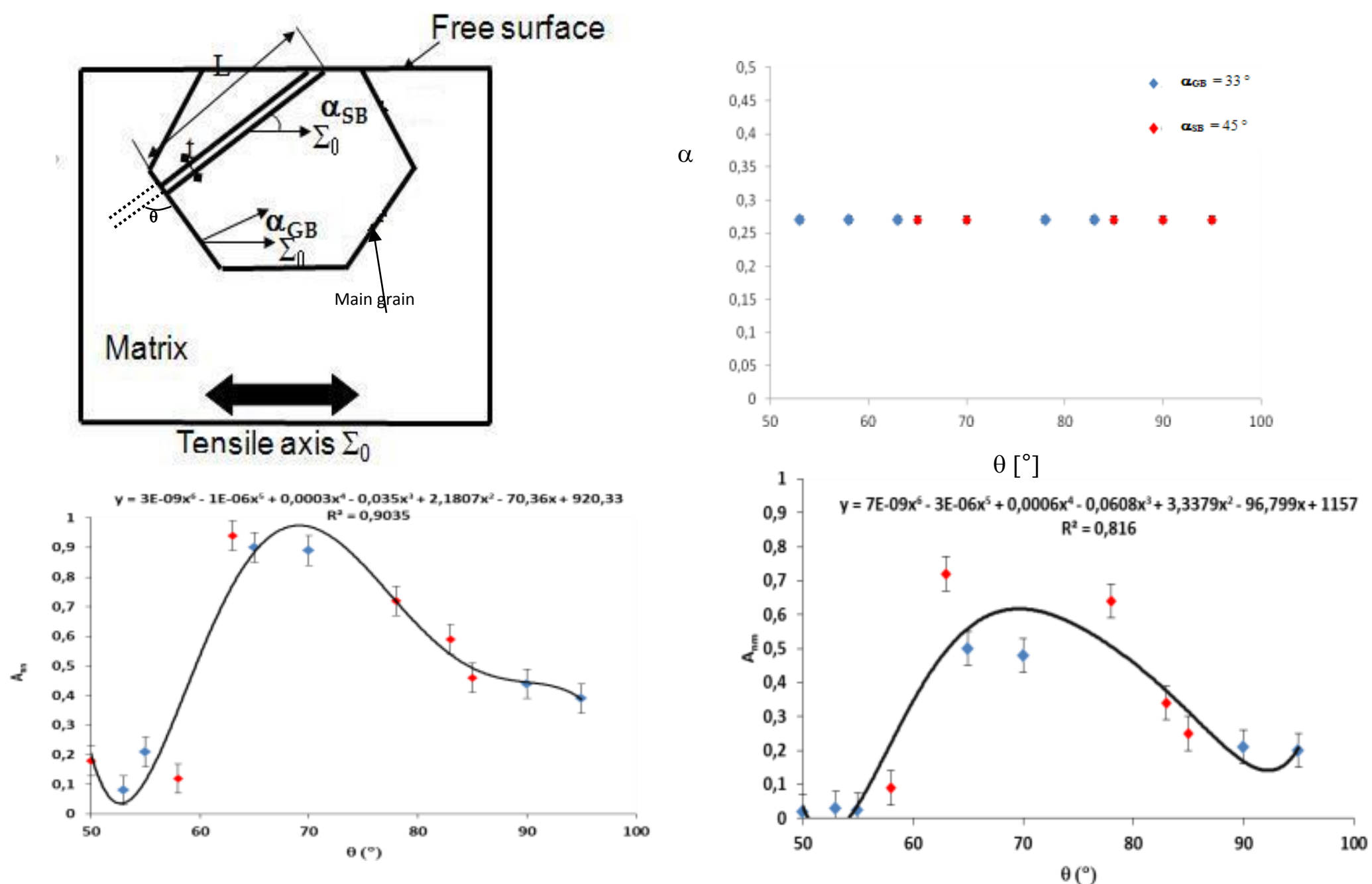


\section{3-Effect of additional parallel clear bands}
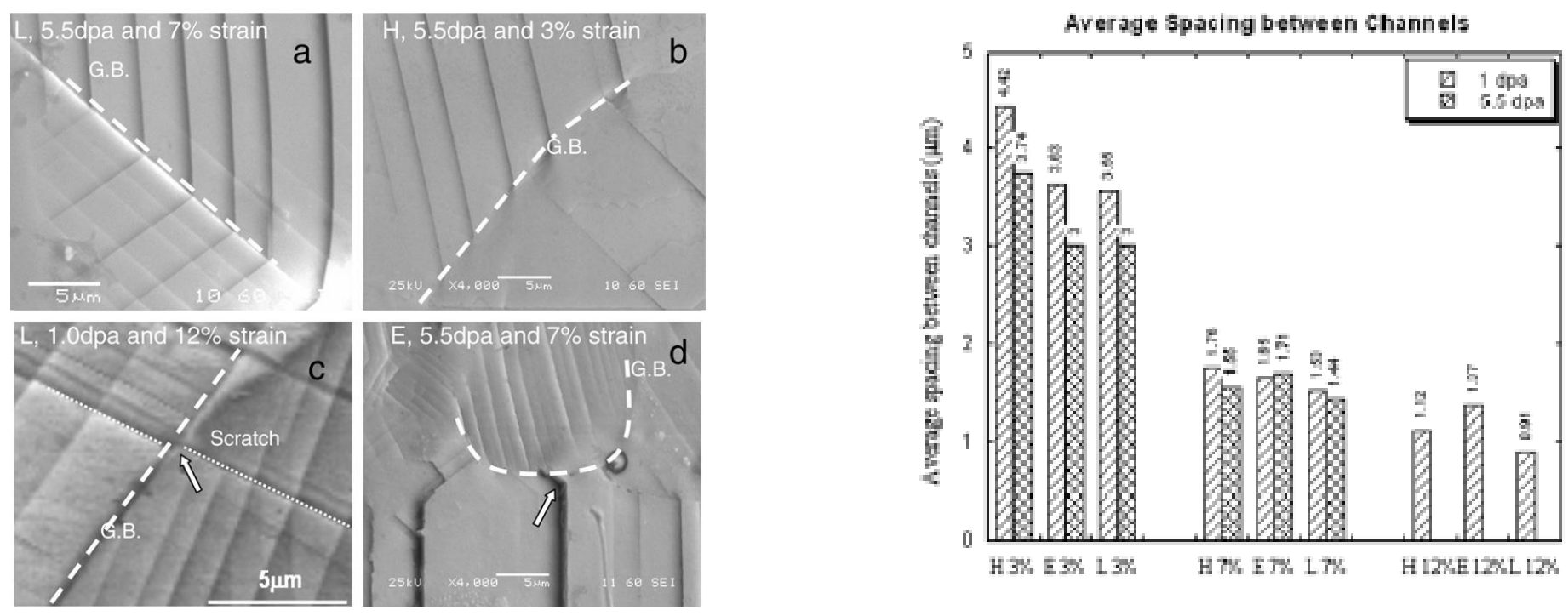

(Jiao et al., 2007)

Following TEM observations:

Grain size:

Channel thickness:

Inter-channel spacing:
$\mathrm{L}=10 \mu \mathrm{m}$

$\mathrm{t}=50 \mathrm{~nm}$

$\mathrm{d}=1-5 \mu \mathrm{m}$ 


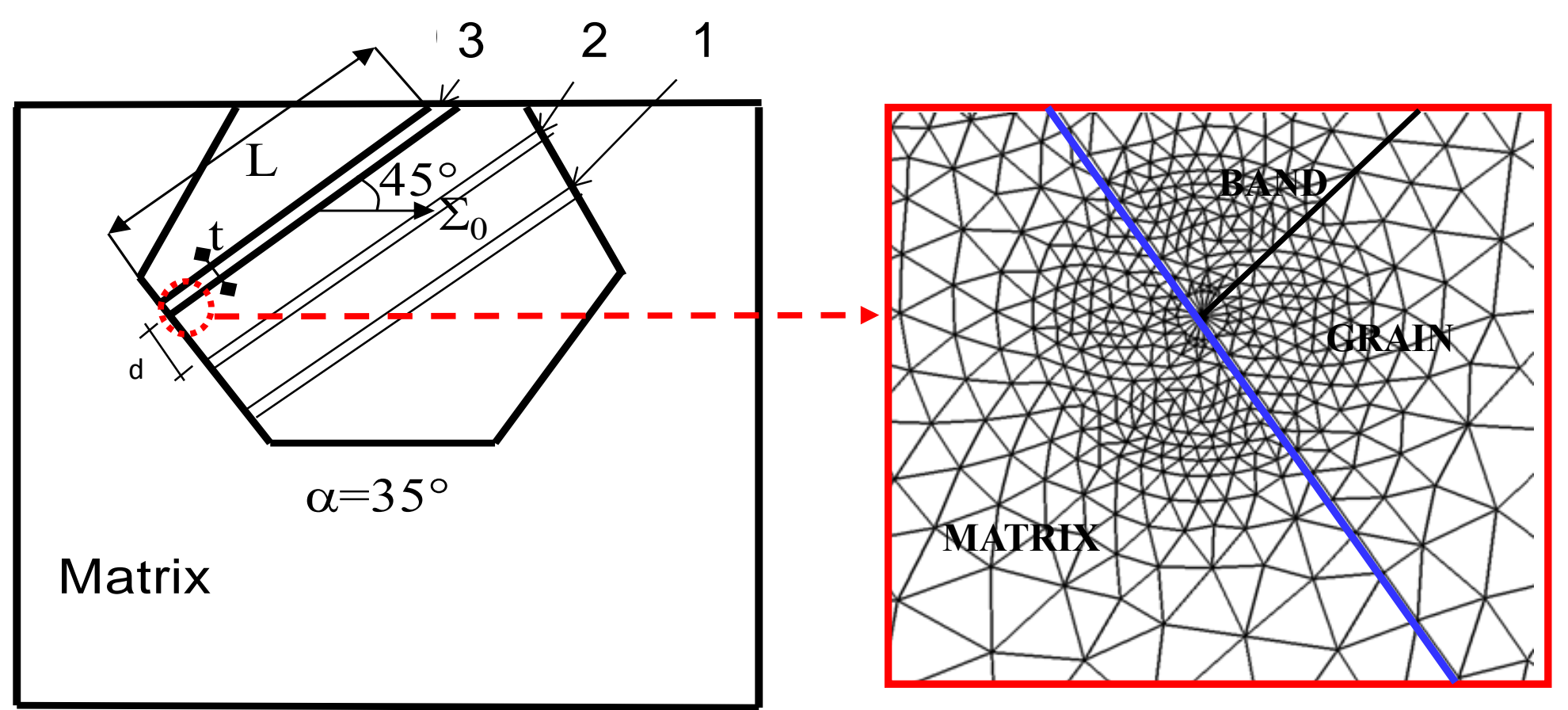

Modified FE meshes allowing the study of the influence of 0,1 or 2 neighbouring channel(s) on the GB stress field. 


\section{3- Effect of additional parallel clear bands}

Influence of the inter-channel spacing:

$$
d=1-5 \mu m
$$

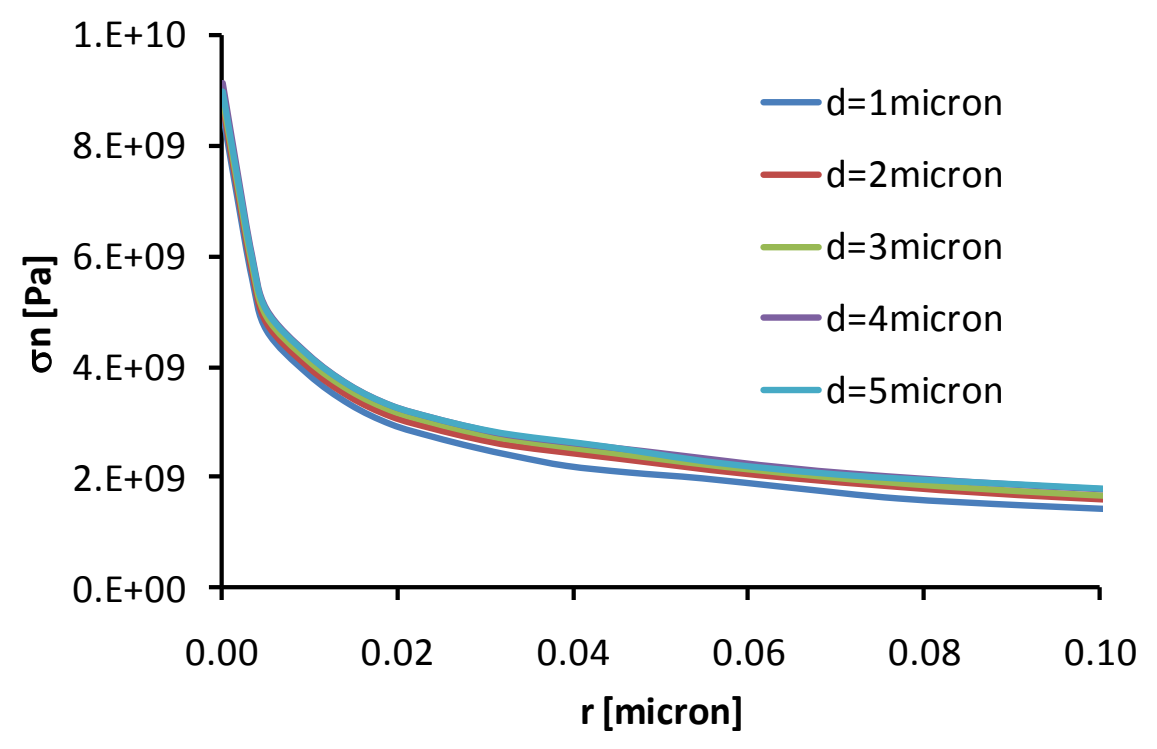

channel 3

For spacing belonging to the physical range of variation, only a negligible effect of the precise value of the spacing is found $\rightarrow$ Its exact value does not influence predictions. 


\section{Cea 3- PARALLEL SLIP BANDS}

Reference : isolated clear band $\left(\alpha_{S B}=45^{\circ}\right): A_{n n}=0,72$

Grain boundary orientation $\alpha_{\mathrm{GB}}=35^{\circ} /$ the tensile axis

SB 6

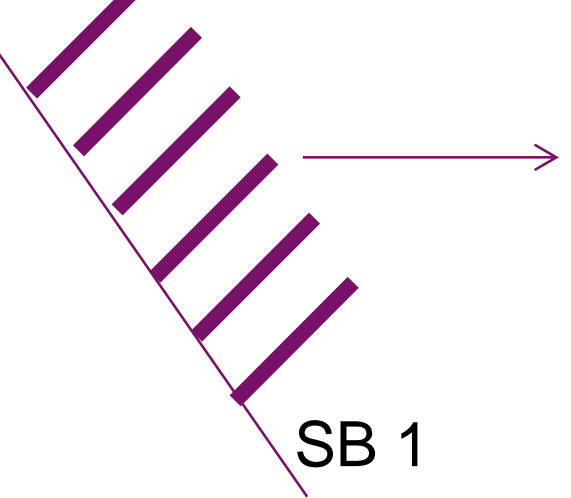

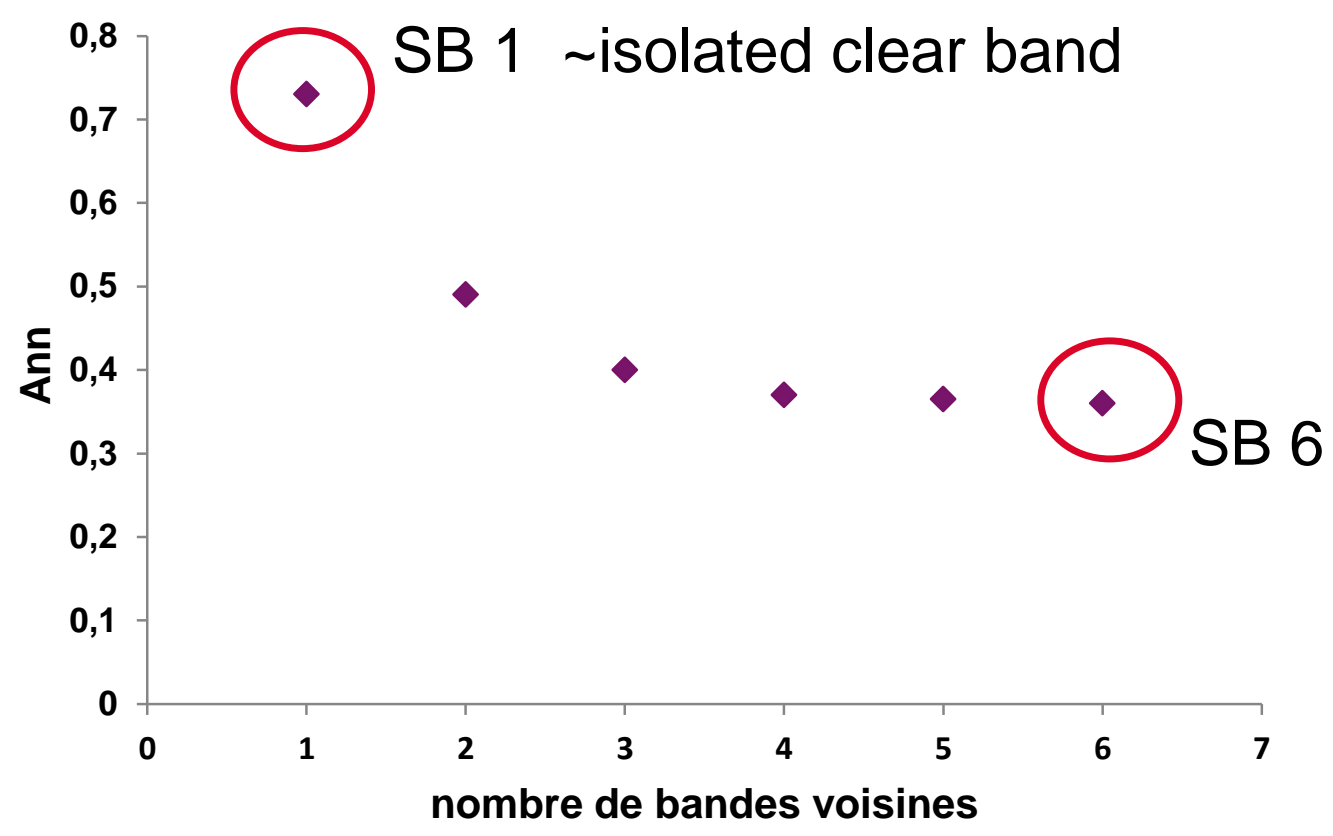

High screening effect: the stress singularity is divided by about two with respect to the reference case of an isolated clear band 


\section{Pile-ups}

Suitable if parallel dislocations pile-up on the same atomic slip system.

Fracture mechanics was applied during the fifties leading

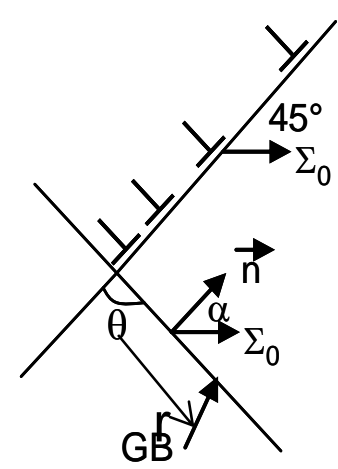
to clos-form expressions of the remote stress leading to GB fracture
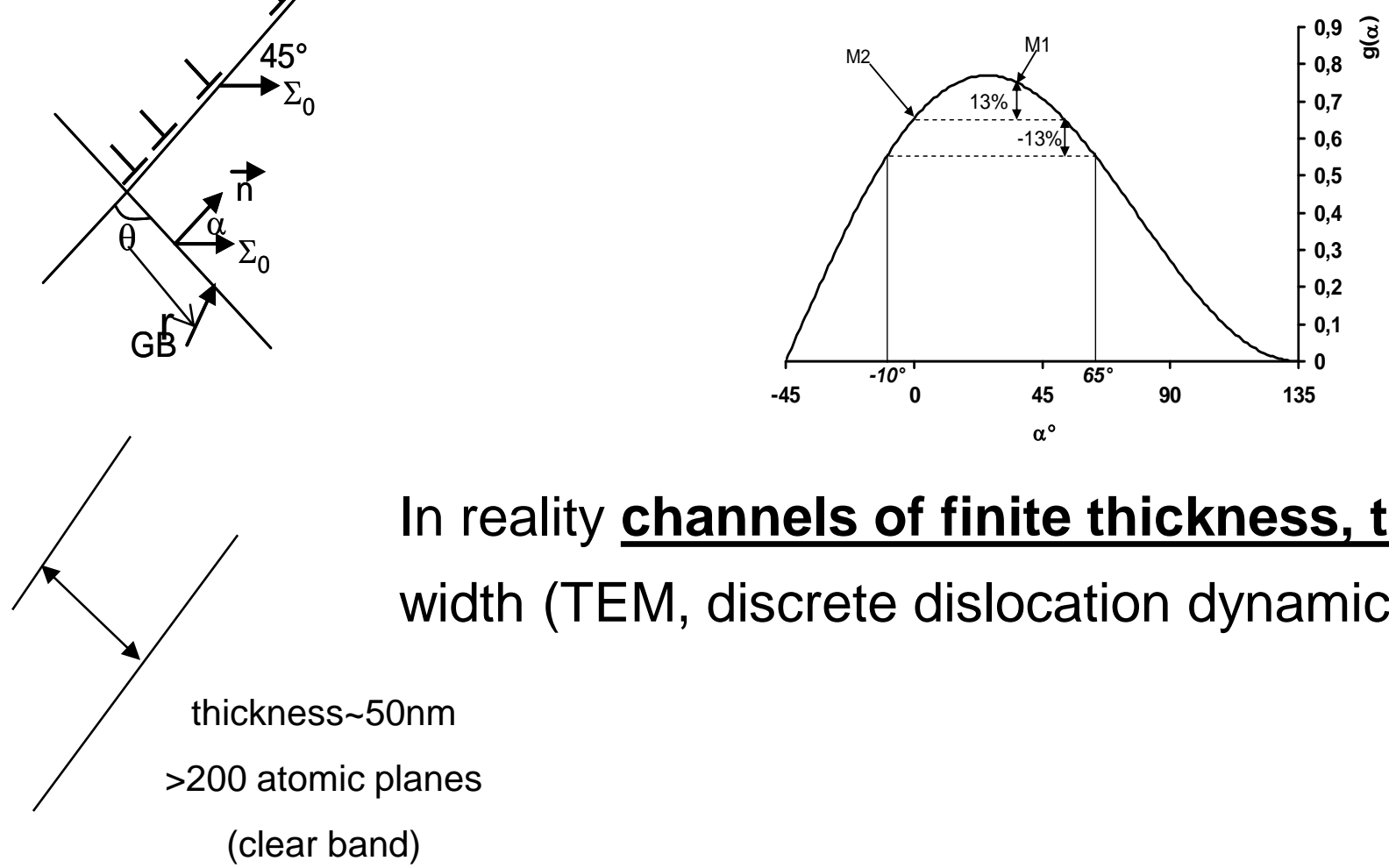

May we predict grain boundary fracture for the two kinds of slip localization? 


\section{Cea 4- Double fracture criterion (Leguillon, 2002; Taylor et al., 2005)}

(i) Stress criterion applied to the previous GB normal stress fields

If $0<r<a_{c}$ then $\sigma_{n n}(r)<\sigma_{c}$

The universal bounding assumption allows the evaluation of the local brittle fracture stress depending on the fracture energy (Rose et al., 1981; Rice and Wang, 1989)

normal stress $(r)$

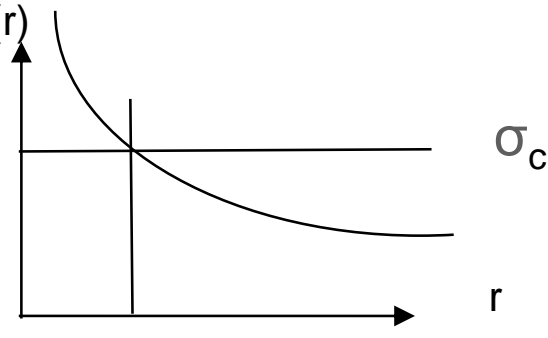

$a_{c}$

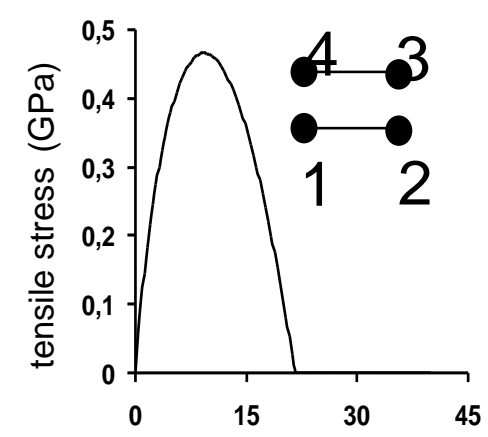

separation $\mathrm{nm}$

$$
\sigma_{c}=e \sqrt{\frac{Y \gamma_{\text {fract }}}{2 d_{0}}}
$$

with $Y$ the Young 's modulus and $\mathrm{d}_{0}$ the distance between two atomic planes.

(ii) Energy balance equation (finite fracture mechanics)

$$
\int_{0}^{a_{c}} J(a) d a=\gamma_{\text {fract }} a_{c}=\left(2 \gamma_{s}-\gamma_{G B}\right) a_{c}
$$

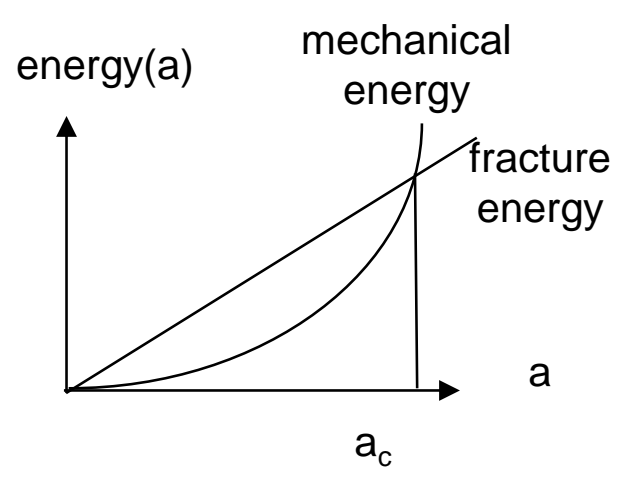




\section{4-CLOSE-FORM EXPRESSIONS} FOR PREDICTING GB FRACTURE

\section{(Sauzay \& Vor, Eng. Fract. Mech. 2013)}

Two equations and two unknown values $\left(\Sigma_{\mathrm{c}}\right.$ and $\left.\mathrm{a}_{\mathrm{c}}\right)$ ?

remote stress to $\mathrm{GB}$ fracture initiation

crack nucleus of finite length

The remote critical tensile stress to GB microcrack initiation is given by:

$$
\Sigma_{c}=\left(1 / f\left(\alpha_{S B}\right)\right)\left(\tau_{0}+\left(\frac{2 \lambda}{Y C(\theta)}\right)^{1-\lambda} A_{n n}(\theta)^{1-2 \lambda}\left(\frac{t}{L}\right)^{1 / 2}\left(\frac{d_{0}}{t}\right)^{1-\lambda} e \sqrt{\frac{Y \gamma_{\text {fract }}}{2 d_{0}}}\right)
$$

SB \& GB angles $\mu$ lengths material properties

And the critical microcrack length by:

$$
a_{c}=4 \lambda\left(\frac{A_{n n}(\theta)^{2}}{e Y C(\theta)}\right) d_{0}
$$




\section{5- Comparison between predictions and experimental values. Computation of the clear band plastic slips}

The general analytical formula may be written:

$$
\gamma^{p}=C(v) \frac{L}{t} \frac{f \Sigma_{0}-\tau_{0}}{\mu}
$$

Schmid factor: $\mathrm{f}=\mathrm{T} / \Sigma_{0}$, critical shear stress, $\mathrm{T}_{0}$ $L$ \& t: channel length and thickness

(Sauzay, Bavard and Karlsen, JNM, 2010)

The measured values of the lengths \& thickness of individual clear bands have been used in the computations

The predicted plastic slips display the same order of magnitude As the values measured by AFM (surface clear bands) and TEM
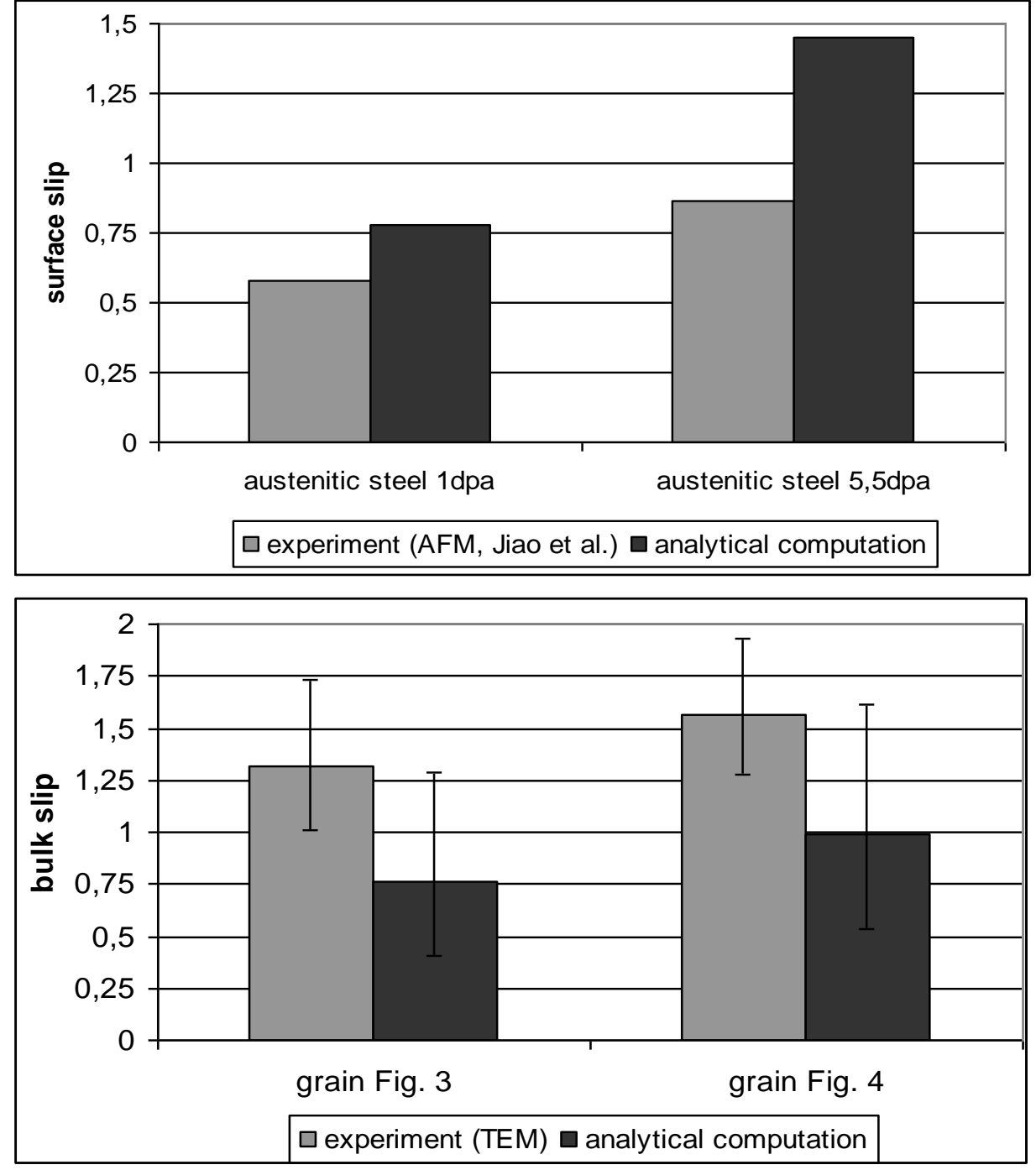


\section{5- Application to irradiation-assisted stress corrosion cracking} (316L)

(Sauzay \& Vor, Eng. Fract. Mech., 2013)

without oxidation:

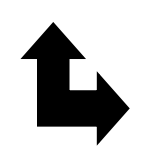

FCC metals/ alloys (316L) : $\gamma_{\mathrm{s}}=2-3 \mathrm{~J} / \mathrm{m}^{2}$

$\gamma_{\mathrm{GB}} \sim 0 .-1.2 \mathrm{~J} / \mathrm{m}^{2}$

(Vitos et al., 1998; Caul et al., 1996; Wolf, 1989)

Post-irradiation tensile tests carried out in argon environment:

Nishioka et al. (2008), Fukuya et al. (2008), Toivonen et al.... (dose: $4 \rightarrow$ 35dpa)

$\rightarrow$ Experimental results for inert environment:

$$
\Sigma_{\mathrm{c}} \sim \Sigma_{\mathrm{y}, \text { irradiated }}
$$

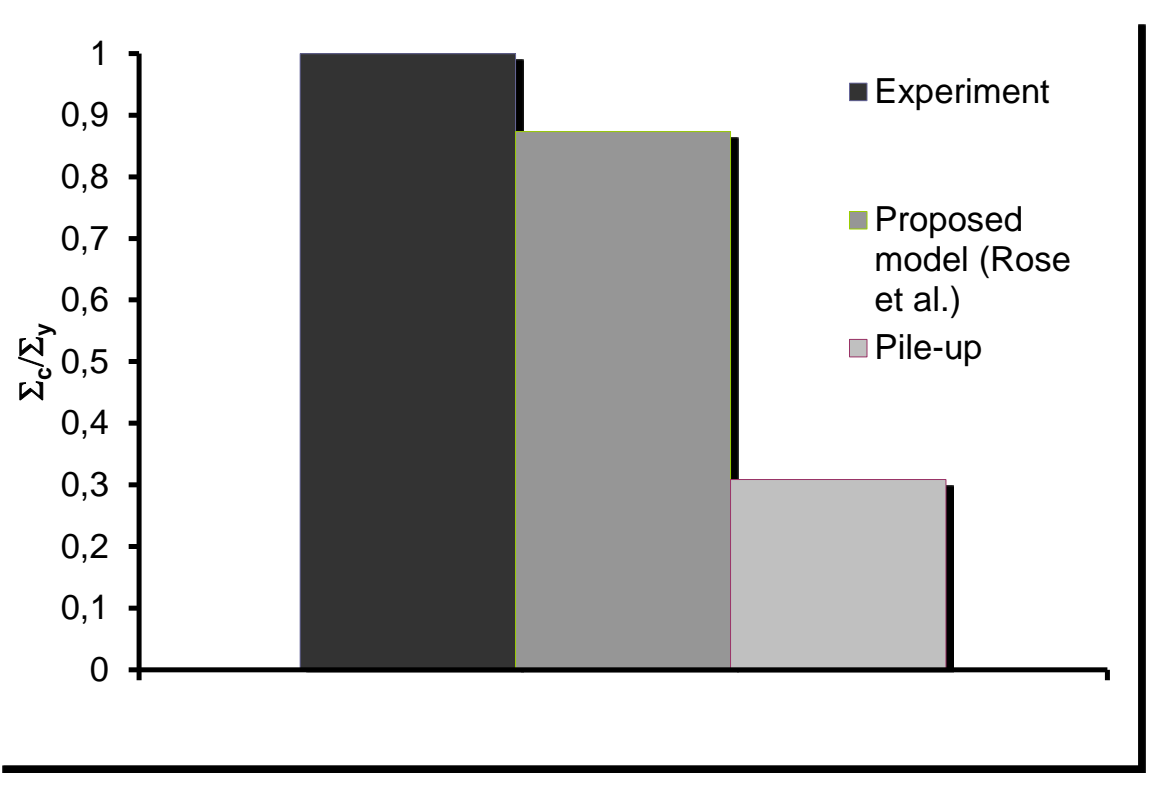

Sauzay and Vor, Eng. Fract. Mech., online, 2013 predictions:

- the proposed criterion (finite thickness: $t=50 \mathrm{~nm}$ )

- the Smith-Barnby criterion (pile-up model)

$\mathrm{L}=50 \mu \mathrm{m}$,

$\gamma_{\mathrm{s}}=2.5 \mathrm{~J} / \mathrm{m}^{2}$, general GB $\left(\gamma_{\mathrm{GB}}=1.2 \mathrm{~J} / \mathrm{m}^{2}\right)$

$\mathrm{f}=0.5, \mathrm{~T}_{0}=60 \mathrm{MPa}$

microstructure data: Nishioka, Fukuya, 08

pile-up model $\rightarrow$ predicted critical stress $~ 30 \%$ of the measured one

no slip localization $\rightarrow$ no GB fracture 


\section{5- Oxidized grain boundary (PWR water environment, high neutron dose?)}

dose $>10 \mathrm{dpa} \rightarrow \mathrm{Cr}<12 \%$ in some of the GBs (radiation induced segregation) (Bruemmer et al., 1999) $\rightarrow$ not enough passivation occurs. (Was, review on IASCC, 2003)

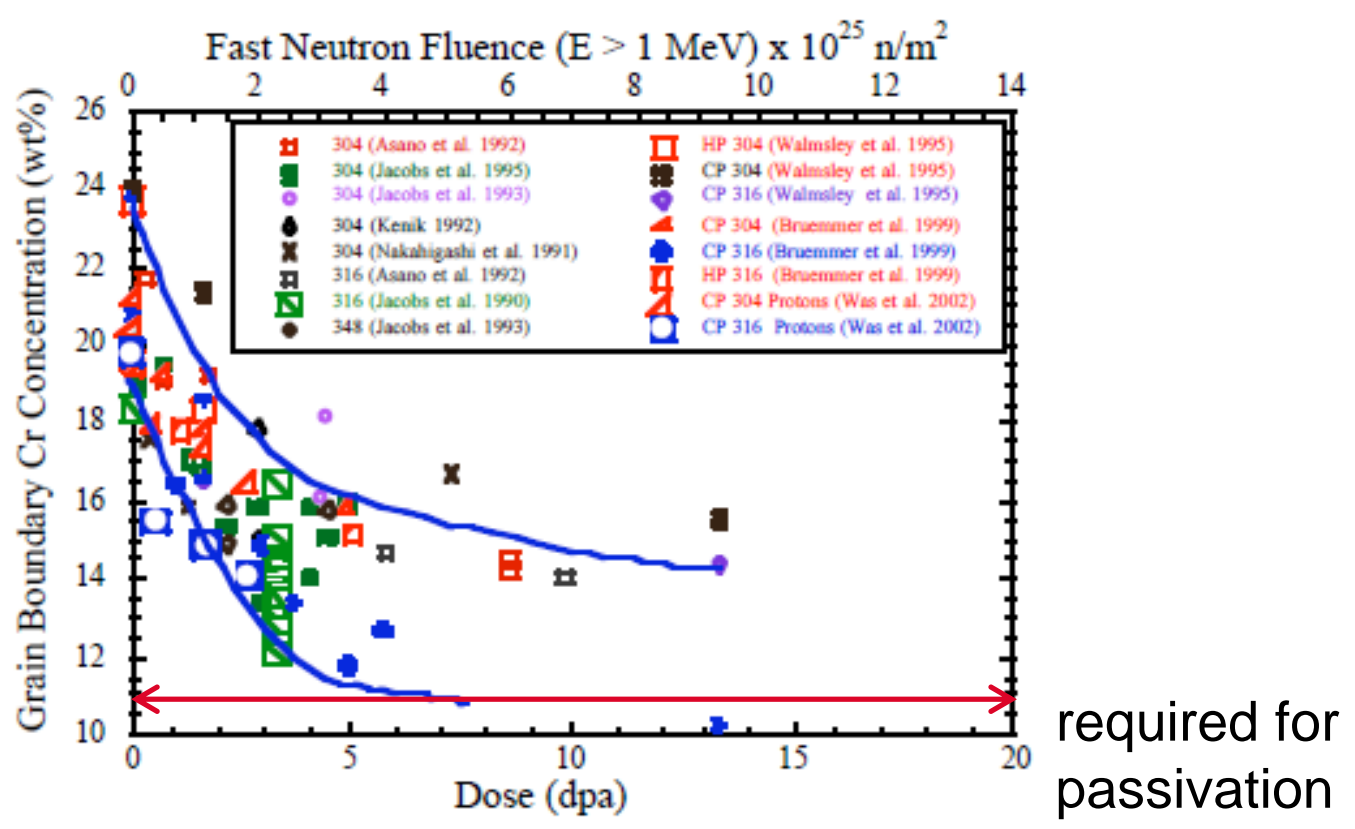

Figure 1. Dose dependence of radiation induced segregation for several 300 -series austenitic stainless steels irradiated at a temperature of about $300^{\circ} \mathrm{C}^{6-13}$

Was, review, 2003 


\section{5- FRACTURE IN PWR WATER}

Hypothesis valid for dose $>10$ dpa at least (to be checked by experimental / numerical studies of oxydation in PWR conditions, see the talk of S. Perrin):

i) the $\mathrm{O}$ diffusivity is high enough to lead to oxydation along the GB for a depth of a few $\mu \mathrm{m}$ (Dugdale et al.,13) $\rightarrow$ typical inter-channel spacing

$\rightarrow$ decrease of the fracture energy, $\left(2 \gamma_{s}-\gamma_{G B}\right)$

ii) the grain boundary is made of Fe-Cr oxyde(s)

iii) $\mathrm{Fe}_{2} \mathrm{O}_{3}, \mathrm{Cr}_{2} \mathrm{O}_{3}$ :

free surface energies computed by ab-initio, strongly dependent on hydratation \& hydroxydation with water molecules $(\mathrm{O} / \mathrm{metal}$ surface termination)

(de Leeuw et al, 2007)

\& collaboration with B. Diawara \& F. Lebreau (DFT, VASP, a+U correction) Grain boundary energy depends strongly on the plane \& O / metal surface termination

$\rightarrow$ Consistent input data? Because the considered surfaces should be consistent with the chosen GB! 
5- (0001) GB and surfaces with Cr termination

Cla (B. Diawara \& F. Lebreau, ESPC)

white: Cr atoms, red: 0 atoms; GB: mirror plus in plane shift

$(10 \overline{1} 2)$

$\mathrm{Cr}_{2} \mathrm{O}_{3}$ (0001) Cr terminated,

no interaction with water

$00 \div 00: 00: 0 /$

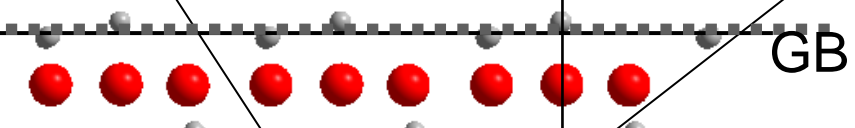

0

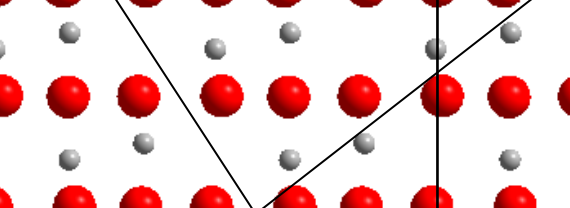

-

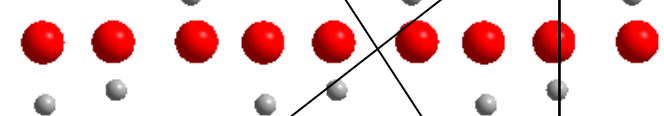

(1014)

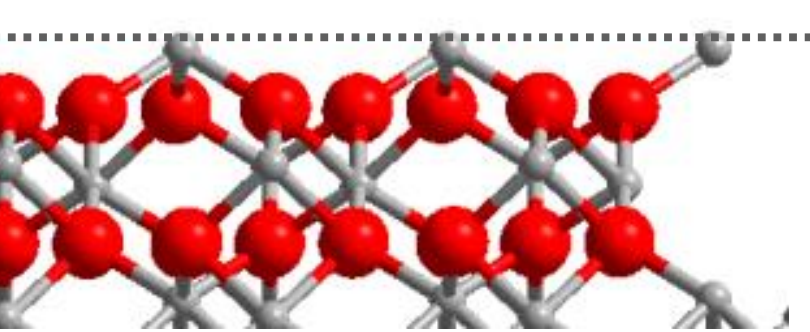

surface

before relaxation

surface

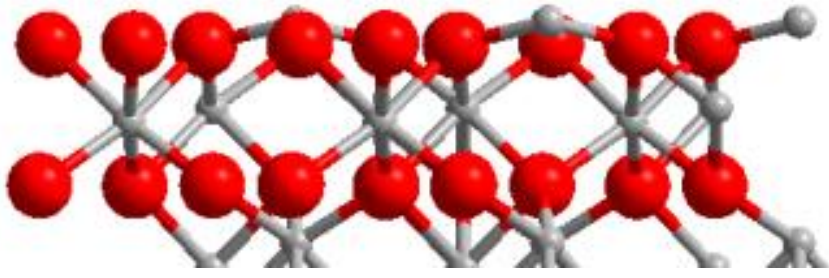

after relaxation

$\mathrm{Cr}_{2} \mathrm{O}_{3}$ (0001) Cr terminated, hydrated (non-dissociated water)

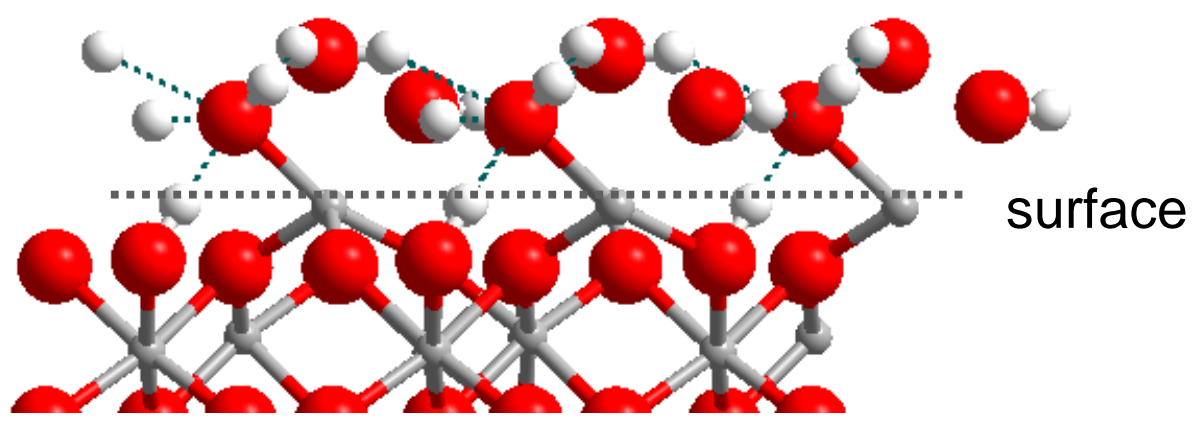

$\mathrm{Cr}_{2} \mathrm{O}_{3}$ (0001) Cr terminated, hydroxylated (dissociated water)

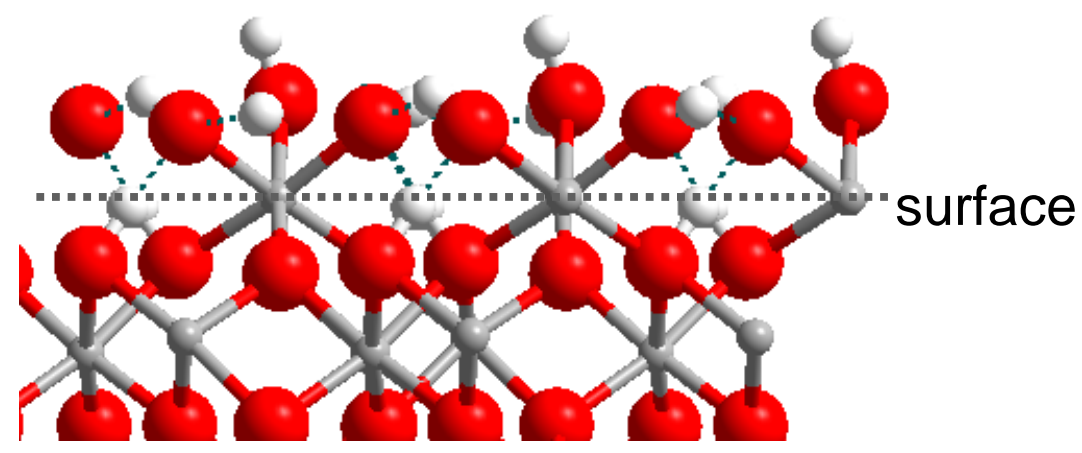




\section{Cea 5- DFT computations of surface \& GB energies of oxides}

Definition of the fracture energy: $\quad \gamma_{\text {fract }}=2 \gamma_{s}{ }^{-} \gamma_{G B}$

${ }^{*} \mathrm{Cr}_{2} \mathrm{O}_{3}$ with $\mathrm{Cr}$ termination

(0001) GB:

hydrated (0001) surface:

Hydroxylated (0001) surface
$0.61 \mathrm{~J} . \mathrm{m}^{-2}$

$1.27 \mathrm{~J} \cdot \mathrm{m}^{-2}$

1.J. $\mathrm{m}^{-2}$

(collaboration with B. Diawara and F. Lebreau)

Lower fracture energy among the four considered GBs

((0001), (10-12) with either $\mathrm{O}$ or $\mathrm{Cr}$ termination)

${ }^{*} \mathrm{Fe}_{2} \mathrm{O}_{3}$ with $\mathrm{Fe}$ termination

(0001) GB

hydrated (0001) surface

hydroxylated (0001) surface

(De Leeuw et al., 2007)
0.73J.m-2 $\sim\left(\mathrm{Cr}_{2} \mathrm{O}_{3}, \mathrm{Al}_{2} \mathrm{O}_{3}\right)$

$1.12 \mathrm{~J} . \mathrm{m}^{-2}$

$1.21 \mathrm{~J} . \mathrm{m}^{-2}$ 
4- Comparison predictions / experiments
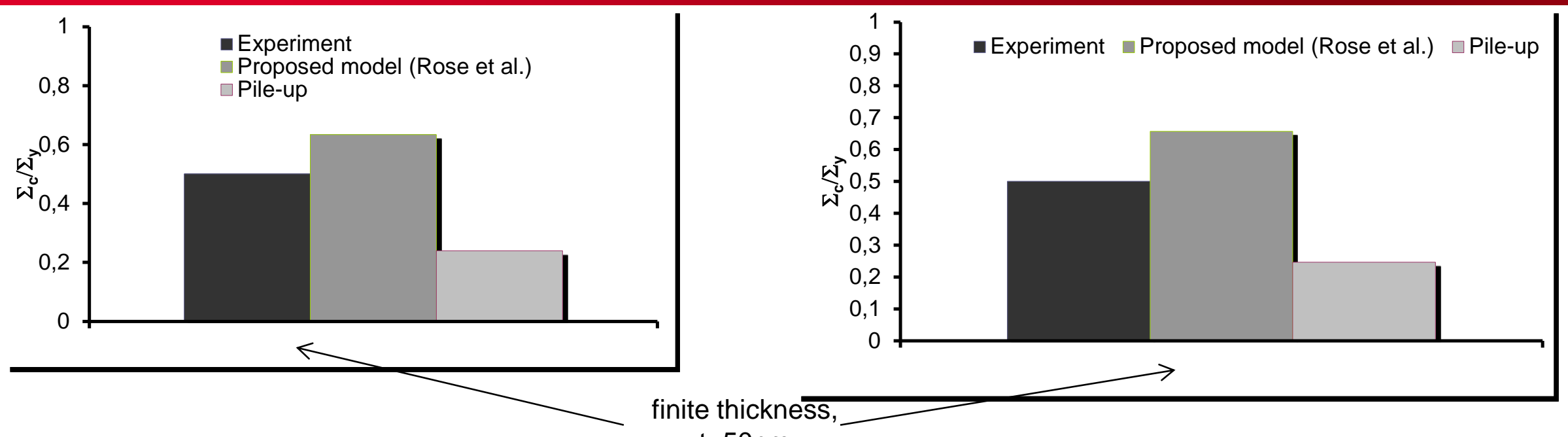

inite thickness, $\mathrm{t}=50 \mathrm{~nm}$

a) hydrated $\mathrm{Fe}_{2} \mathrm{O}_{3}, \quad 2 \gamma_{\mathrm{S}} \gamma_{\mathrm{GB}}=1.51 \mathrm{~J} . \mathrm{m}^{-2}$ (water environment)

b) hydroxylated $\mathrm{Fe}_{2} \mathrm{O}_{3}$, $2 \gamma_{\mathrm{S}}-\mathrm{\gamma}_{\mathrm{GB}}=1.69 \mathrm{~J} . \mathrm{m}^{-2}$ (water environment)

(ab-initio computations:

Leeuw et al., 2007)

experimental data: Nishioka, 08 \& Takakura, $07\left(35 \mathrm{dpa}, \mathrm{T} \approx 320^{\circ} \mathrm{C}\right)$, Hure \& Tanguy (P60, 39dpa, $\left.\mathrm{T}=340^{\circ} \mathrm{C}\right)$ predictions: $t=50 \mathrm{~nm}, \mathrm{~L}=50 \mathrm{~mm}, \mathrm{f}=0.5, \tau_{0}=60 \mathrm{MPa}$

$\rightarrow$ Other GBs with different planes and metal / O termination should be studied before giving general conclusions (L. van Brutzel, CEA Saclay, SCCME) 


\section{CO 5-Comparison predictions / experiments (PWR water tensile tests, $320^{\circ} \mathrm{C}$ )}
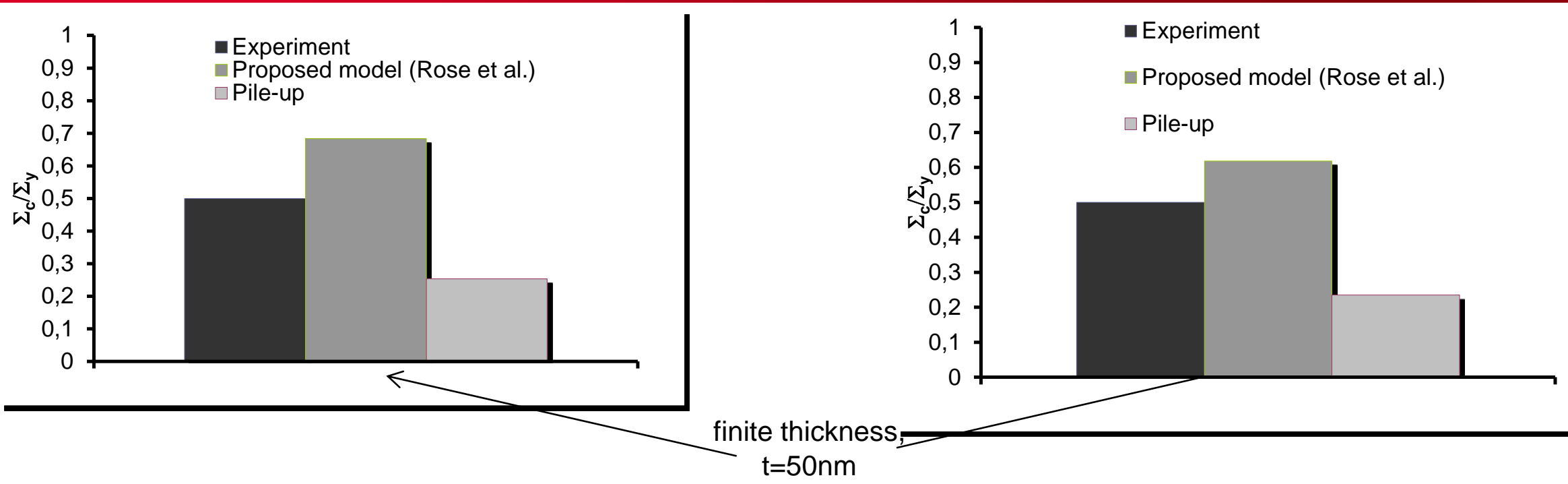
a) hydrated $\mathrm{Cr}_{2} \mathrm{O}_{3}, \quad 2 \gamma_{\mathrm{s}} \gamma_{\mathrm{GB}}=1.9 \mathrm{~J} \cdot \mathrm{m}^{-2}$
(water environment)
b) hydroxylated $\mathrm{Cr}_{2} \mathrm{O}_{3}$,
$2 \gamma_{S}-\gamma_{G B}=1.4 J_{. m}{ }^{-2}$

(ab-initio computations: B. Diawara \& F, lebreau)

experimental data:

Nishioka, 08 \& Takakura, $07\left(35 \mathrm{dpa}, \mathrm{T} \approx 320^{\circ} \mathrm{C}\right)$, Hure \& Tanguy $\left(\mathrm{P} 60,39 \mathrm{dpa}, \mathrm{T}=340^{\circ} \mathrm{C}\right)$ input data: $\mathrm{t}=50 \mathrm{~nm}, \mathrm{~L}=50 \mathrm{~mm}, \mathrm{f}=0.5, \tau_{0}=60 \mathrm{MPa}$

$\rightarrow$ Other GBs with different planes and metal / O termination should be studied but the studied GBs lead to this minimum remote stress to GB fracture 


\section{Cea Effect of irradiation creep in PWR conditions? Flux effects?}

Quick tensile load (100s) followed by a long term relaxation (40 years)

Tensile strain: $0.5 \%$ (remote stress $\sim 00 \mathrm{MPa}$ )

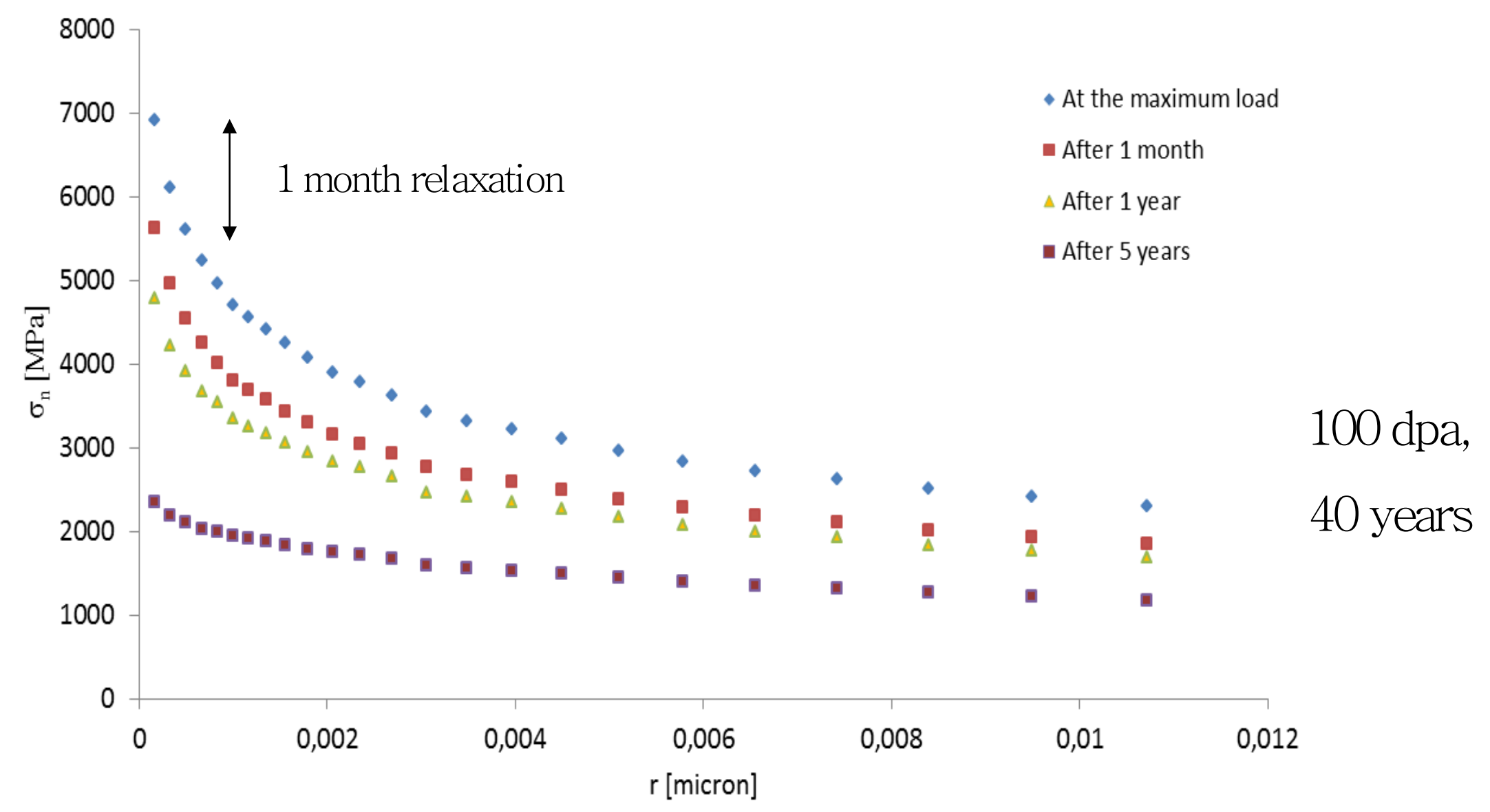


Numerous simulations of various configurations:

slip band inter-

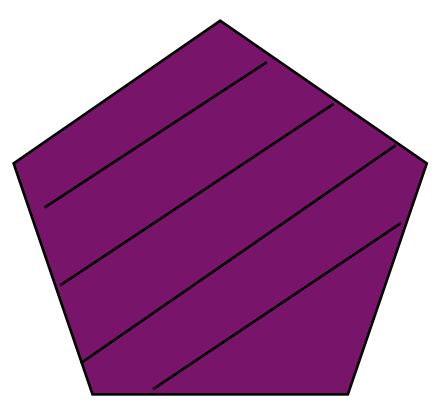

(a)

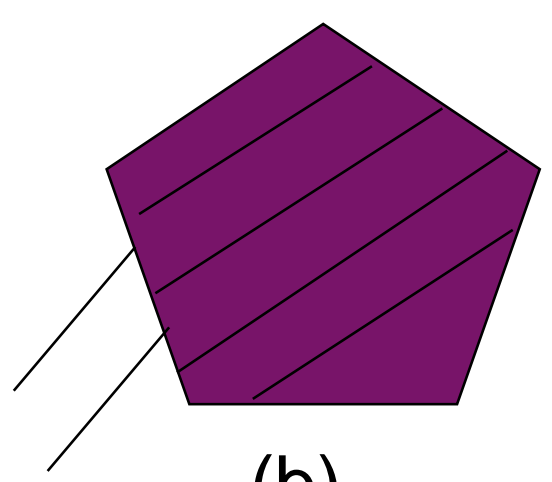

(b)

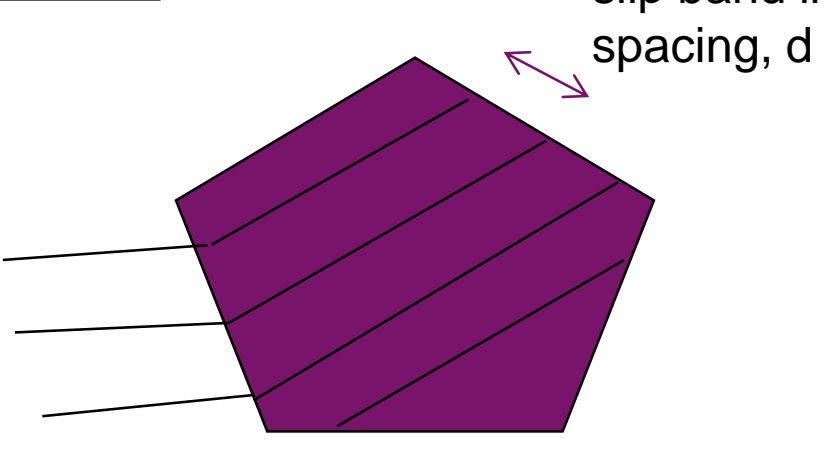

(c)

$\rightarrow$ In agreement with observations, stress fields are the highest and GB crack initiation occurs:

- first when the neighbour grain is empty of clear bands (a)

(IASCC: Fukuya et al., 2011; Was, 2013; Cui et al., 2014; Kacher et al., 2014; fatigue: Laird)

- $\quad$ second if drifted slip bands are produced in the neighbour grain (b), GB crack initiation may occur later (IASCC: McCurtey and Was)

- And only scarcely in case of twin boundaries (IASCC: McCurtey and Was, 2011; Cui et al,, 2014; CSC: Alexandru and Was; Tan et al., 2005; fatigue : Liu et al., 1992; Lim and Raj, 1984) 


\section{Conclusions}

- The numerical evaluation of the nteractions between slip channels of finite thickess, t, and grain boundaries lead to:

i) Local stress fields much lower than the ones predicted by the pile-up theory

ii) Far away from the slip band corner $(\mathrm{t}<\mathrm{r}<<\mathrm{L})$, pile-up solutions and FE results are very close whatever the $t$ thickness

- Close-form expressions are proposed, based on numerous FE results. They are valid for large ranges of:

(i) grain size and slip band thickness

(ii) slip band plasticity parameters

(iii) remote stress

They do not depend on the values of the isotropic elasticity coefficients

The computed and measured channel plastic slip display the same orders of magnitude (50-100\%) 


\section{6- Conclusions}

Fracture Mechanics based on the stress fields

This allows a rigorous prediction of GB microcrack initiation, analytical formula

$\rightarrow$ Two times higher remote stress to GB microcrack initiation

$\rightarrow$ No slip localization would not lead to fracture

$\rightarrow$ Input parameter: fracture energy ab-initio computations $\rightarrow$ surface \& GB energies

with respect to pile-up prediction

$\rightarrow$ encouraging results concerning SSRT tests:

- in inert environment,

- PWR environment, as no inverse identification of parameters is used

The modelling of the differents kinds of interactions between channels and GBs lead to the same conclusions as the recent experimental measurements and observations

Irradiation creep in PWR conditions does not seem to lead to efficient relaxation considering some of the experimental characteristic corrosion times.

Work is in progress for coupling GB diffusion of $O$ with $G B$ fracture using cohesive zone modelling, based on experimental and numerical studies of the oxidation processes in PWR conditions. 
Sauzay, Bavard and Karlsen, JNM, 2010

Evrard and Sauzay, JNM, 2010

Sauzay and Vor, Eng. Fract. Mech., 2013

Sauzay and Ould Moussa, Int. J. Fract., 2013 


\section{Cea WORK IN PROGRESS}

Comparison between observations and predictions

$\rightarrow$ Modelling an observed bicrystal of Incolloy 600
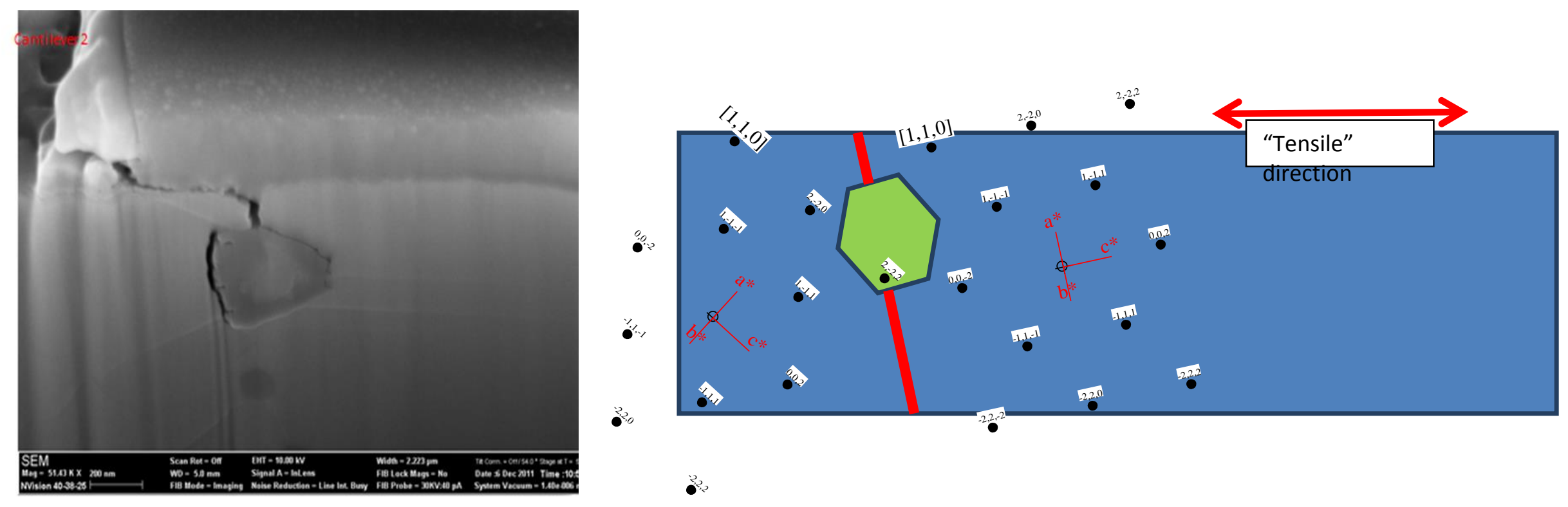

Grain boundary fracture crystallographic orientation 


\section{CeA WORK IN PROGRESS}

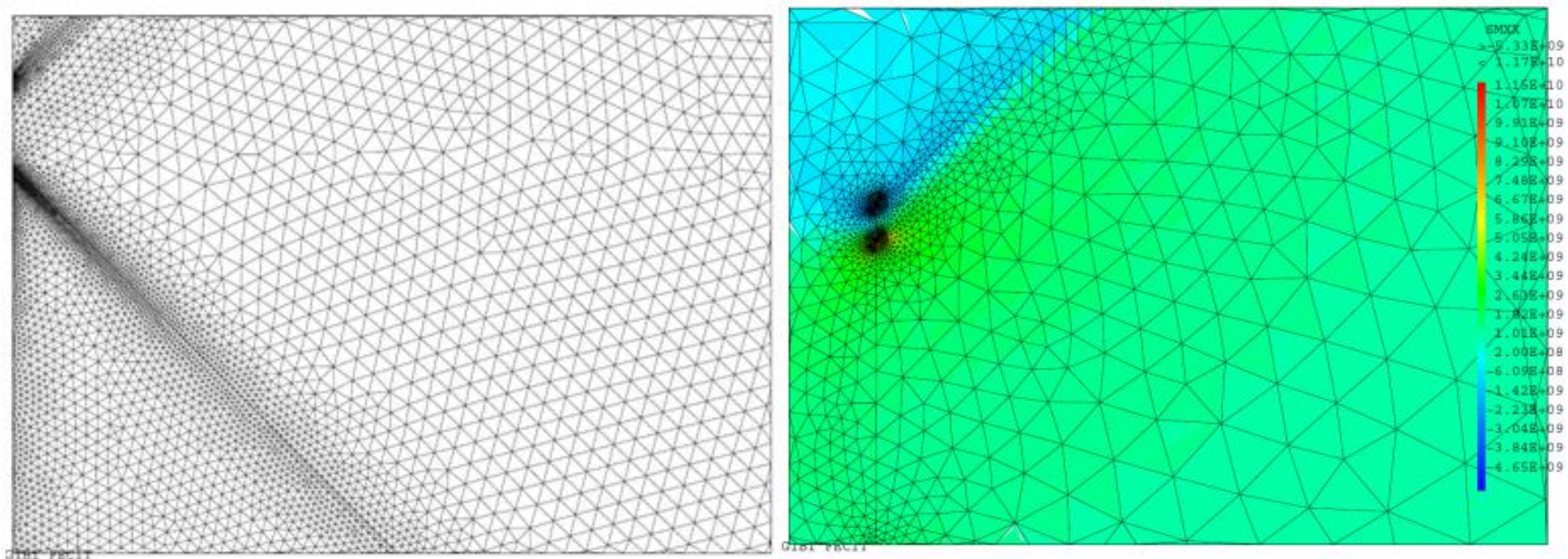

FE meshes

isovalues of the GB normal stress

$\rightarrow$ Analysis of GB stress fields, fracture mechanics, use of inputs provided by MD computations using ReaxFF potentials (B. Diawara, Chimie Paris; L. van Brutzel, CEA) ${ }^{39}$ 


\section{Cea Work in progress:}

\section{Stress Corrosion Cracking: coupled numerical approach}

The coupling between at least two mechanisms should be modelled:

- grain boundary diffusion $\rightarrow$ weakening of GB strength

- GB microcrack opening $\rightarrow$ faster GB diffusion $(\mathrm{O}, \mathrm{H})$

FE computations including:

Solving of GB diffusion equation, using D depending on GB $\mathrm{Cr} \%$ Cohesive Zone modelling (GB fracture)

And the influence of corrosion defects (vacancies, cavities) \& irradiation bubbles may be investigated as well

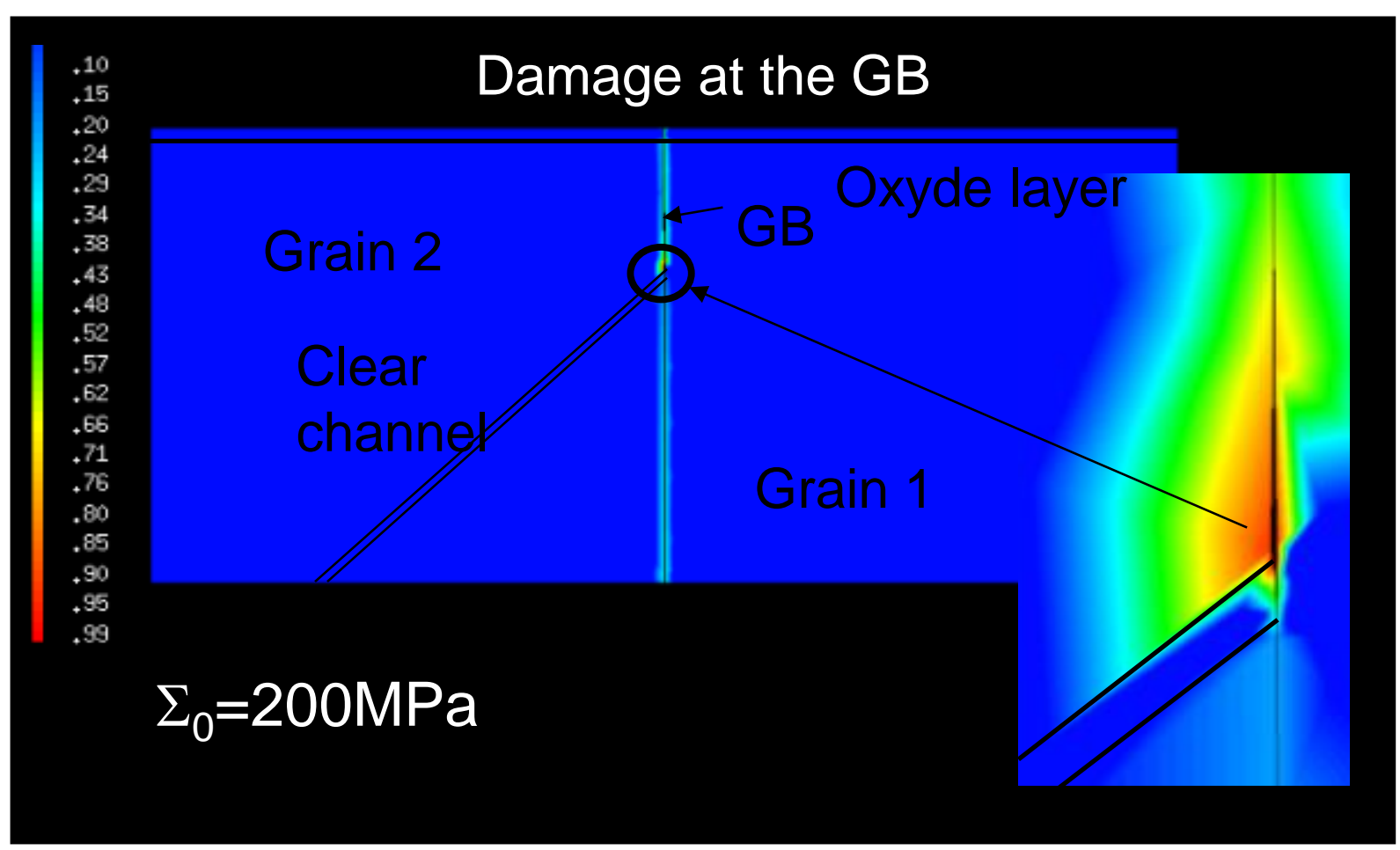


Taking into account the interactions between clear bands and grain boundaries

Twin GBs:

Direct

Transmission (conservation of the Burgers Vector)

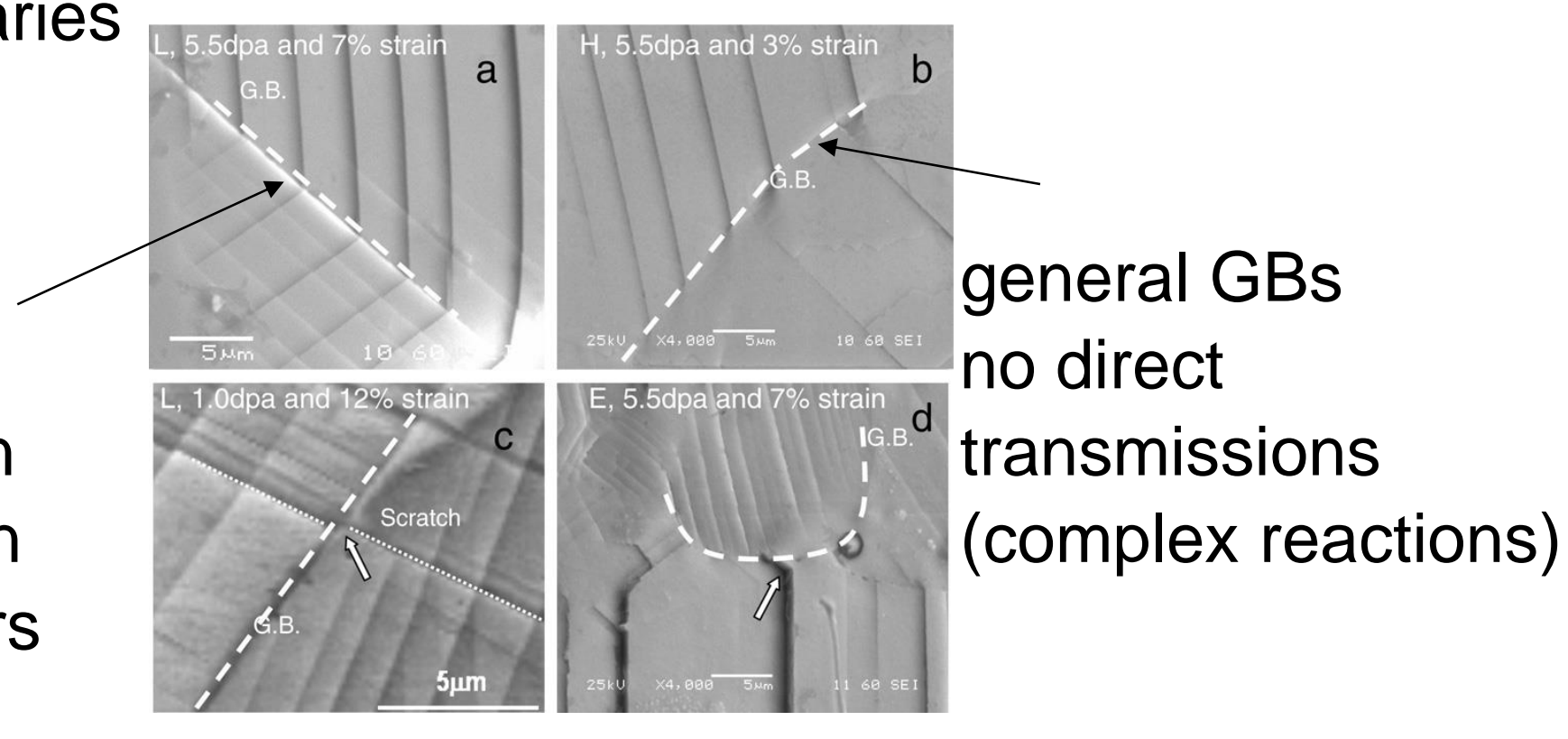

Copper and 316L: low SFE energy $\rightarrow$ about $50 \%$ of the GBs are twin ones

$\rightarrow$ Three cases of interactions with neighbour grains should be distinguished

Clear band thickness $t=50 \mathrm{~nm}$, inter-spacing $d=1000-4000 \mathrm{~nm}$ 


\section{6- SLIP BANDS IN THE NEIGHBOUR GRAIN}

First case: slip transmission (twin boundaries)

No stress concentration is observed whatever the considered tilt misorientation between both crystals

$\rightarrow$ Easy accomodation due to the interconnecting slip bands,

$\rightarrow$ No crack initiation is expected in agreement with many observations of literature (IASCC, SCC, fatigue...).

Other alternative explanations:

low GB self-diffusion coefficient low GB energy $\rightarrow$ high GB fracture energy: $2 \gamma_{s}-\gamma_{G B}{ }^{\text {PAGE } 42}$ 


\section{6- SLIP BANDS IN THE NEIGHBOUR GRAIN}

First case: slip transmission (twin boundaries)

No stress concentration is observed whatever the considered tilt misorientation between both crystals

$\rightarrow$ Easy accomodation due to the interconnecting slip bands,

$\rightarrow$ No crack initiation is expected in agreement with many observations of literature (IASCC, SCC, fatigue...).

Other alternative explanations:

low GB self-diffusion coefficient low GB energy $\rightarrow$ high GB fracture energy: $2 \gamma_{s}-\gamma_{G B}{ }^{\text {PAGE } 43}$ 
Second case: drifted impact location (general boundaries)

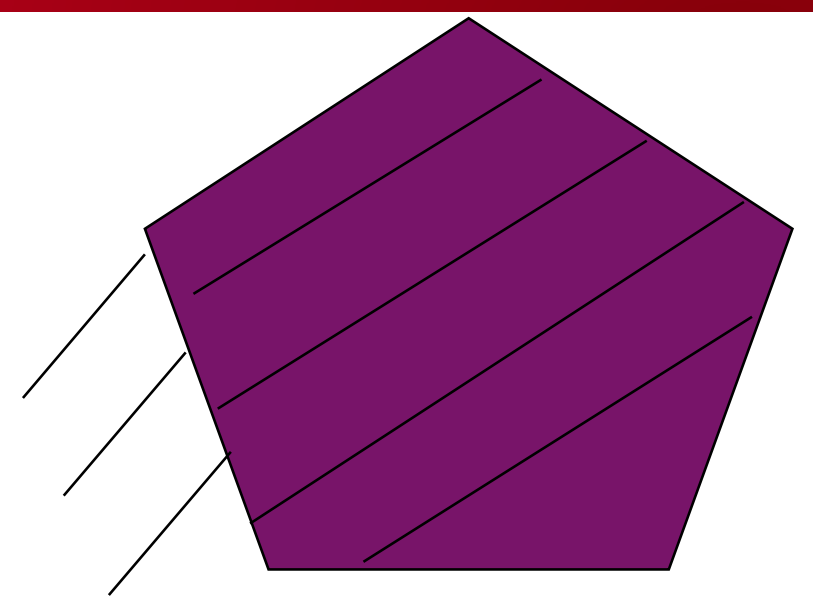

A double screening effect occurs due to the upper \& lower slip bands

$\rightarrow$ The stress singularity coefficient is once more divided by about 2

Third case: no slip band in the neigbhour grain (see part 1)

$\rightarrow$ In agreement with observations showing that high stress/ fields occur first when the neighbour grain is empty of clear bands, then if slip bands are drifted and scarcely in case of twin boundaries (Guo et al., 2014; McMurtrey et al., 2015) 
Straightforward computation for the pile-up because of the LEFM singularity: $\mathrm{G}>0$ even if the crack length is equal to $a=0$ (Smith \& Barnby, 1967)

Using an energy balance, a criterion of GB crack initiation can be formulated:

Released elastic energy

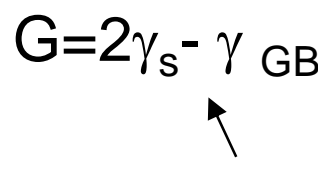

surface energy

(Griffith criterion, brittle fracture)

$\rightarrow$ Critical remote tensile stress, $\Sigma_{\text {crit }}$, leading to GB microcrack initiation

$$
\mathrm{G} \sim \mathrm{K}^{2} / \mathrm{Y} \text { with } \mathrm{K} \sim \Sigma \sqrt{ } \mathrm{a}
$$

Slip band of finite thickness, $t>0, G(0)=0$ because: $a=1-\lambda<0.5$

$\rightarrow$ Energy balance using an a priori unknown finite crack length, $a_{c}>0$ (Pugno, 2004)

$\rightarrow$ Double fracture criterion (Leguillon, 2002) :

$\left\{\begin{array}{l}\text { (i) energy balance equation } \\ \text { (ii) stress criterion }\end{array}\right.$

Physical interpretation: brittle fracture at the GB scale and atomistic theory of fracture, cohesive zone modelling 


\section{2- Stress singularities \& fracture initiation}

Analogy with a crack of length a embedded in an elastic medium: Lile-up a

Linear elastic fracture mechanics (LEFM):

Asymptotic expansion:

$$
\sigma_{i j}(r, \theta) \propto \frac{1}{r^{1-\lambda}} \quad \text { or equivalently: } u_{i}(r, \theta) \propto r^{\lambda}
$$

If $1-\lambda=0.5$ then, the elastic energy release rate is such that:

application the Griffith criterion for microcrack initiation prediction:

$\mathrm{G}(\mathrm{L})^{*} \mathrm{da}=\mathrm{V}_{\text {tract }}{ }^{*} \mathrm{da} \quad$ with: $\quad \mathrm{da} \rightarrow 0$ (infinitesimal crack increment) $V_{\text {fract: }}$ : fracture energy $\left(\mathrm{J} / \mathrm{m}^{2}\right)$

Similar to a LEFM crack

If $1-\lambda<0.5$ then, the elastic energy release rate is such that:

the Griffith criterion is unable to predict any microcrack initiation

(Well-known drawback of the Griffith criterion) 


\section{2- Computation of $\mathbf{J}\left(\mathbf{a}, f \Sigma_{0}-\tau_{0}\right) \quad$ (Short cracks of various lengths, $\left.\mathbf{a}\right)$}

- $\mathrm{G} \theta$ procedure, numerical error $<5 \%$

in the case of a homogeneous medium subjected to mode I \& mode II

by comparison with the classical analytical solution

- Dependence with respect to the crack length, a

$\rightarrow$ Exponent $2 \lambda-1$ (Leguillon, 2002) in the case of the crack emerging from a $V$ notch

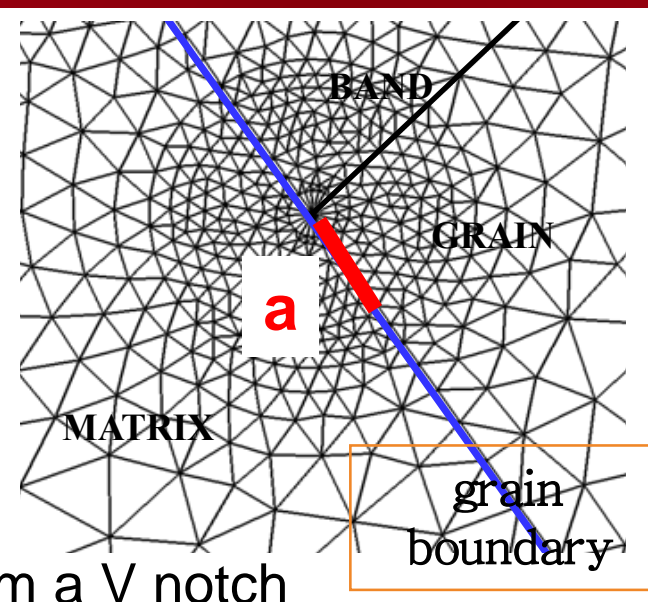

- Square dependence with respect to the « driving stress »,

$$
f \Sigma_{0}-\tau_{0}
$$

$\rightarrow$ Analytical formula for the $\mathrm{J}$ integral and the cumulative energy from 0 to $\mathrm{a}_{\mathrm{c}}$

$$
J\left(a, f \Sigma_{0}-\tau_{0}\right)=C\left(f \Sigma_{0}-\tau_{0}\right)^{2} L\left(\frac{a}{t}\right)^{2 \lambda-1}
$$
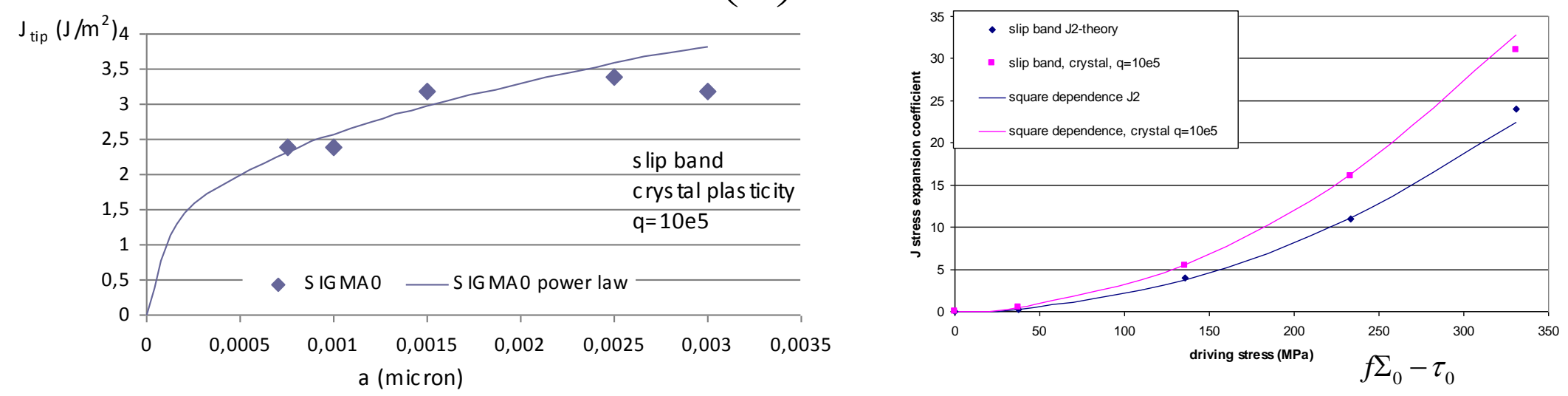

$$
f \Sigma_{0}-\tau_{0}
$$




\section{5- PARALLEL SLIP BANDS}

Reference case: isolated slip band of the same orientation

GB angle: $0^{\circ} \rightarrow$ same screening effect

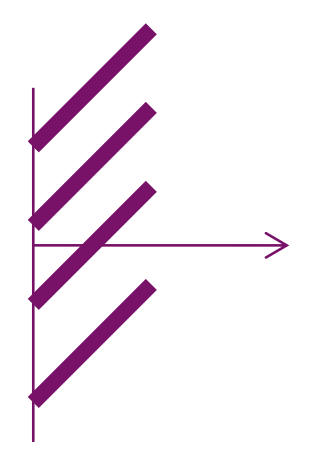

GB angle $90^{\circ} \rightarrow$ negligible screening effect

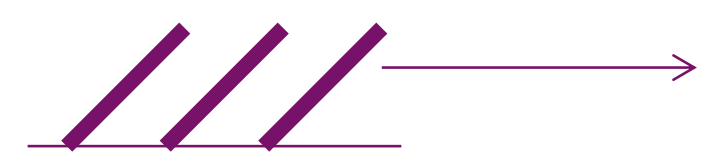

GB damage concerns only GBs which are enough inclined with respect to the tensile axis $\left(0^{\circ}-40^{\circ}\right)$. As grains are covered by many parallel slip bands, the screening effect should be taken into account

$\rightarrow$ fair predictions of GB fracture in both inert and PWR environments 
How to take into account $\mathrm{T}_{0}$ and $\mathrm{H}$ in the analytical formulae? The driving force is given by:

$$
T=\left(f \Sigma_{0}-\tau_{0}-H \gamma^{p}\right)
$$
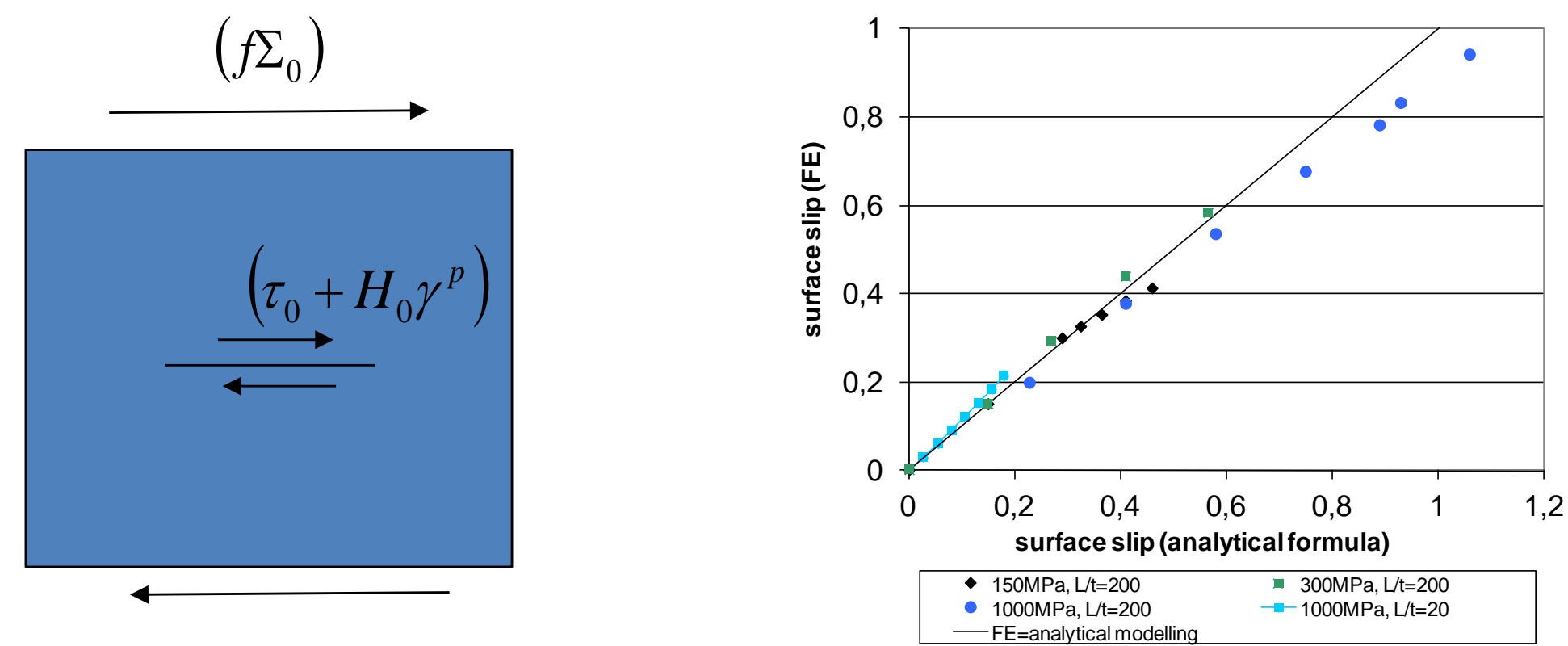

The general analytical formulae may be written:

$$
\left\{\begin{array}{c}
\gamma^{p}=F\left(\mu, \nu, \tau_{0}, H, t, L, f, \Sigma_{0}\right) \\
\sigma_{n n}(r)=A_{n n}(\theta)\left(f \Sigma_{0}-\tau_{0}-H \gamma^{p}\right) \sqrt{\frac{L}{t}}\left(\frac{t}{r}\right)^{1-\lambda}+\Sigma_{n}^{\infty}
\end{array}\right.
$$

Sauzay et al., $2002 \& 2010$ experimental validation with W. Karlsen, TEM, Perfect) 


\section{C2 ${ }^{5-}$ Effect of irradiation creep: how do GB stress fields relax?}

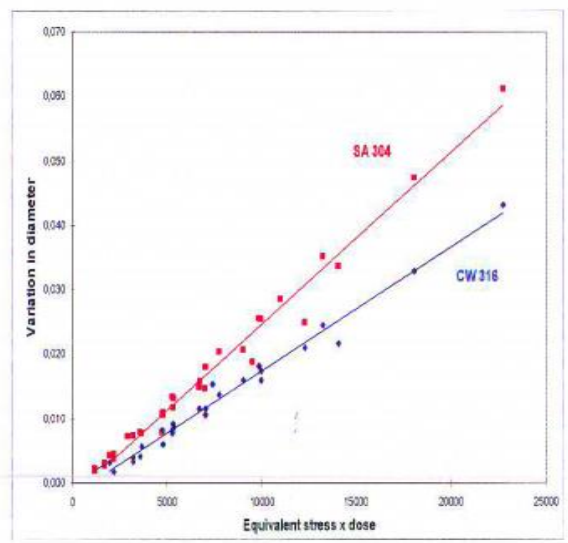

Lemaire et al., Fontevraud conference, 2010

Fiqure 5: Variation of mean diameter of CW316 and SA 304L pressurized tubes versus dose and siress level.

Only very crude assumptions have been made assuming partition of:

- plastic deformation (irradiation defects, clear bands)

$\rightarrow$ crystal FCC plasticity, favoured single slip, perfect plasticity

- viscoplastic deformation (diffusion, climb of dislocation)

at the grain scale: phenomenological modelling directly inspired by the PhD work of J. Garnier)

viscoplastic strain rate tensor proportionnal to:

i) irradiation dose

ii) deviatoric stress tensor

$\rightarrow$ Implementation of a user's subroutine umat.

(cold-worked 316 steel (strain: 12\%), OSIRIS / BOR-60, $330^{\circ} \mathrm{C}$ )

$A=2.310^{-20} \mathrm{~Pa}^{-1} \mathrm{~s}^{-1} \quad$ (dose $~ 10$ dpas during 40 years, no dose*stress threshold)

$\mathrm{A}=2.310^{-19} \mathrm{~Pa}^{-1} \mathrm{~s}^{-1}$ (dose $\sim 100$ dpas during 40 years, no dose* stress threshold) 


\section{Cea 5- Influence of irradiation creep on GB normal stress fields}

Quick tensile load (100s) followed by a long term relaxation (40 years) Tensile strain: $0.5 \%$ (remote stress $900 \mathrm{MPa}$ )

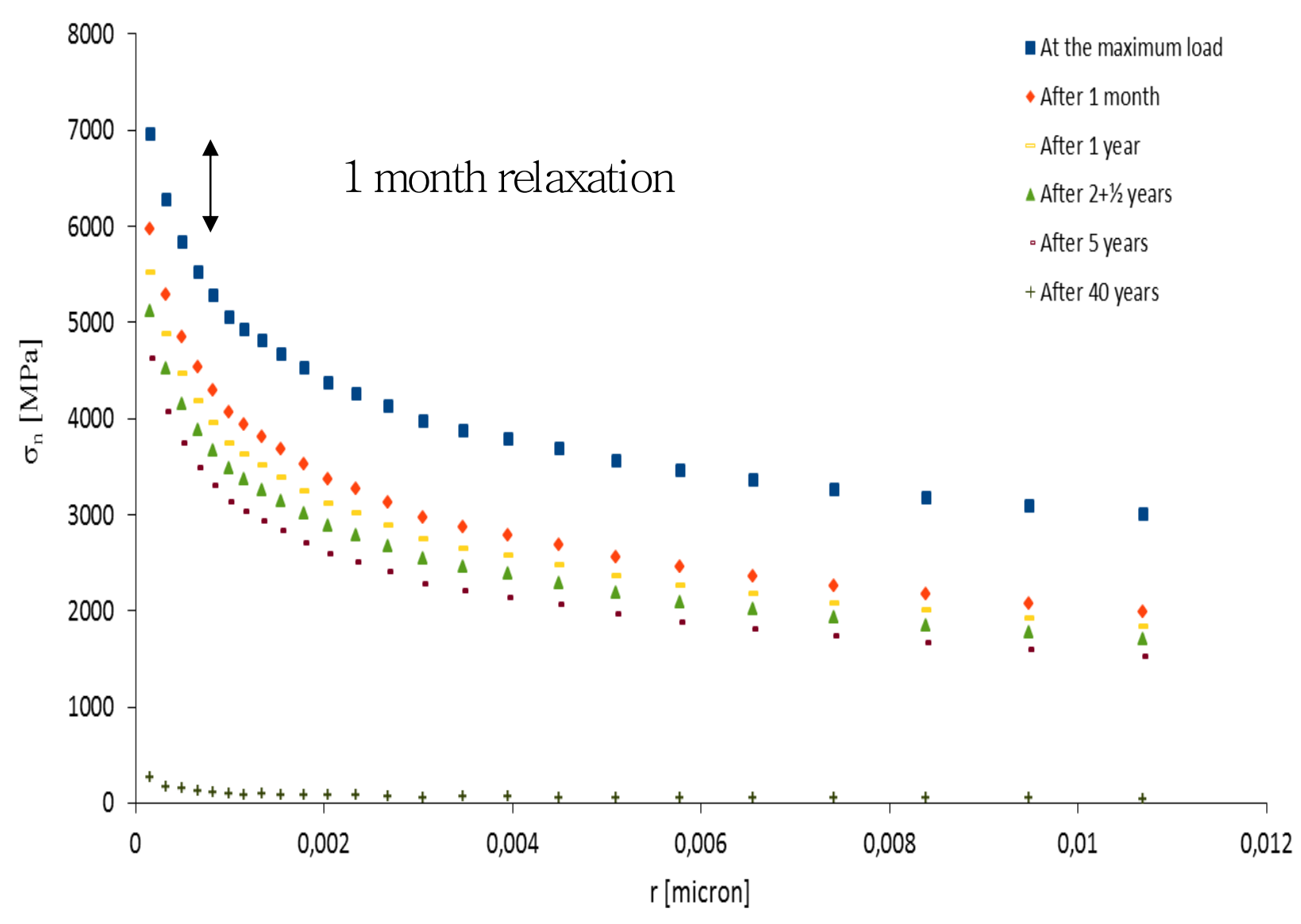

10 dpa,

40 years 


\section{Cea 4- Effect of irradiation creep}

Quick tensile load (100s) followed by a long term relaxation (40 years)

Tensile strain: $0.5 \%$ (remote stress $\sim 900 \mathrm{MPa}$ )

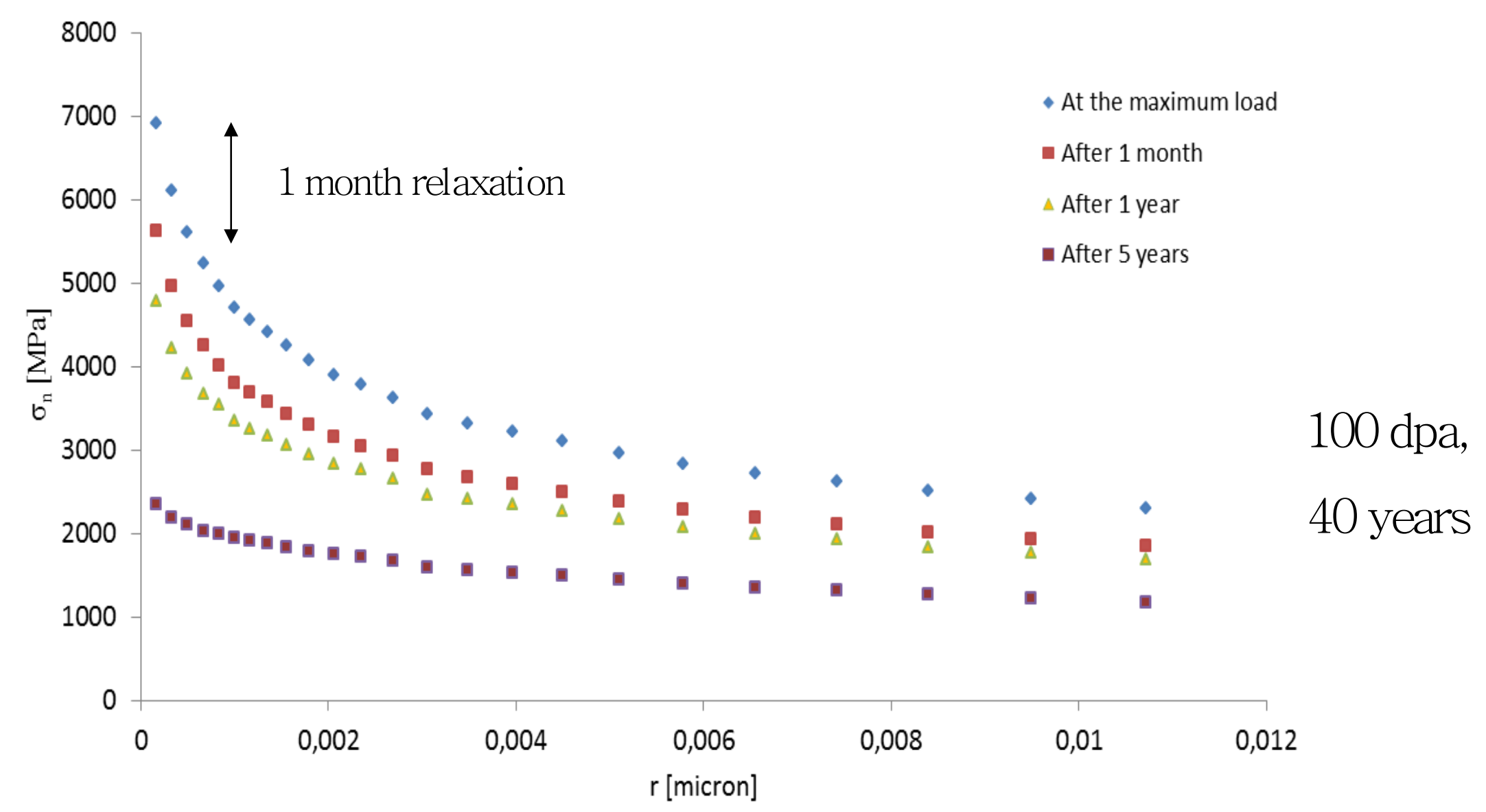




\section{5- Effect of irradiation creep}

Effect of irradiation creep:

Huge relaxation of the GB stress field after $\sim 40$ years

But limited relaxation for a few months (linear creep).

Due to the rather complex history of components (reloading/relax) (structural analysis, see Pokor et al., Fontevraud, 2010):

grain boundaries may be submitted to very high stress concentrations during at least several months due to:

- clear bands

- bands induced by previous cold-working? (Couvant, 05)

- deformation twins (Bruemmer \& Thomas)

In PWR conditions, such local GB stress loading during a few months may be enough to lead to SCC (see SCK experiments, P60 project) 


\section{6- DISCUSSION ABOUT IASCC}

Is the previous modelling in agreement with the well-known data about IASCC mechanims (Was, 2003)?

Channeling more or less saturated

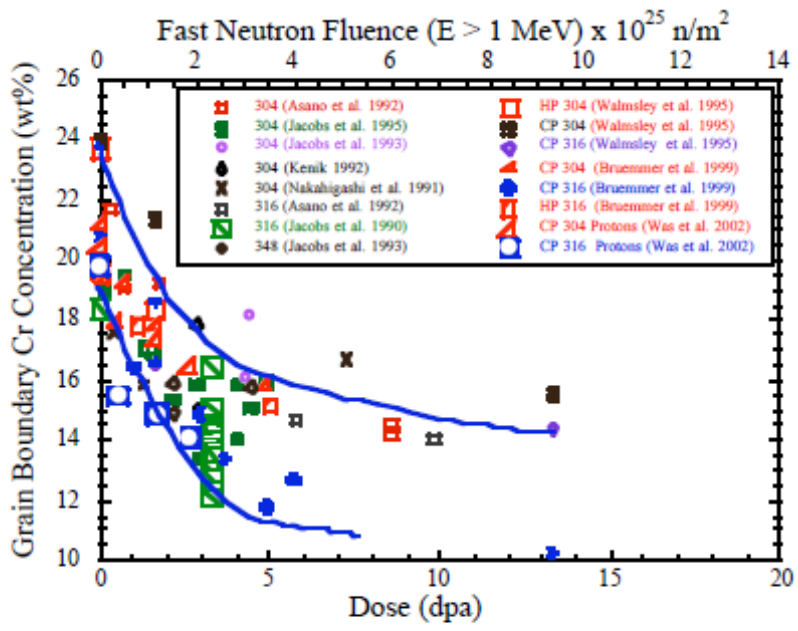

Figure 1. Dose dependence of radiation induced segregation for several 300 -series austenitic stainless steels irradiated at a temperature of about $300^{\circ} \mathrm{C}^{6-13}$

Hardness, loops, channels:

saturation before $10 \mathrm{dpa}$. But what about $\mathrm{Cr}$ GB content?

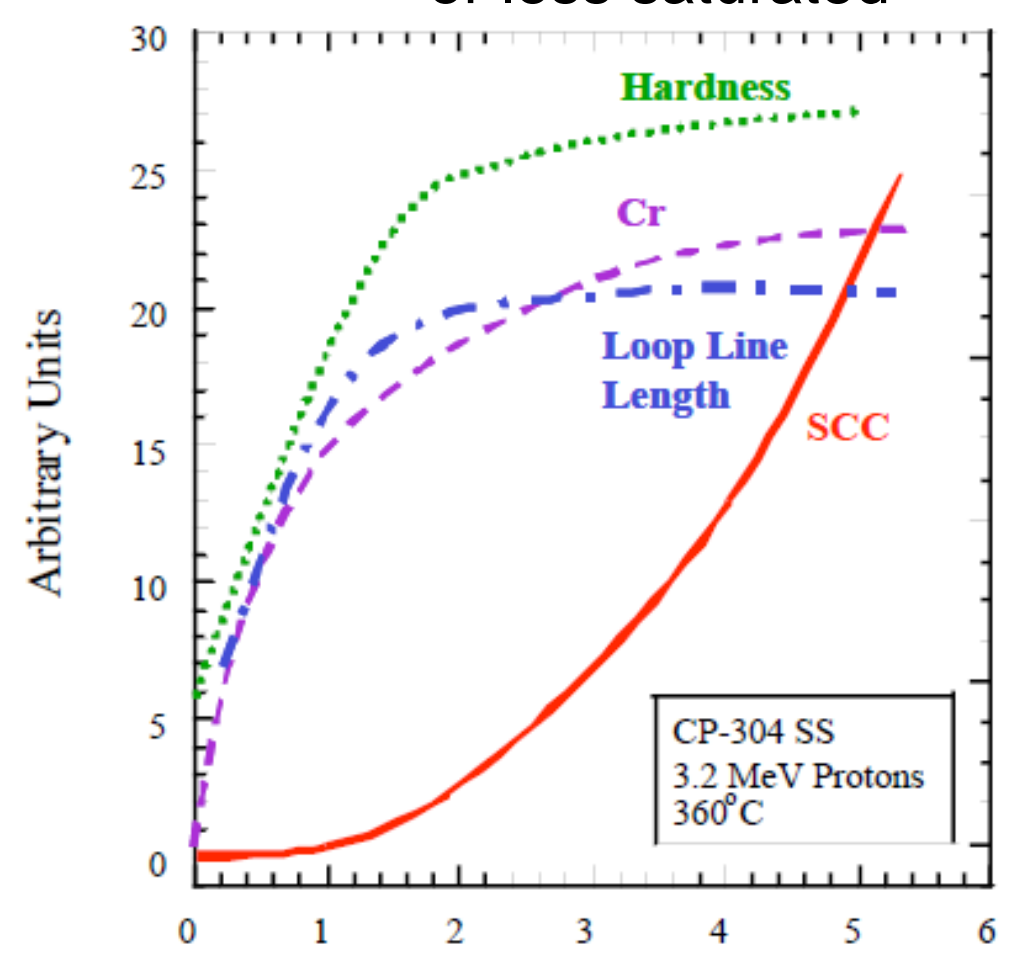

Cr depletion increases with dose even > 10dpa 


\section{cea}

“Possible partial explanation » of the threshold evolution with dose

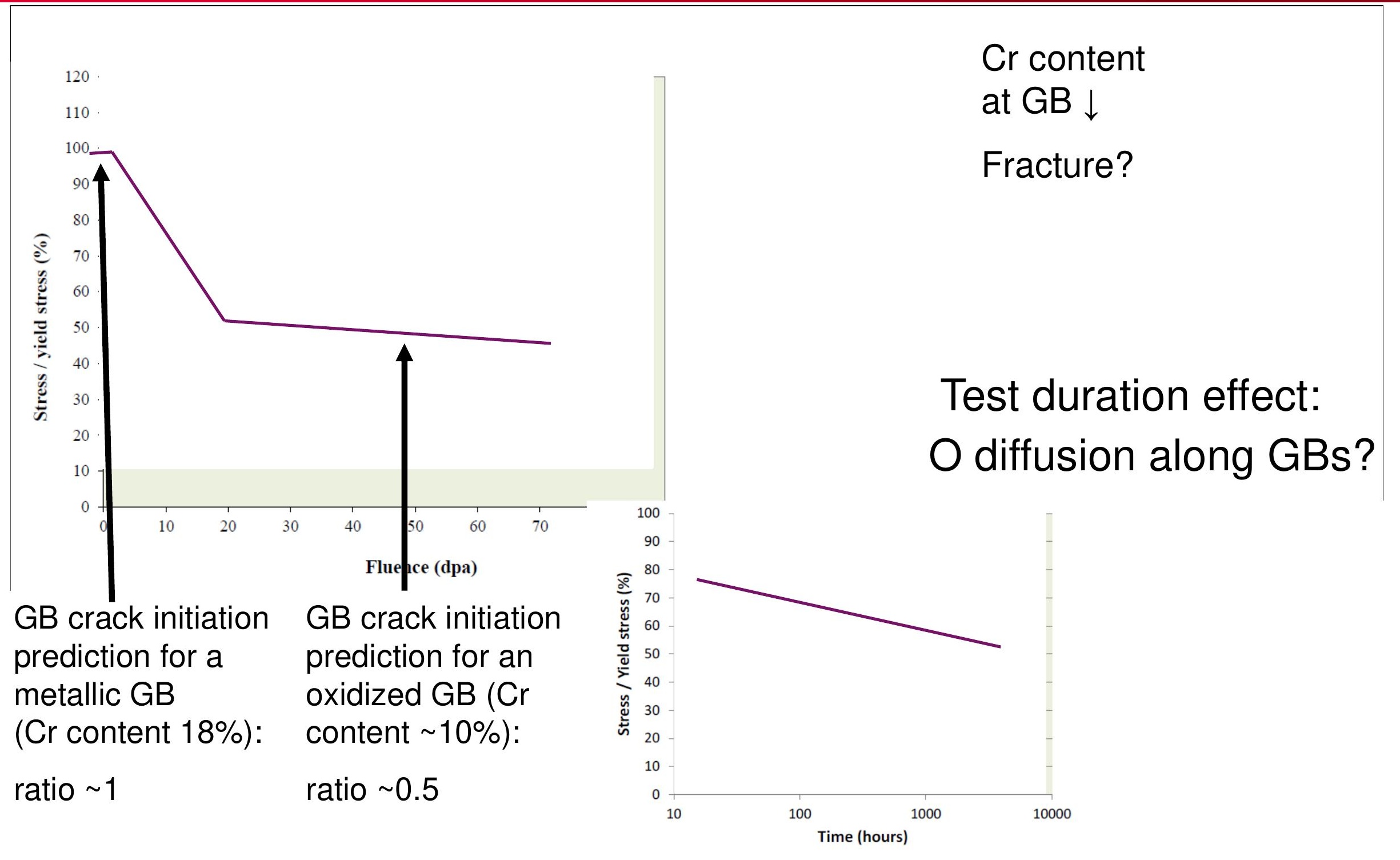


- TEM observations of Thomas \& Bruemmer (99) twin bands intersecting a crack in a PWR baffle bolt (316L, CW) Oxide - twin bands interactions

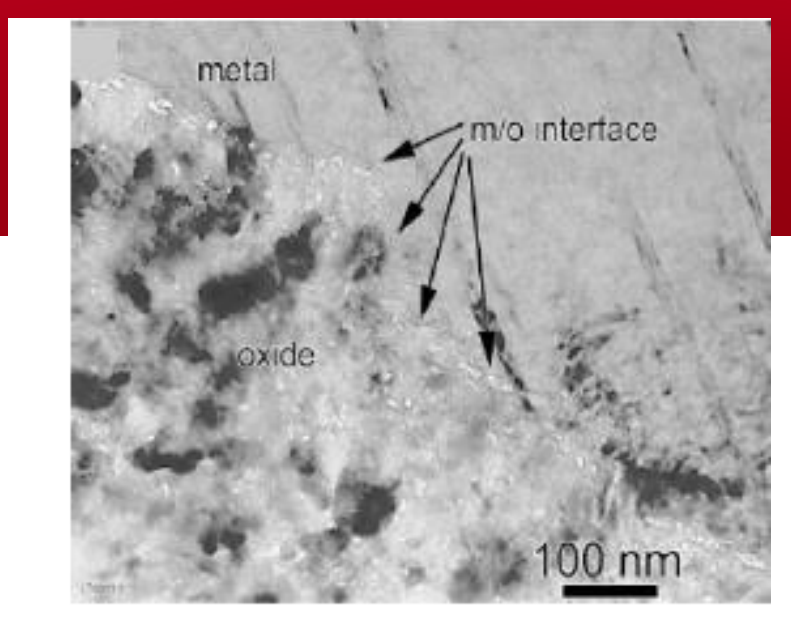

-deformation-induced twins \& GB damage Schematic mechanism of twin-induced GB cracking, and distribution of atomic stress $\sigma_{y y}(\mathrm{GPa})$ near a GB at (b) $3.3 \%$, (c) $3.4 \%$ and (d) $3.7 \%$ tensile strain. The twin boundaries and GBs are outlined by red dots. Tensile loading is applied along $Y$ axis. (Zhang et al., 2012; Mo; Molecular Dynamics)
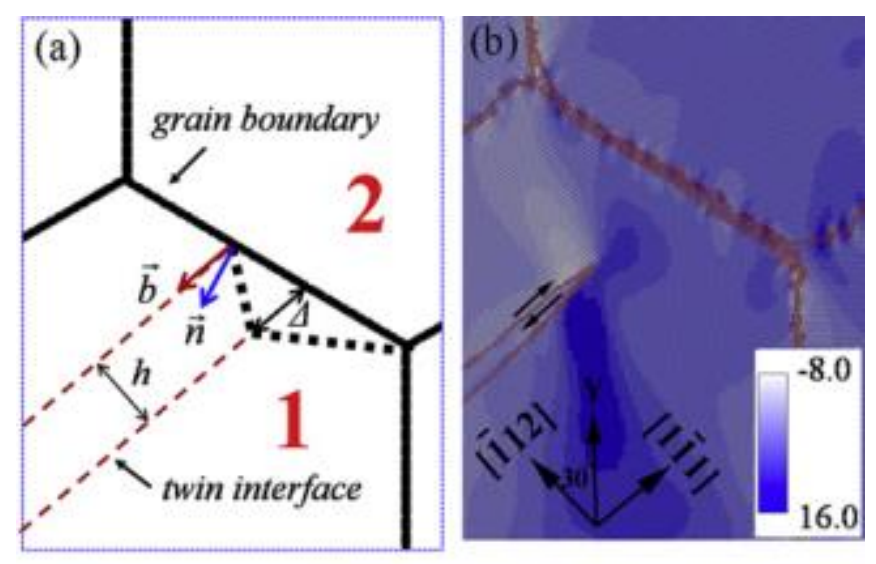

Micromechanical approach:

i) computations of GB stress fields due to the impingement of thin twin bands (slip + rotation) ii) leading to a new GB fracture criterion (oxide fracture, interaction with oxidation)
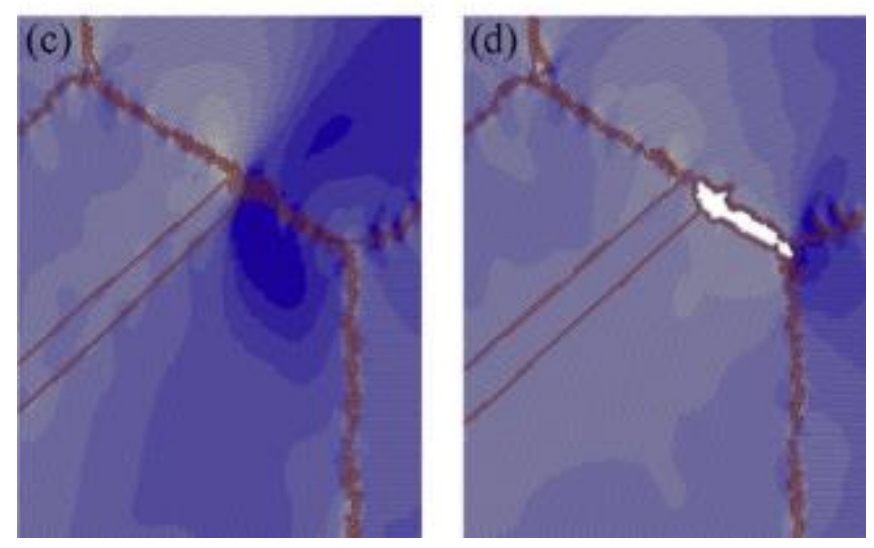
Outputs:

Crack initiation time

Short crack propagation rate

Random effect of microstructure barriers

$\rightarrow$ Statistical modelling of multicrack growth \& coalescence such as INITEAC or EDF software 


\section{6- IRRADIATION CREEP}

Prediction of crystalline viscoplasticity laws modelling irradiation creep. Modelling annihilation / production of dislocations lines as well as their interaction with irradiation defects (climb). Coupling with cluster dynamics. Homogeneisation with and without channelling

$\rightarrow$ Effect of physically-based irradiation creep laws on the relaxation of GB stress fields induced by twin bands or slip bands 


\section{$\mathrm{CO}$ 6-Slip localization:}

mechanisms (channeling, twinning) and macroscopic behaviour

Material Science, dislocation dynamics:

$\rightarrow$ Prediction of the slip band thickness and inter-spacing depending on:

- material

- temperature

- defect characteristics

- loading conditions (tensile/cyclic loading)

Scale transition: polycrystalline homogeneisation

$\rightarrow$ Instead of considering a homogeneous plastic deformation in the whole grain:

- modelling localized plasticity in each grain

- modifying the localization rule: spherical grain $\rightarrow$ ellipsoidal slip bands

Three scales:

-channels

-grain

-matrix

which mimics

the other grains

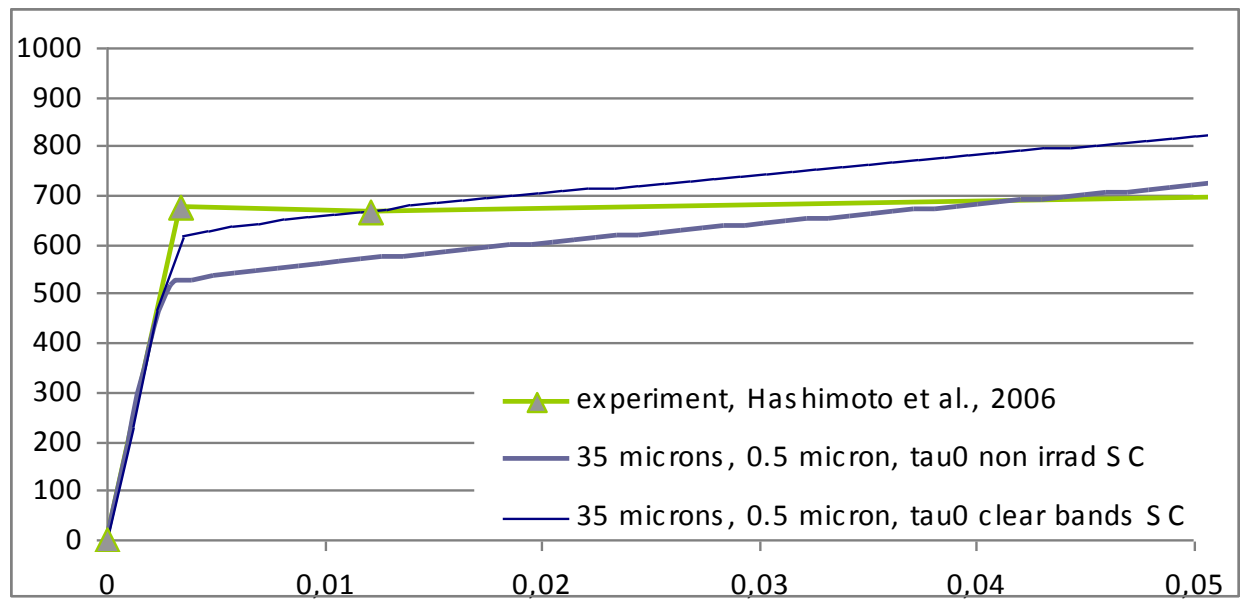


Austenite: strong anisotropy of cubic elasticity:
$A=3.3$ similar to the copper one: $E_{111}>3$
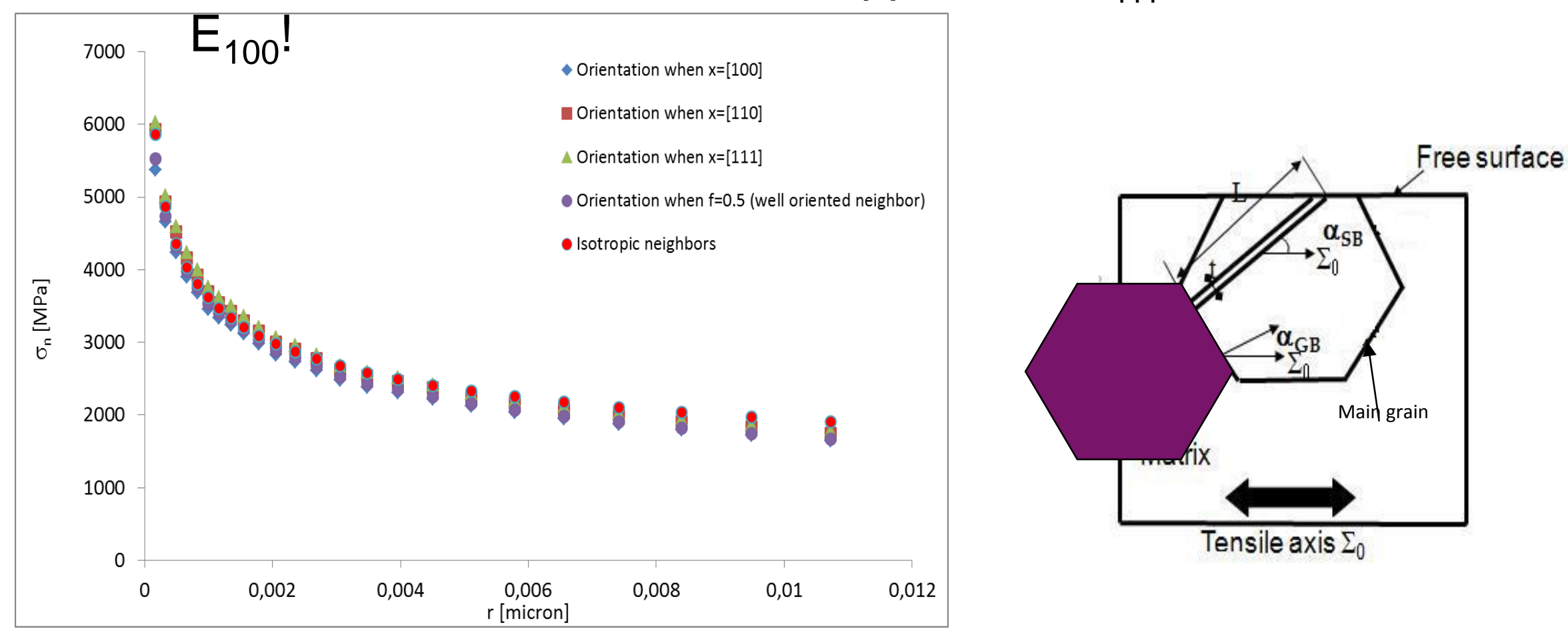

Variation induced by the random orientation of the neighbour grain: $< \pm 5 \% \rightarrow$ the effect is weak

$\rightarrow$ Probably slight effect on GB fracture 


\section{5- DISCUSSION ABOUT IASCC}

Is the previous modelling in agreement with the well-known data about IASCC mechanims (Was, 2003)?
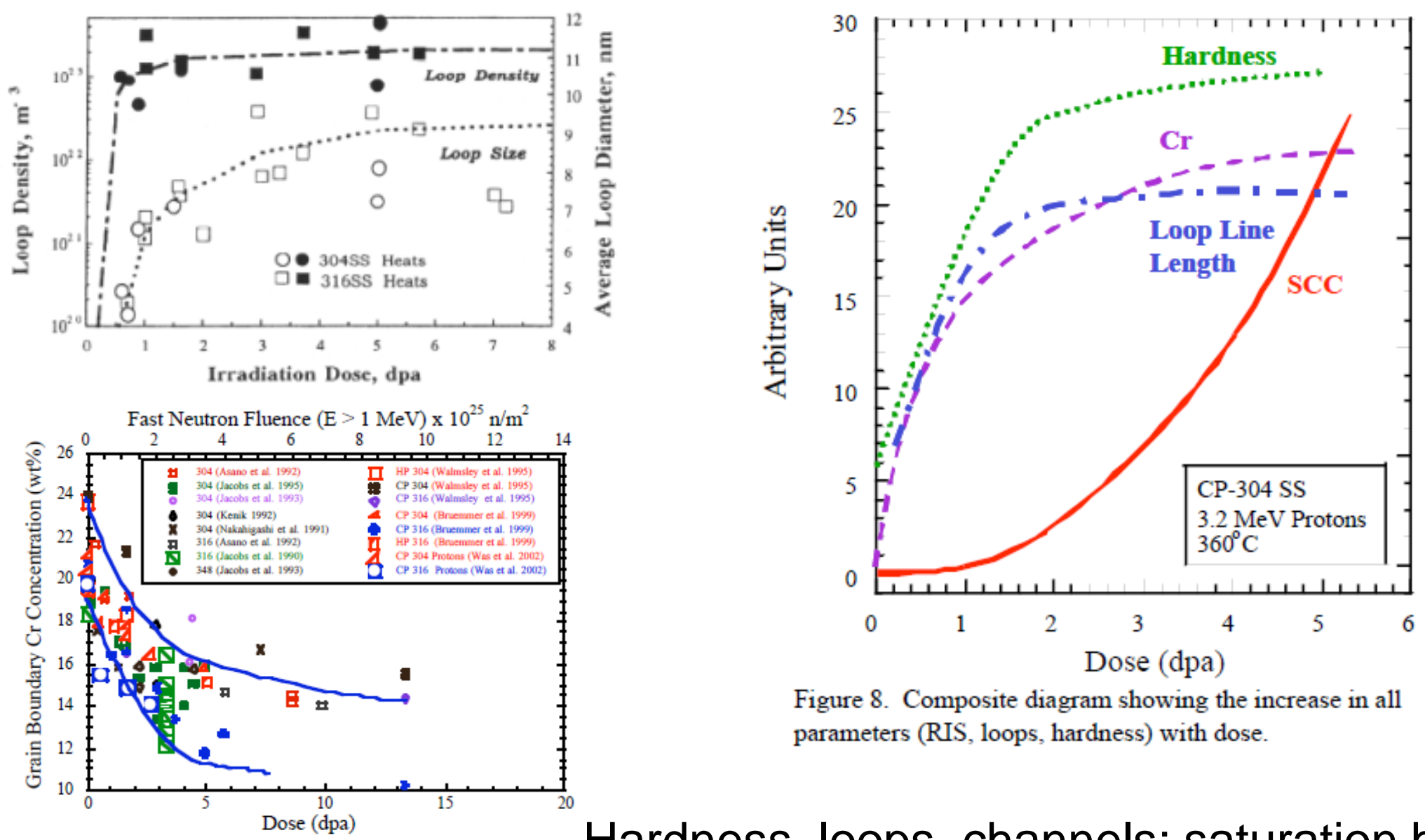

Figure 8. Composite diagram showing the increase in all parameters (RIS, loops, hardness) with dose.

Figure 1. Dose dependence of radiation induced segregation for several 300 -series austenitic stainless steels irradiated at a temperature of about $300^{\circ} \mathrm{C}^{6-13}$
Hardness, loops, channels: saturation before 10 dpa. But what about $\mathrm{Cr}$ GB content? | PAGE 61 


\section{5- DISCUSSION ABOUT IASCC}

Removal of small obstacles for a short ageing duration $\rightarrow$ Channel coverage: $\quad 65 / \mathrm{mm}^{2}$ (without ageing)

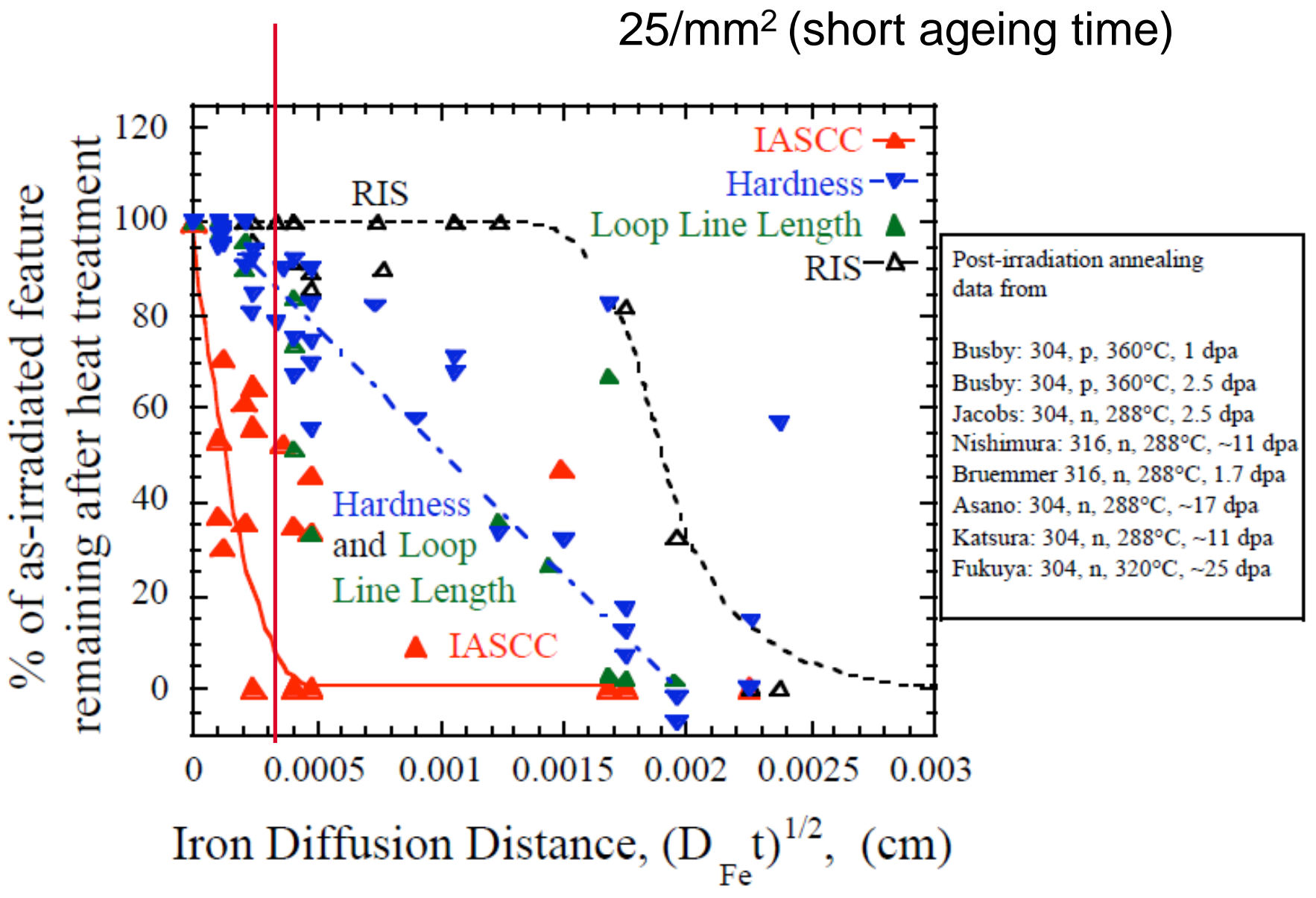

Figure 12. Removal of RIS, dislocation microstructure as measured by loop line length and hardness with extent of annealing as measured by $(\mathrm{Dt})^{1 / 2}$ for iron, to account for annealing at different times and temperatures. ${ }^{54,} 68-70$ 


\section{5- DISCUSSION ABOUT IASCC}

Influence of stacking-fault energy which affects slip localization:

316 SS SFE $=25 \mathrm{~J} / \mathrm{m}^{2} \quad / \quad 304 S S$ SFE $=10 \mathrm{~J} / \mathrm{m}^{2}$ more planar

No channeling

/ Channeling

No GB cracks

/ GB cracks (SSRT) (Bailat et al., Busby et al.)

Similar results concerning the effect of $\mathrm{Ni}$ content / chemical composition of SS on slip localization and GB fracture (Jiao et al., 2005)

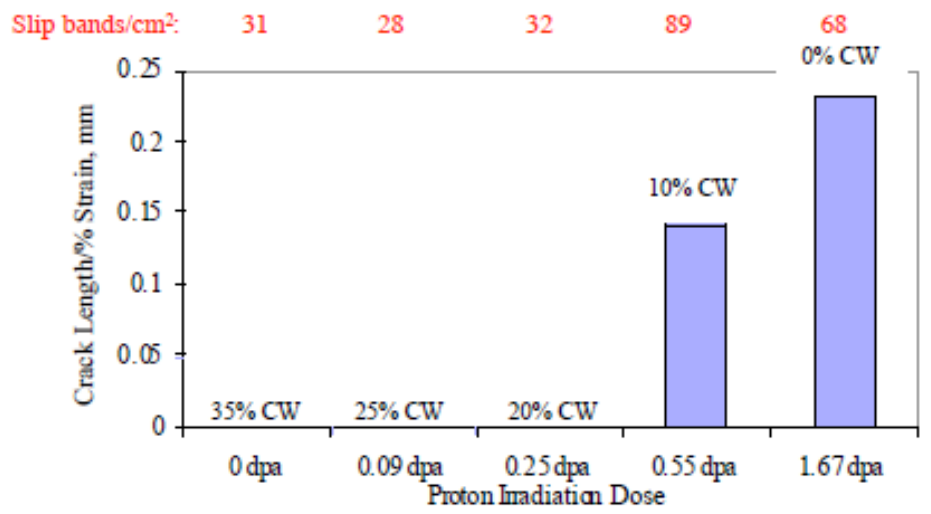

Figure 13. Degree of IASCC in 304SS samples with the same hardness but with different combinations of hardening by cold work and irradiation using $3.2 \mathrm{MeV}$ protons at $360 \mathrm{C}$. (from ref. 71 )

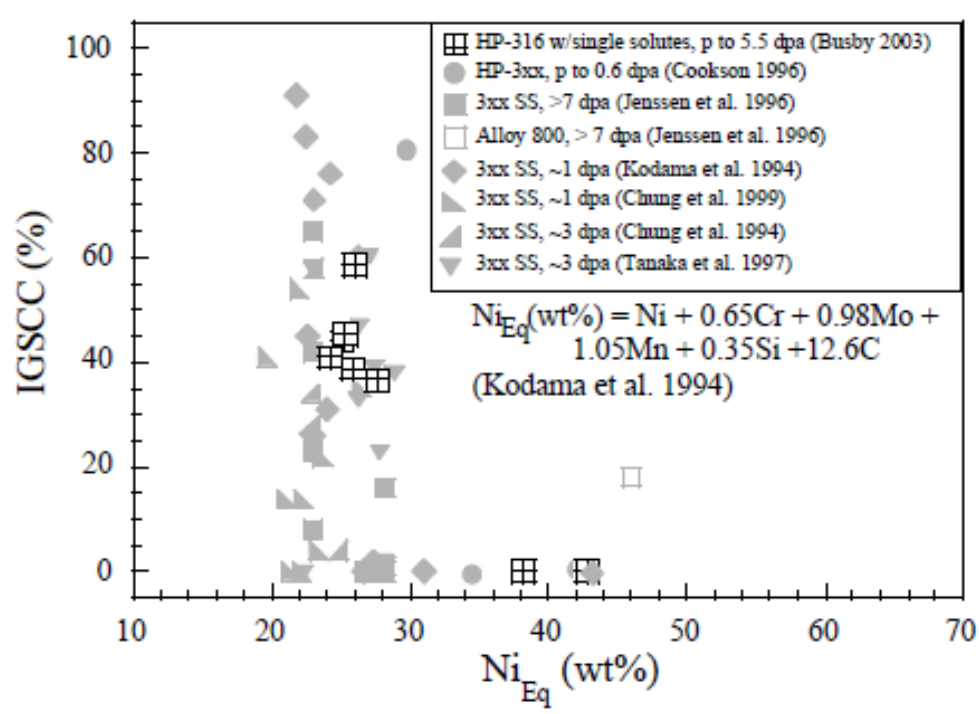

Figure 14. IGSCC susceptibility as measured by \%IG cracking in SSRT tests as a function of $\mathrm{Ni}$ equivalent determined using data from Kodama et al. ${ }^{72}$ 

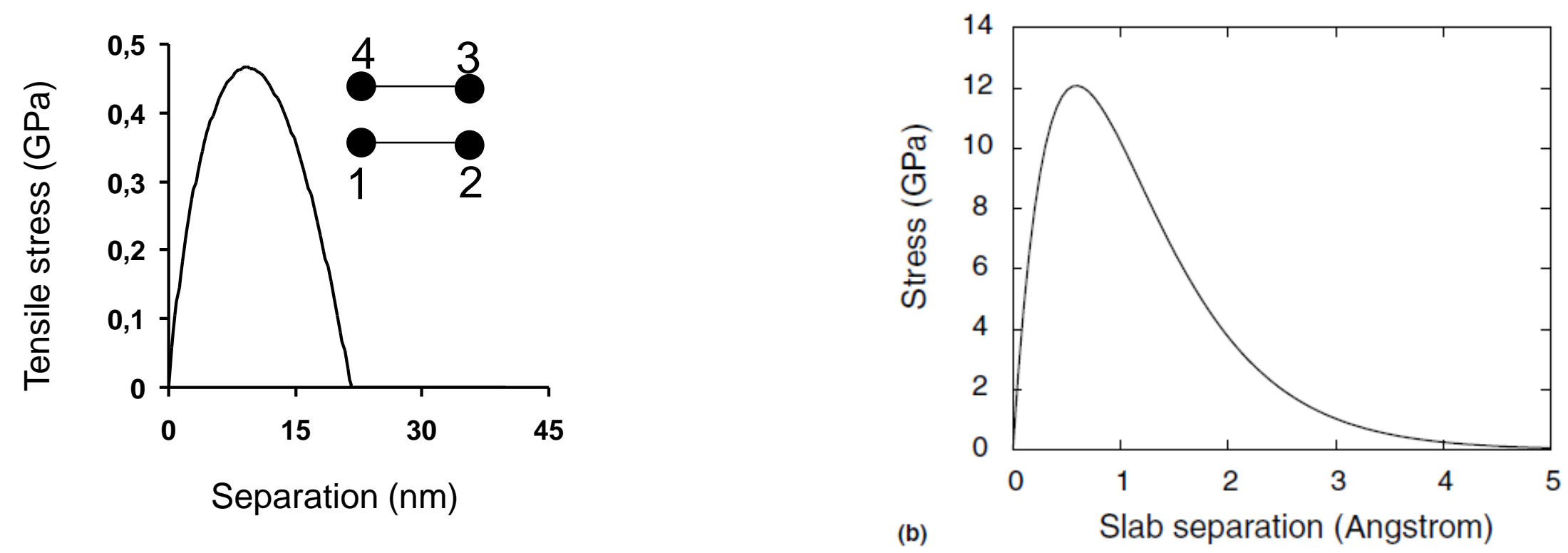

Fig. 2. (a) Excess energy versus $\delta=L^{\mathrm{e}}-d_{0}$ (diamonds) for decohesion of fcc aluminum along a pair of adjacent (111) planes. Solid curve corresponds to the universal binding curve fit to first principles calculations of decohesion whereby rigid slabs (without internal relaxation) are separated. (b) Stress versus $\delta$ (traction curve) for decohesion of pure aluminum. 
- Variability in the microstructure lengths in a given polycrystal, $L \& t$, and GB / slip band angles. Three D microstructures.

- influence of neighbour grains:

slip bands in the neighbour grain

- more physically-based modelling of the interactions between slip bands and grains boundaries

singular GBs: possible slip transmission general GBs: no transmission but absorption

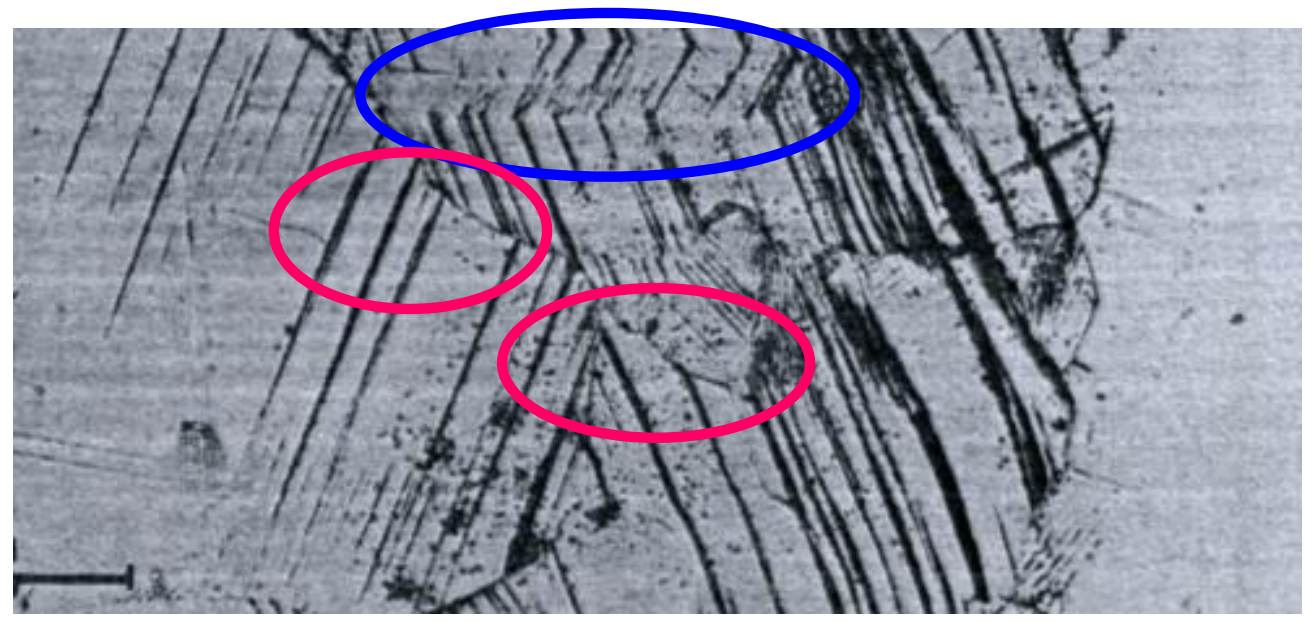

Rasmussen and Pedersen, 1980 Copper polycrystal, cyclic loading

Dislocation - GB interactions: Lee and Robertson Couzinie, Deschamps and Priester... 


\section{Thermo-elasticity computations (Saada, 1960)}

$$
\mathrm{L} / \mathrm{t}=1000
$$

$\mathrm{L} / \mathrm{t}=100$
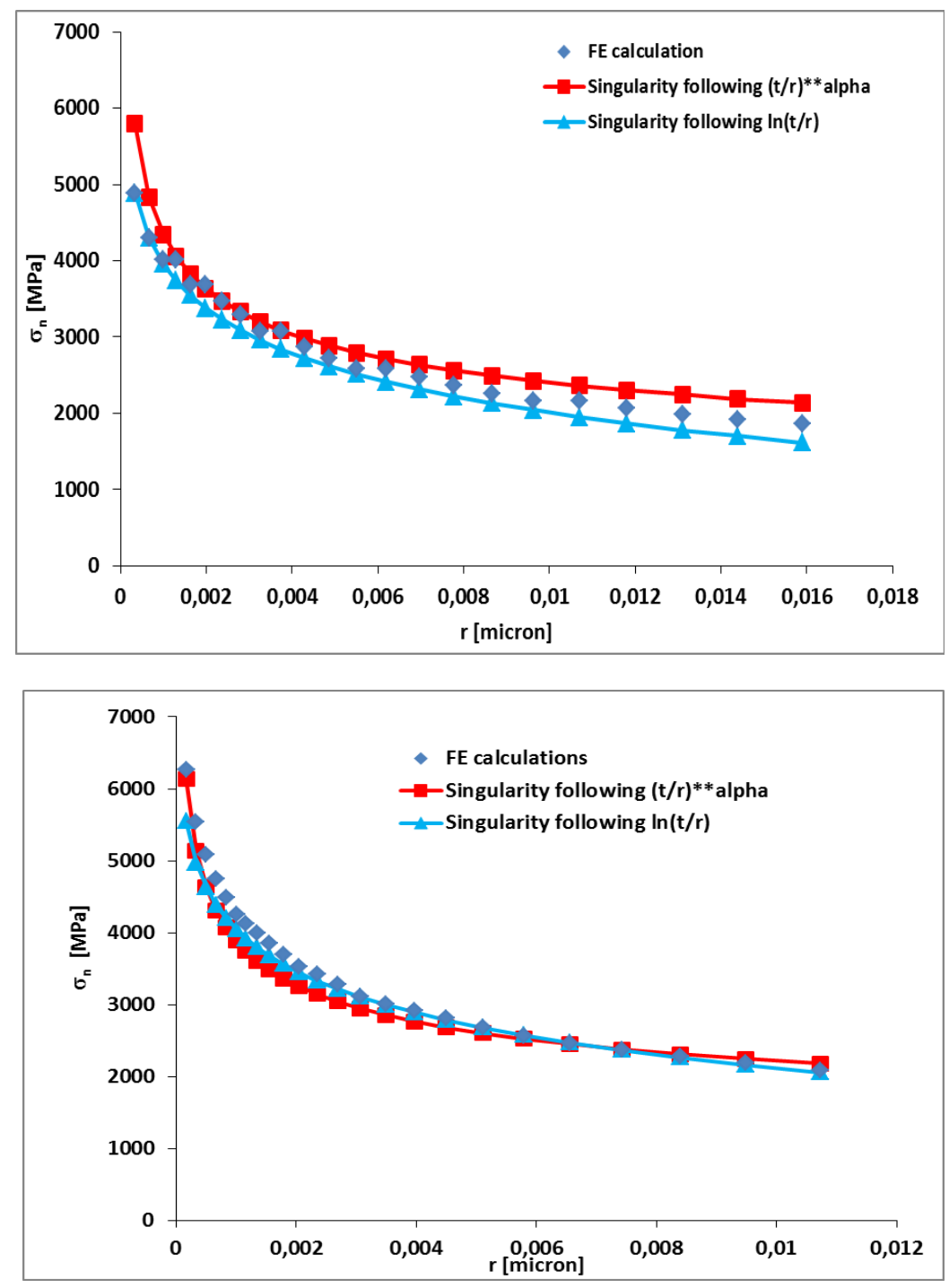


\section{Dislocations (Volterra, Orowan, Taylor...)}

Edge dislocation: lineic defect in a perfect lattice
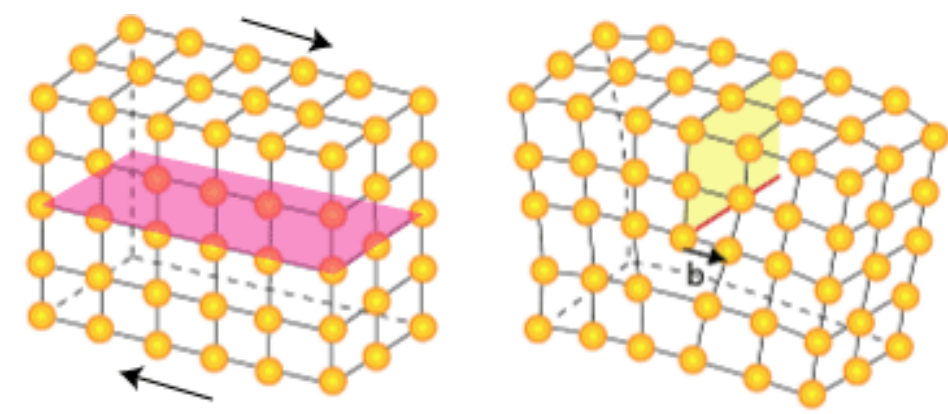

red dislocation line

Burgers vector, $b$

Stress field in the linear elastic framework: $\sigma_{i j}{ }^{d i s l o c}(r, \theta)=U_{i j}(\theta) \frac{\mu b}{r}$

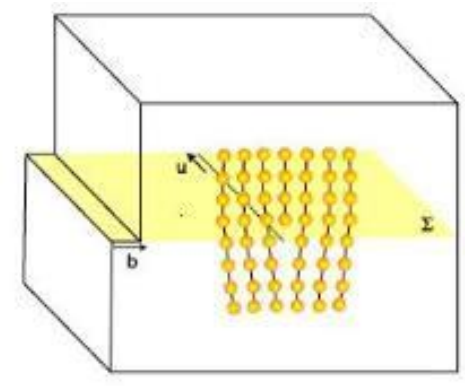

yellow slip plane

Dislocation production \& glide $\rightarrow$ plastic slip

Easy slip system: computation of the resolved shear stress, $\mathrm{T}$ minimum value of $b$, maximum value of the inter- slip plane distance Example: Face-Centred Cubic metals $\rightarrow 12$ easy slip planes 


\section{Final remarks}

Thanks to the stress fields induced by either pile-ups or slip bands, the critical fracture stress computed using atomistic approaches, the local stresses close to grain boundaries display similar orders of magnitude. GB brittle fracture may be predicted for remote stresses close to the experimentally applied ones.

More 'usual' crystalline FE computations allow the evaluation of stress gradients close to GBs (see for instance Diard et al., 2005), but the GB stresses are much lower than the critical brittle fracture stresses

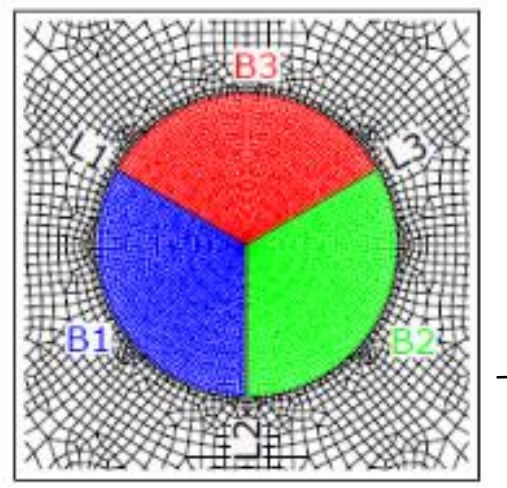

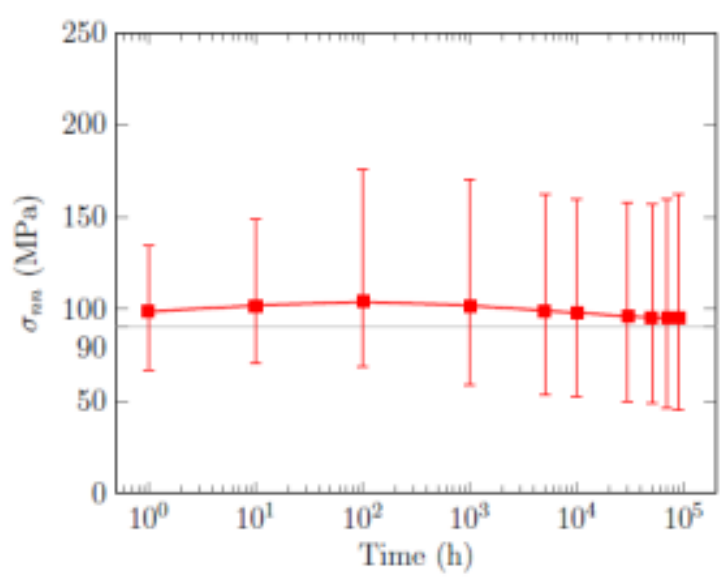

(b) Creep at $600 \mathrm{C}$ under $\sigma^{e n g}=90 \mathrm{MPa}$
R. Lim

PhD, dec. 2011

stress fields at triple points crystallographic orientations 


\section{Effect of the critical shear stress (clear band)}

This parameter, $\mathrm{T}_{0}$, affects the microplasticity threshold

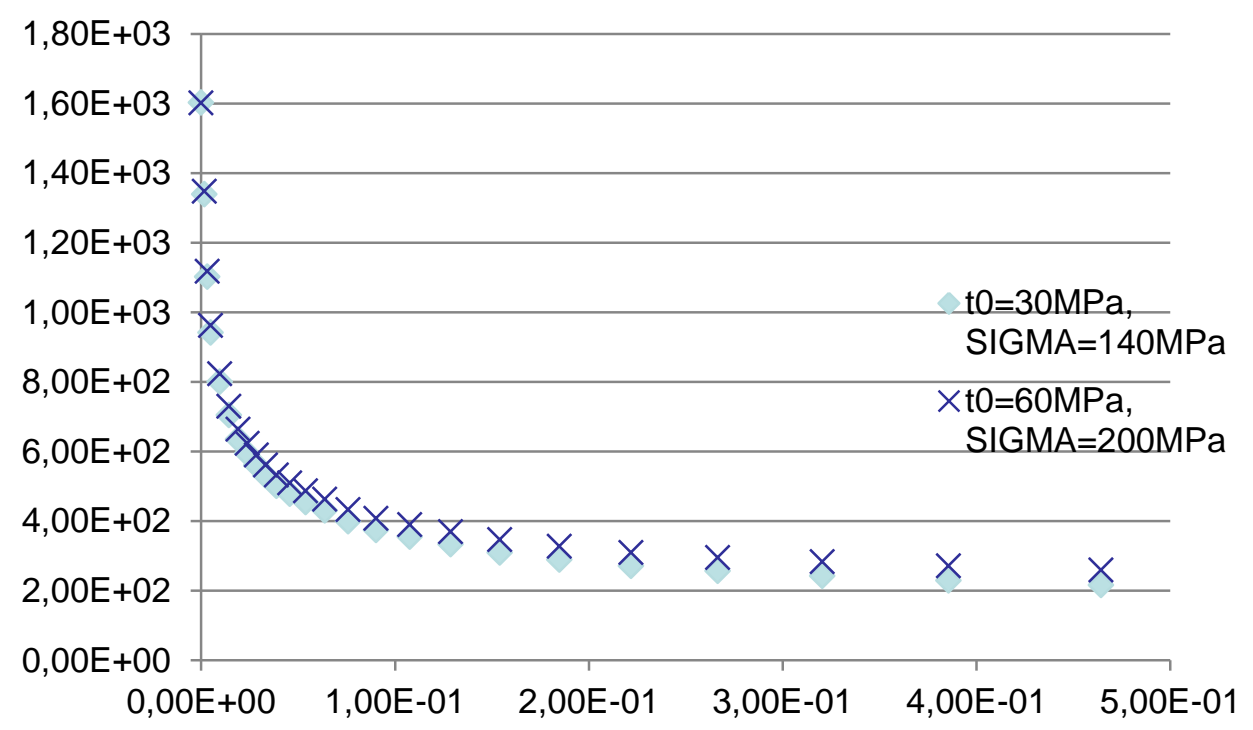

A simple drift should be taken into account The effect is negligible provided the macroscopic stress is much higher than the channel critical shear stress 


\section{Effect of the hardening slope (clear band)}

This parameter, $\mathrm{H}$, affects the stress level induced by hardening:

$\mathrm{H} \sim 1 \mathrm{MPa} \quad \rightarrow$ perfect plasticity

$\mathrm{H}>>1 \mathrm{MPa} \quad \rightarrow$ strong hardening
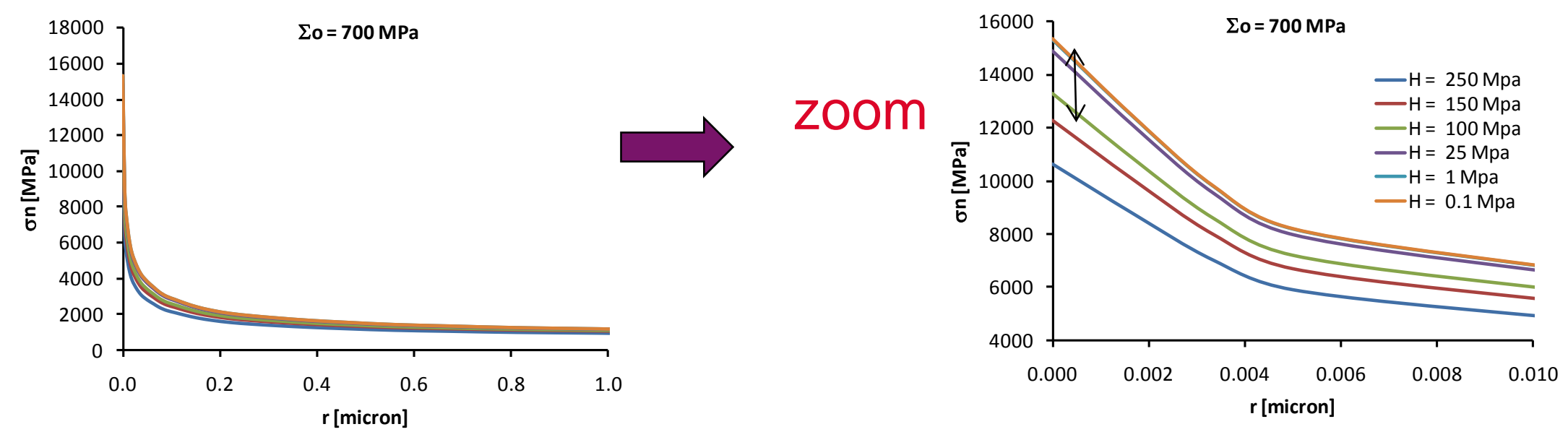

The higher the $\mathrm{H}$ value, the lower the GB normal stress

(lower load transfer from the clear band to the GB)

Refering to the stage I monotonic deformation slope : $\mathrm{H}<\mu / 2000 \sim 30 \mathrm{MPa}$

$\rightarrow$ Rather weak effect of the slope value in this range of variation $\sim 10 \%$ 


\section{Master curve equation}

Adjustment of the two parameters, A' and B' for proposing more general equations:

$$
\begin{aligned}
& \Sigma_{n}(r)=\frac{f \Sigma_{0}-\left(\tau_{0}-H \gamma^{p}\right)}{\sqrt{2 \pi r}}\left(A^{\prime} \sqrt{t}+B^{\prime} \sqrt{L}\right)+\Sigma_{n}^{\infty} \\
& \gamma^{p}=F\left(\mu, v, \tau_{0}, H, t, L, f, \Sigma_{0}\right)
\end{aligned}
$$

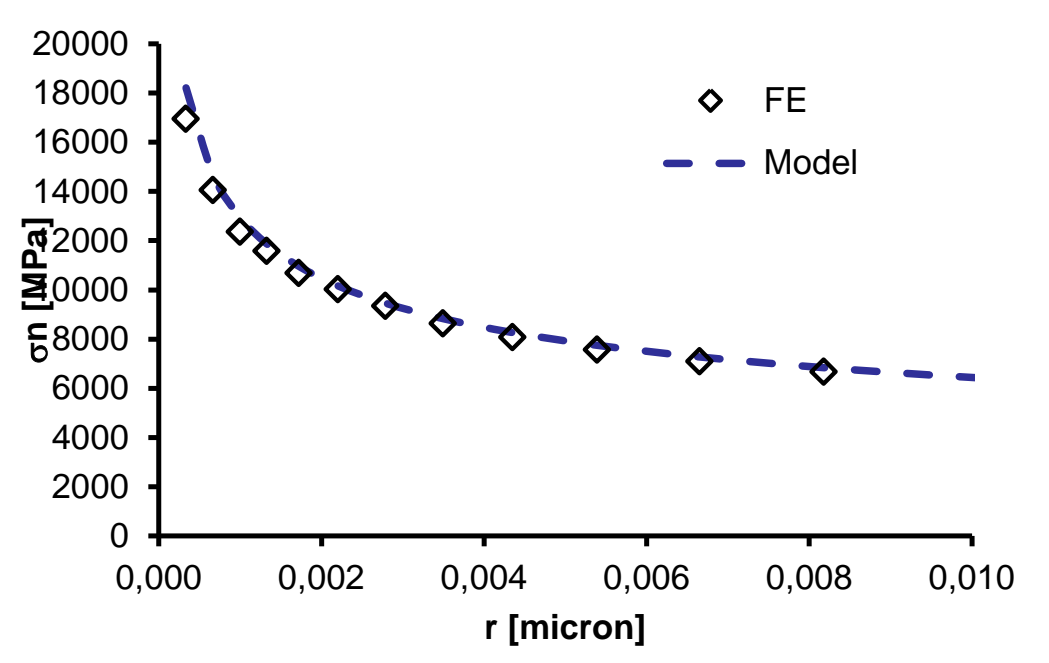

$t=50 \mathrm{~nm}, \mathrm{~L}=10 \mu \mathrm{m}$

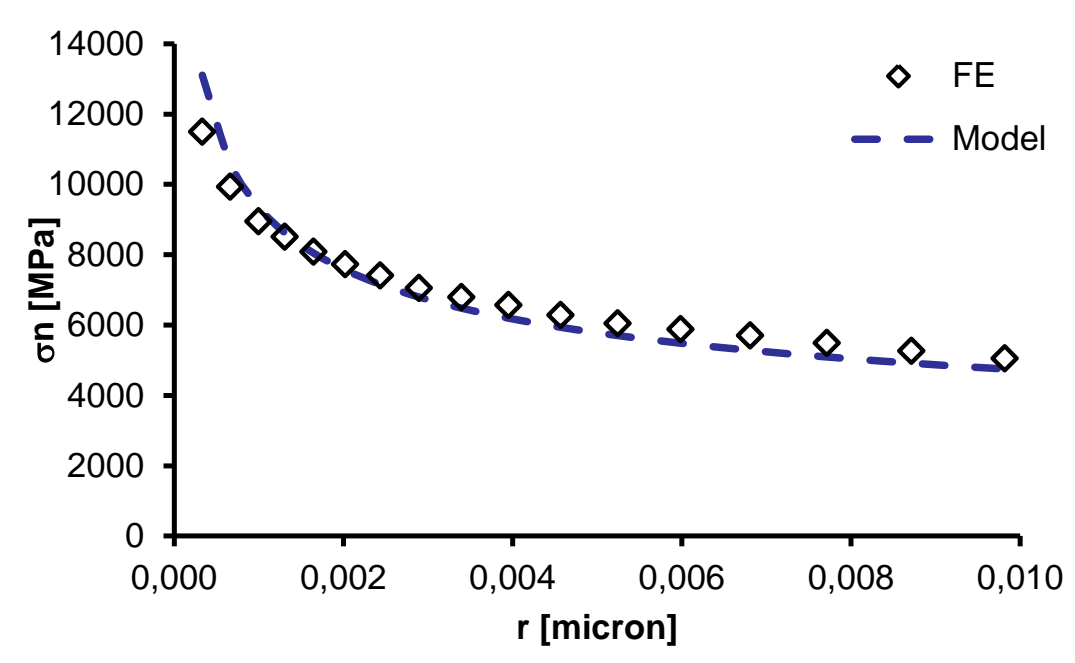

$t=500 \mathrm{~nm}, \mathrm{~L}=10 \mu \mathrm{m}$ 


\section{Weak effect of the latent hardening parameter, q}

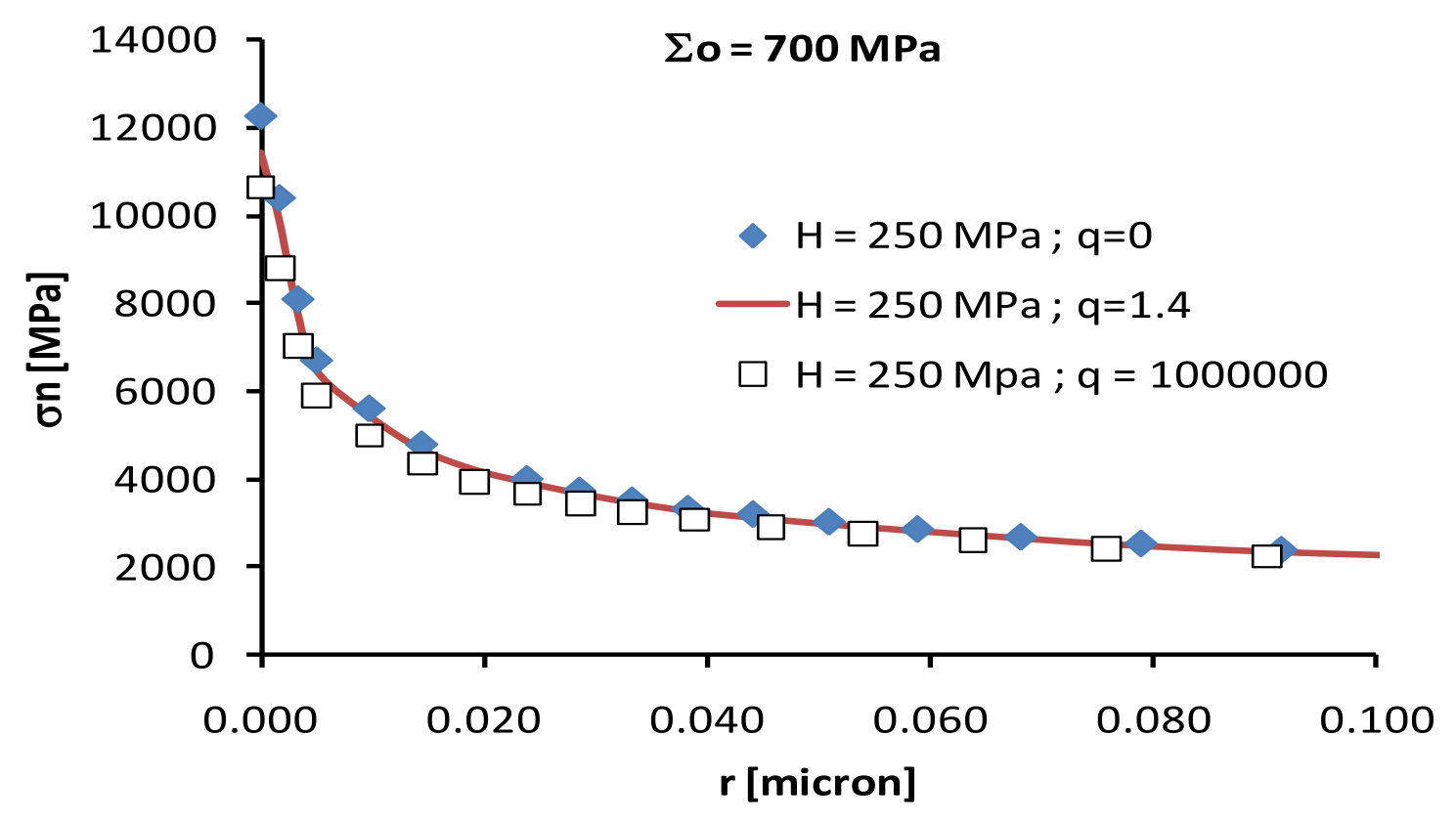

$q=1$ easy secondary slip

$\mathrm{q}=1.4$ intermediate behaviour

$\mathrm{q}>>1$ single slip

Eng. Fract. Mech., 2013 


\section{Effect of crystalline elastic anisotropy (a=3.3 copper, 316L)}
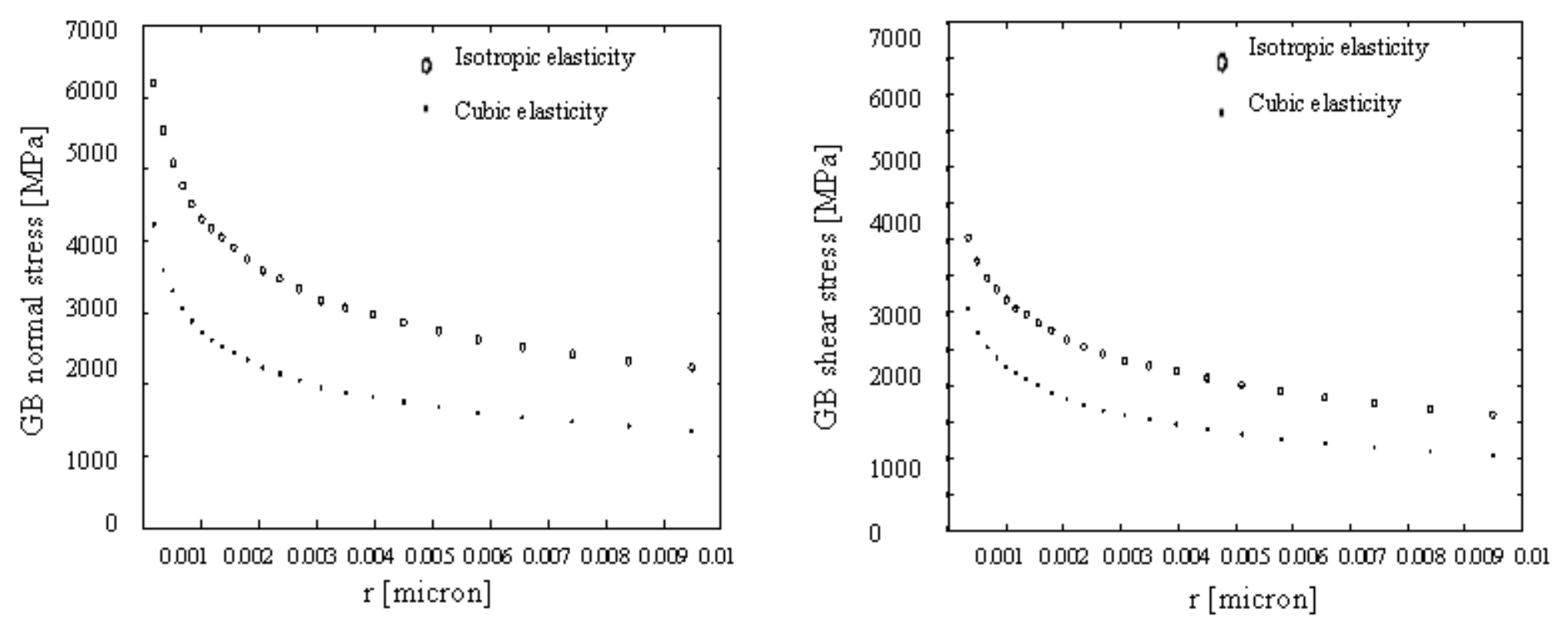

The Young and shear moduli of well-oriented ones are lower than the average one because $a=3.3>1$

$\rightarrow$ lower mean grain shear stress \& effective Schmid factor

$\rightarrow$ lower GB stress for the same remote stress amplitude Additional scatter effects if neighbour grain orientations are taken into account (Sauzay, Acta Mater., 2007) 


\section{Computation of mean channel plastic slip (JNM, 2010)}

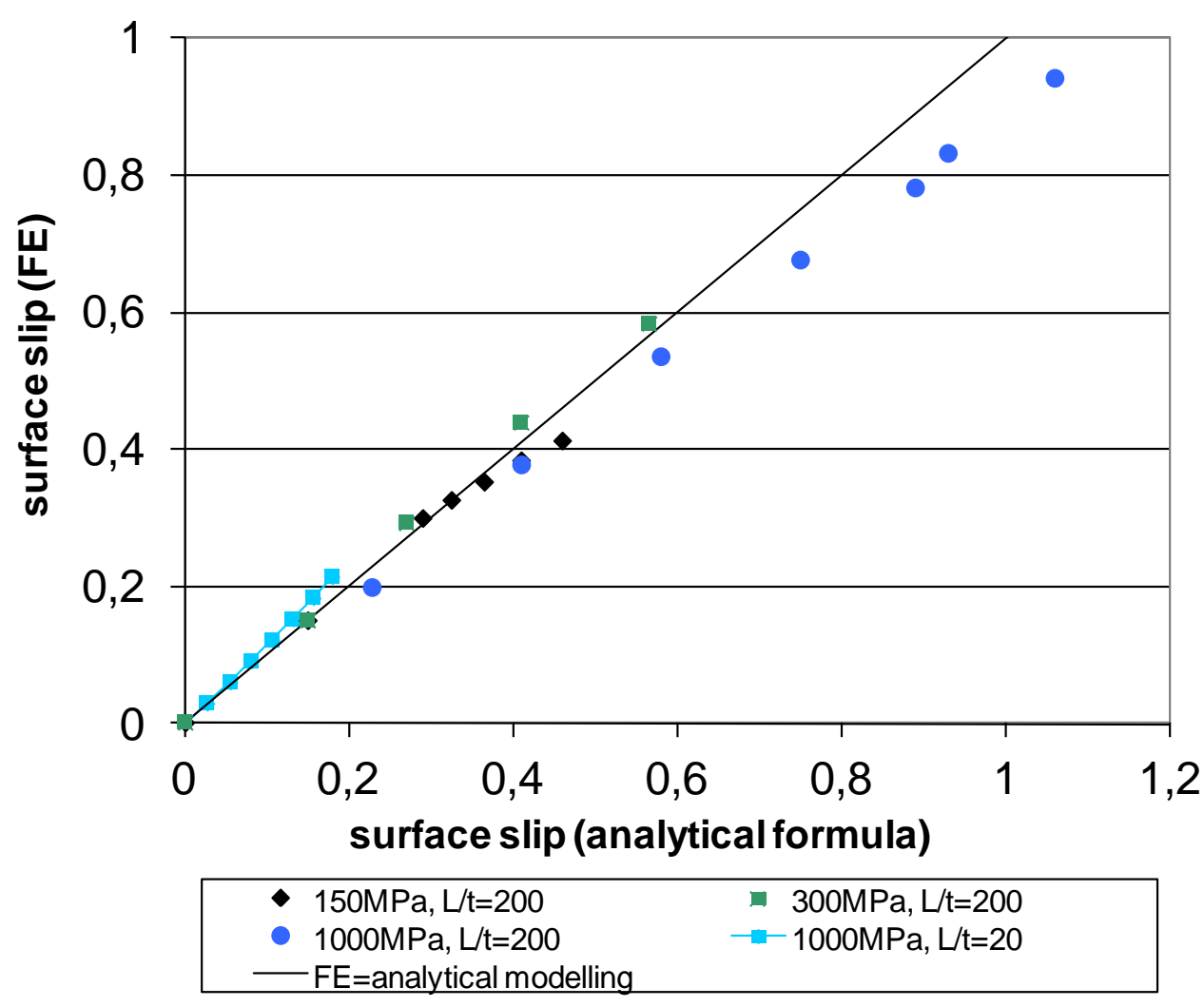

Experimental validation for:

- surface slip bands (AFM, Jiao \& Was)

- bulk slip bands (shearing of channels by other ones) 

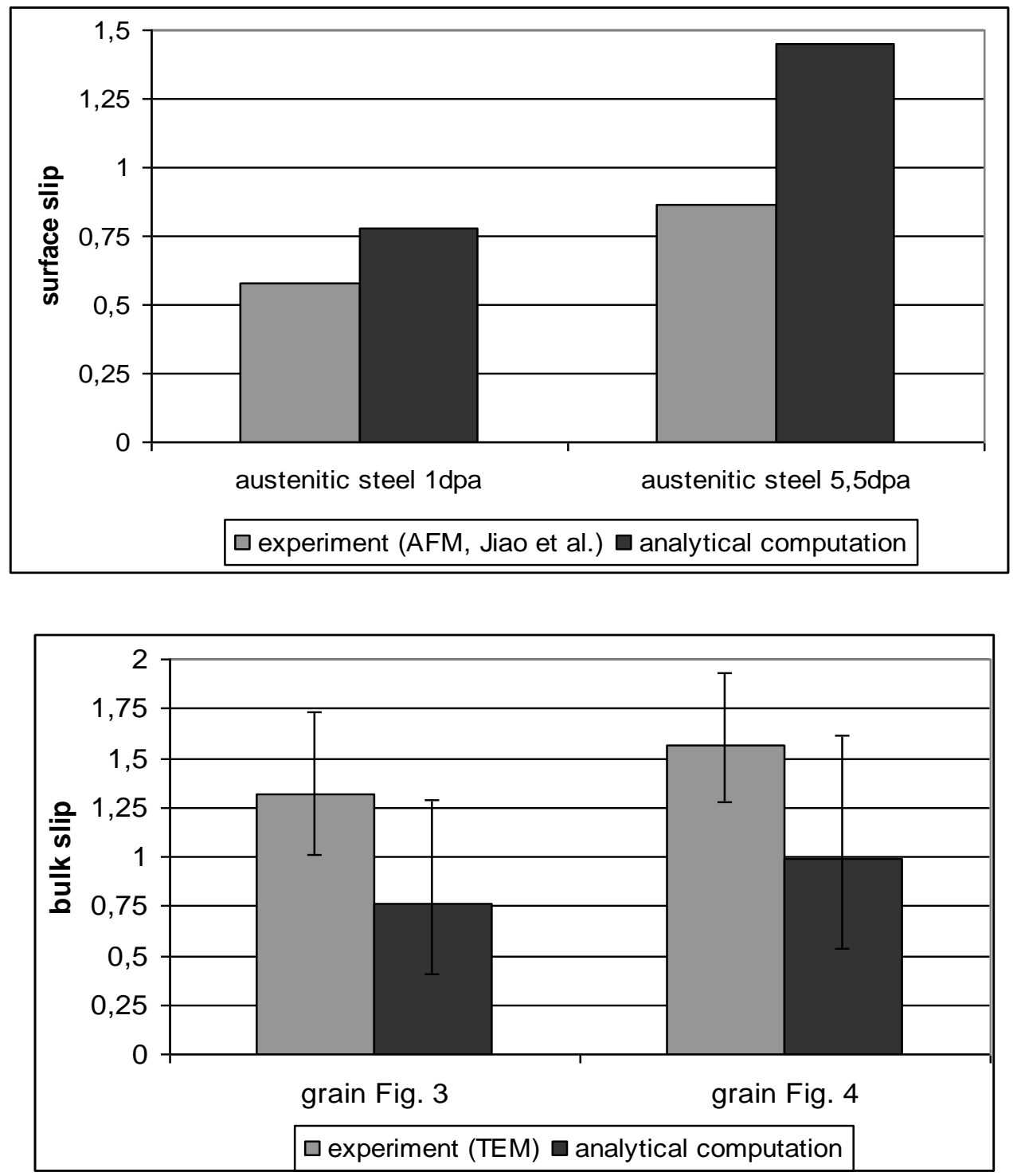


\section{3- Effect of crystalline elastic anisotropy (a=3.3 copper, 316L)}
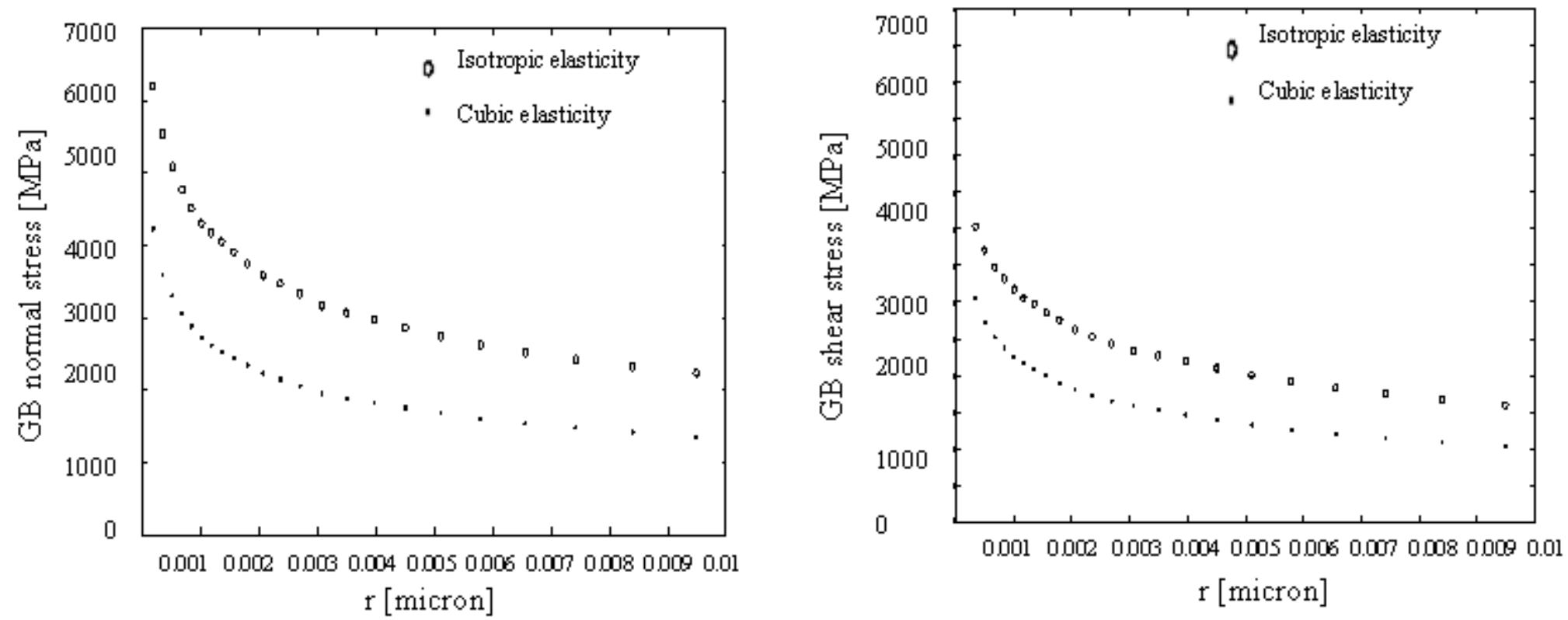

The Young and shear moduli of well-oriented ones are lower than the average one because $a=3.3>1$

$\rightarrow$ lower mean grain shear stress \& effective Schmid factor

$\rightarrow$ lower GB stress for the same remote stress amplitude Additional scatter effects if neighbour grain orientations are taken into account (Sauzay, Acta Mater., 2007) 


\section{Effect of the critical shear stress (clear band)}

This parameter, $\mathrm{T}_{0}$, affects the microplasticity threshold

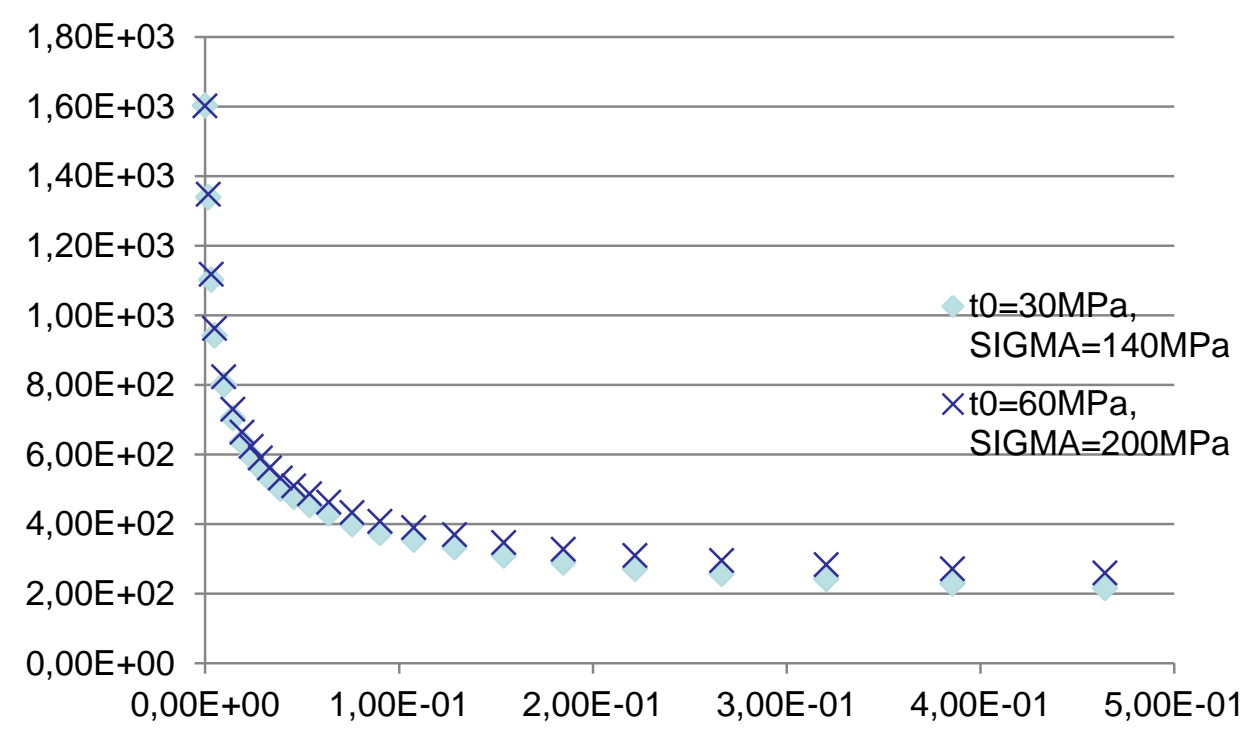

A simple drift should be taken into account The effect is negligible provided the macroscopic stress is much higher than the channel critical shear stress 
Effect of the slip band thickness, $\mathrm{t}$

Ratio between

the critical remote stresses computed by:

the finite-thickness SB theory

the pile-up theory (Smith and Barny, 1967)

irradiation channels ( $\left.{ }^{*} 2\right)$

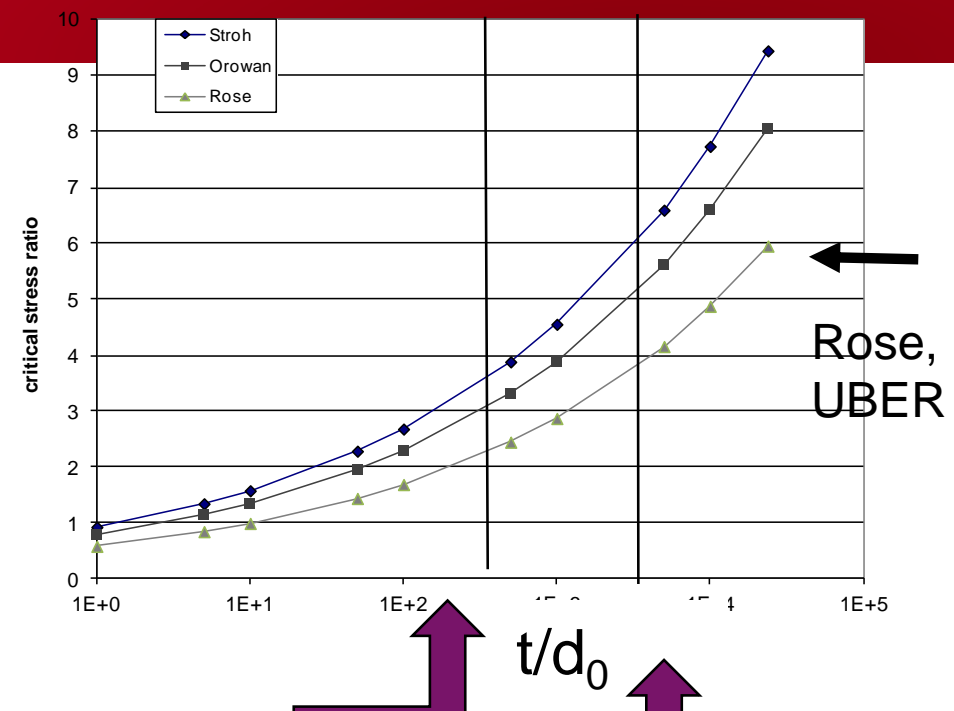

persistent slip bands $\left({ }^{\star} 3.5\right)$

Effect of slip band angle, $\alpha_{\mathrm{SB}}$, and GB angle, $\alpha_{\mathrm{GB}}$

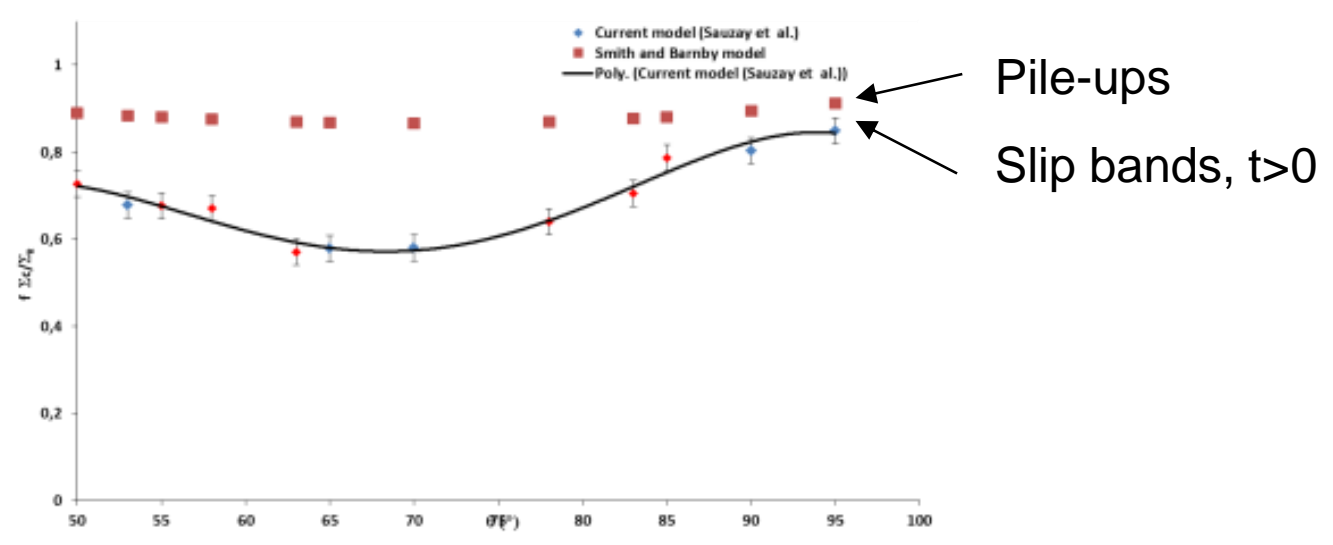

